\title{
Seltene Erkrankungen des Mittelohres und der lateralen Schädelbasis
}

Rare Diseases of the Middle Ear and Lateral Skull Base

(ㅇ) (1) $\odot \Theta$

Autorin

Nora M. Weiss

Institut

Klinik für Hals-Nasen-Ohrenheilkunde, Kopf- und Halschirurgie

„Otto Körner“ der Universitätsmedizin Rostock, Deutschland

Schlüsselwörter

Differenzialdiagnose, Otorrhoe, Otalgie, seltene Entität, Manifestation, Otitis media

Key words

Differential diagnosis, otorrhoea, otalgia, rare entity, manifestation, otitis media

Bibliografie

Laryngo-Rhino-Otol 2021; 100: S1-S30

DOI 10.1055/a-1347-4171

ISSN 0935-8943

(c) 2021. The Author(s).

This is an open access article published by Thieme under the terms of the Creative Commons Attribution-NonDerivative-NonCommercial-License, permitting copying and reproduction so long as the original work is given appropriate credit. Contents may not be used for commecial purposes, or adapted, remixed, transformed or built upon. (https://creativecommons. org/licenses/by-nc-nd/4.0/)

Georg Thieme Verlag KG, Rüdigerstraße 14,

70469 Stuttgart, Germany

Korrespondenzadresse

Dr. med. Nora M. Weiss

Univ. HNO-Klinik

Doberaner Straße 137-139

D-18057 Rostock

nora-magdalena.weiss@med.uni-rostock.de

\section{ZUSAMMENFASSUNG}

Otalgie, Otorrhoe, Tinnitus und Hörminderung zählen zu den häufigsten ohrbezogenen Symptomen, die zum Aufsuchen eines Hals-Nasen-Ohrenarztes führen. Weiterhin spielen Gleichgewichtsstörungen und Affektionen der Hirnnervenfunktion für eine Konsultation eine Rolle. In großen akademi- schen Zentren, aber auch in der HNO-ärztlichen Grundversorgung kommt der Erkennung von seltenen Erkrankungen des Mittelohres und der lateralen Schädelbasis eine zentrale Rolle zu, da sie häufig eine interdisziplinäre Zusammenarbeit erfordern um die korrekte Diagnose zu stellen und eine adäquate Behandlung zu initiieren. Die folgende Arbeit gibt einerseits eine Übersicht über seltene Formen von osteologischen, neoplastischen, hämatologischen, autoimmunologischen und infektiologischen Erkrankungen sowie Fehlbildungen, die sich im Mittelohr und der lateralen Schädelbasis manifestieren können, andererseits soll ein Überblick über internistische Erkrankungen gegeben werden, deren Manifestation im Mittelohr selten ist.

Die Kenntnis von seltenen Erkrankungen des Mittelohrs und der Schädelbasis ist für die Qualitätssicherung in der Patientenversorgung und insbesondere auch bei entsprechenden chirurgischen Maßnahmen wesentlich. Insbesondere bei untypischen, komplizierten und langwierigeren Krankheitsverläufen muss an seltene Differenzialdiagnosen gedacht werden.

\section{ABSTRACT}

Otalgia, otorrhea and hearing loss are the most common earrelated symptoms that lead to the consultation of an otolaryngologist. Furthermore, balance disorders and affections of the cranial nerve function may play a role in the consultation. In large academic centres, but also in primary care, the identification of rare diseases of the middle ear and the lateral skull base is essential, as these diseases often require interdisciplinary approaches to establish the correct diagnosis and to initiate safe and adequate treatments. This review provides an overview of rare bone, neoplastic, haematological, autoimmunological and infectious disorders as well as malformations that may manifest in the middle ear and the lateral skull base. Knowledge of rare disorders is an essential factor ensuring the quality of patient care, in particular surgical procedures. Notably, in untypical, complicated, and prolonged disease courses, rare differential diagnoses need to be considered. 


\section{Inhaltsverzeichnis}

1. Einleitung

2. Fehlbildungen

$2.1 \quad$ Kleine und große Ohrfehlbildungen Erkrankungen des Knochens Paget-Syndrom)

Osteogenesis imperfecta

Fibröse Dysplasie „Marmorknochenkrankheit“)

Langerhanszell-Histiozytose

Unifokales eosinophiles Granulom

Hand-Schüller-Christian-Syndrom

Letterer-Siwe-Syndrom

\section{Proteus-Syndrom}

Granulomatose mit Polyangiitis (Churg-Strauss-Syndrom)

Rheumatoide Arthritis

Neoplasien

Leukämie des Schläfenbeines

Myelom des Schläfenbeines

Maligne epitheliale Neoplasien

Glanduläre Neoplasien

Adenom

Pleomorphes Adenom

Adenoidzystisches Karzinom

Adenokarzinome

Karzinoid des Mittelohres

Sarkome

Osteogenes Sarkom

Rhabdomyosarkom

Chondrosarkom

Metastasen

Teratom

Vestibularisschwannom
Anomalien und Malformationen der großen Schläfenbeingefäße 6

Morbus Paget (Osteodystrophia deformans, Ostitis deformans,

Osteopetrose („Albers-Schönberg-Syndrom“,

Erkrankungen des autoimmunologischen Formenkreises

Eosinophile Granulomatose mit Polyangiitis

Rezidivierende Polychondritis (Relapsing polychondritis)

Neoplasien des hämatopoetischen Systems

Paragangliome des Schläfenbeins (tympano-juguläre Paragangliome) 16

Benigne Blut- und Lymphgefäßneoplasien

Raumforderungen des inneren Gehörganges, des Innenohres, des Kleinhirnbrückenwinkels und der Pyramidenspitze
Epidermoidzyste

$\begin{array}{ll}\text { Infektiologische Erkrankungen } & 19\end{array}$

Tuberkulose 19

Otosyphilis 19

Otitis externa necroticans 19

Cholera 19

Varia 19

Pneumatozele des Schläfenbeins 19

Otogene primäre Mukozele des Mastoids $\quad 19$

Otogener Pneumocephalus 19

Spontane (Meningo-)Enzephalozele 20

Ektopes Hirngewebe 20

Idiopathisches oder spontanes Hämatotympanon 20

Gorham-Stout-Syndrom 20

Cholesteringranulom 20

$\begin{array}{lll}7.9 & \text { Riesenzellgranulom } & 21\end{array}$

Fazit $\quad 21$

Danksagungen $\quad 21$

Interessenskonflikt 22

Literatur 22

\section{Einleitung}

Otalgie, Otorrhoe und Hörminderung zählen zu den häufigsten ohrbezogenen Symptomen, die zum Aufsuchen eines Hals-Nasen-Ohrenarztes führen. Ebenso können Gleichgewichtsstörungen und Affektionen der Hirnnervenfunktion in der Konsultation eine Rolle spielen. Neben den häufigsten dafür ursächlichen Erkrankungen wie bspw. der akuten Otitis media können diese Symptome auch Hinweise auf systemische Erkrankungen sein, die sich als otologische Erstmanifestation zeigen, aber eine weiterführende internistische Behandlung erfordern. Weiterhin können Hör- und Gleichgewichtsstörungen, Tinnitus und Ausfälle der kaudalen Hirnnerven auf neurologische Erkrankungsbilder hinweisen oder Erstmanifestation von Tumoren und Läsionen des Schläfenbeines sein. Neben den häufigen Erkrankungen, in denen der Hals-Nasen-Ohrenarzt klinische Routine aufweist und sichere Behandlungsmöglichkeiten zur Verfügung hat, kommt daher sowohl in großen akademischen Zentren, aber auch in der Grundversorgung der Differenzierung von seltenen Erkrankungen des Mittelohres und der lateralen Schädelbasis eine zentrale Rolle zu. Seltene Erkrankungen des Mittelohres und der lateralen Schädelbasis erfordern in der Regel eine interdisziplinäre Zusammenarbeit, um sowohl die korrekte Diagnose zu stellen, als auch eine adäquate Behandlung zu initiieren. Hinter einer bekannten Symptomatik kann sich eine seltene Entität verbergen, die jedoch im Vergleich zu den häufigen Erkrankungen/ Ursachen eine andere, komplexere Abklärung bzw. weiterführende Behandlung erfordert. Ein Schwerpunkt dieser Übersichtarbeit liegt deshalb auf seltenen osteologischen, neoplastischen, hämatologischen, autoimmunologischen und infektiologischen Erkrankungen sowie Fehlbildungen mit Manifestation im Mittelohr und der lateralen Schädelbasis. Weiterhin soll die Notwendigkeit der 
interdisziplinären Zusammenarbeit aufgezeigt werden, welche insbesondere dann von Bedeutung ist, wenn die Erstsymptomatik einer Erkrankung zur Konsultation eines Hals-Nasen-Ohrenarzt führt, die Diagnose einer seltenen Erkrankung jedoch die Notwendigkeit einer weiteren Behandlung durch andere Fachdisziplinen nach sich zieht. Zum Beispiel können so Mittelohr und laterale Schädelbasis prinzipiell Manifestationsort von allen systemischen Erkrankungen sein, die an Knochen und Schleimhaut auftreten. > Tab. 1 zeigt eine Übersicht der typischen Symptomatik von Erkrankungen, die sich in Mittelohr und lateraler Schädelbasis manifestieren können.

\section{Fehlbildungen}

\subsection{Kleine und große Ohrfehlbildungen}

Fehlbildung des Mittelohres sind häufig mit Fehlbildungen des äußeren Ohres (v. a. der Ohrmuschel) verbunden oder können im Rahmen von Syndromen auftreten. Je nach Ausprägung und involvierter Strukturen werden nach Jahrsdoerfer verschiedene Schweregrade unterteilt [1-3]. Die Entwicklung von Mittelohr und äußerem Ohr findet zu unterschiedlichen Gestationszeitpunkten statt und kann durch Genetik oder toxische Einwirkungen beeinflusst werden. Die Kombination mit Innenohrfehlbildungen ist selten, muss aber für die spätere Behandlung berücksichtigt werden [2,4]. Bei der sogenannten „kleinen Fehlbildung“ bestehen normal weite Mittelohrräume, Trommelfell und Gehörgang. Betroffen sind meist die Ossikel wie bspw. der Stapes [5]. Weitere mögliche Veränderungen betreffen auch die anderen Ossikel und können durch knöcherne Brücken, Verwachsungen ( $\triangleright$ Abb. 1) oder Aplasien zu einer Fixation bzw. Unterbrechung der Kette führen [6].

Bei der "großen Ohrfehlbildung“ kommt es zu einer fehlenden Ausbildung des Gehörgangs. Dadurch bedingt ist eine Rückverlagerung des Kiefergelenks wodurch es zu einer Verlagerung des Mastoid nach anterior kommt. Die Folge ist eine Fehlentwicklung des Mittelohrraums. Betroffene verfügen über ein allenfalls rudimentäres Os tympanicum. Minderentwicklung von Mastoid und Gehörgang können den Verlauf des Nervus fazialis im Fallop'schen Kanal beeinflussen. Es kommt zu einer Vorverlagerung des Nerven im tympanalen und mastoidalen Verlauf, was zu einer Lokalisation im ovalen Fenster oder in der Rundfensternische führt [7]. Die Inzidenz der großen Ohrfehlbildung liegt zwischen 1:8'000-1:10'000 [2,8].

Fehlbildungen des Mittelohres können auch im Rahmen von Fehlbildungssyndromen auftreten. In 20-30\% besteht die Fehlbildung beidseitig [9], bei $7 \%$ ist sie mit angeborenen Fehlbildungskomplexen assoziiert. Häufig besteht eine Kombination mit weiteren Fehlbildungen der ersten beiden Kiemenbögen wie bspw. einer Unterkieferhypoplasie, z. B. beim Symptom-Komplex der oculoauriculo-vertebralen Dysplasie (Goldenhar-Syndrom) [10]. Die symmetrisch auftretende Dysostosis mandibulofacialis (TreacherCollins-Syndrom) weist eine Hypoplasie des Unterkiefers und Jochbein, eine lateral abfallende Lidachse und Lidanomalie auf [11, 12]. Weiter ist die Dysostosis acrofacialis (synonym Dysostosis otomandibularis, Nager-Syndrom) abzugrenzen, welche keine okulären Symptome aufweist. Zusätzlich kann es auch bei kraniofazialen Dysostosen wie der Dysostosis craniofacialis (Crouzon-Syndrom) oder der Akrozephalosyndaktylie (Apert-Syndrom) sowie bei Fehlbildungssyndromen mit Fehlbildungen der Wirbelsäule wie dem Klippel-Feil-Syndrom oder dem Wildervanck-Syndrom zu Mittelohr- fehlbildungen kommen. Zusätzlich werden Fälle von Fehlbildungen an Mittelohr und äußerem Ohr als unerwünschtes Ereignis bei Medikamenteinnahme während der Schwangerschaft beschrieben, z. B. im Rahmen der Embryopathie bei Einnahme von Thalidomid $\left(\right.$ Contergan $\left.^{\circledR}\right)$ [13].

Die Behandlung von Fehlbildungen besteht neben kosmetischen Aspekten in einer chirurgischen funktionellen Rehabilitation des Gehörs. Diese kann konventionell audiologisch, chirurgisch oder kombiniert durchgeführt werden. Die Entscheidung über die therapeutischen Optionen hängt vom Alter des Patienten und dem Schweregrad der Fehlbildung ab. Das Alter des Patienten hat einen Einfluss auf den Reifegrad des auditorischen Systems und damit die Fähigkeit, von der (bilateralen) Stimulation zu profitieren. Der Schweregrad der Fehlbildung limitiert die Art der Hörrehabilitation [14]. Intraoperativ findet sich meist eine schlitzförmige Anlage des Mittelohrs mit geringer Pneumatisierung und nur rudimentären Gehörknöchelchen (Hammer-Amboss-Konglomerat) [15]. Die rekonstruktive Chirurgie ist in der Regel auf Patienten mit günstigen anatomischen Bedingungen bzw. auf leichte Fälle beschränkt, in denen eine Gehörgangsplastik in Kombination mit einer Ossikuloplastik durchgeführt werden kann [14]. Aktive Mittelohrimplantate bieten eine geeignete Alternative [16]. Bei besonders schwerwiegenden Fehlbildungen des Schläfenbeins kann das Risiko der Implantation eines aktiven Mittelohrimplantats, u. a. aufgrund einer Vorverlagerung des Nervus fazialis im tympanomastoidalen Verlauf oder von begleitenden Gefäßanomalien (siehe Folgeabschnitt) hoch sein, sodass Knochenleitungshörsysteme zu bevorzugen sind $[14,15]$.

\section{Klinisches Beispiel: kongenitaler Stapesfußplattendefekt}

Entwicklungsbiologisch entstammen Malleus und Incus aus dem Knorpel des ersten Kiemenbogens, während der Stapesüberbau aus Knorpel des zweiten Kiemenbogens entsteht. Die Stapesfußplatte entsteht wie das Ringband aus der otischen Kapsel. Hierbei entstehen die zentrale Fußplatte sowie der Steigbügelüberbau in der Embryoanalentwicklung aus der Neuralleiste [17], während der äußere Teil der Stapesfußplatte und das Ringband mesodermalen Ursprungs sind. Eine Dysplasie des Innenohrs ist oft mit einer fehlgebildeten otischen Kapsel assoziiert, was zu einer angeborenen Schwäche oder Fistelbildung in der Stapesfußplatte oder im Ringband führen kann. Darüber hinaus können Druckschwankungen im Liquor zu einer Verdünnung der Stapesfußplatte oder zu Rissen im Ringband führen. In der Folge sind Patienten mit Innenohrdysplasie nach einem Trauma oder Barotrauma anfälliger für Oto- oder Rhinoliquorrhoe mit dem damit verbundenen Risiko für Schwindel, Ertaubung und rezidivierende otogene Meningitiden ( $\mathbf{A b b} . \mathbf{2}$ ) [18-20].

\subsection{Anomalien und Malformationen der großen Schläfenbeingefäße}

Eine Vorverlagerung des Sinus sigmoideus, ein Hochstand des Bulbus Venae jugularis oder der Arteria carotis interna können zu Problemen in der chirurgischen Versorgung der kleinen und großen Ohrfehlbildungen führen. Dies spielt insbesondere bei der Neuanlage eines Gehörgangs, bei der Ossikuloplastik oder bei der Anlage implantierbarer Hörgeräte eine Rolle [1, 7, 15, 21]. Weiter kann eine nicht wie üblicherweise zurückgebildete Arteria stapedia ( $\triangleright$ Abb. 3) zu Kom- 

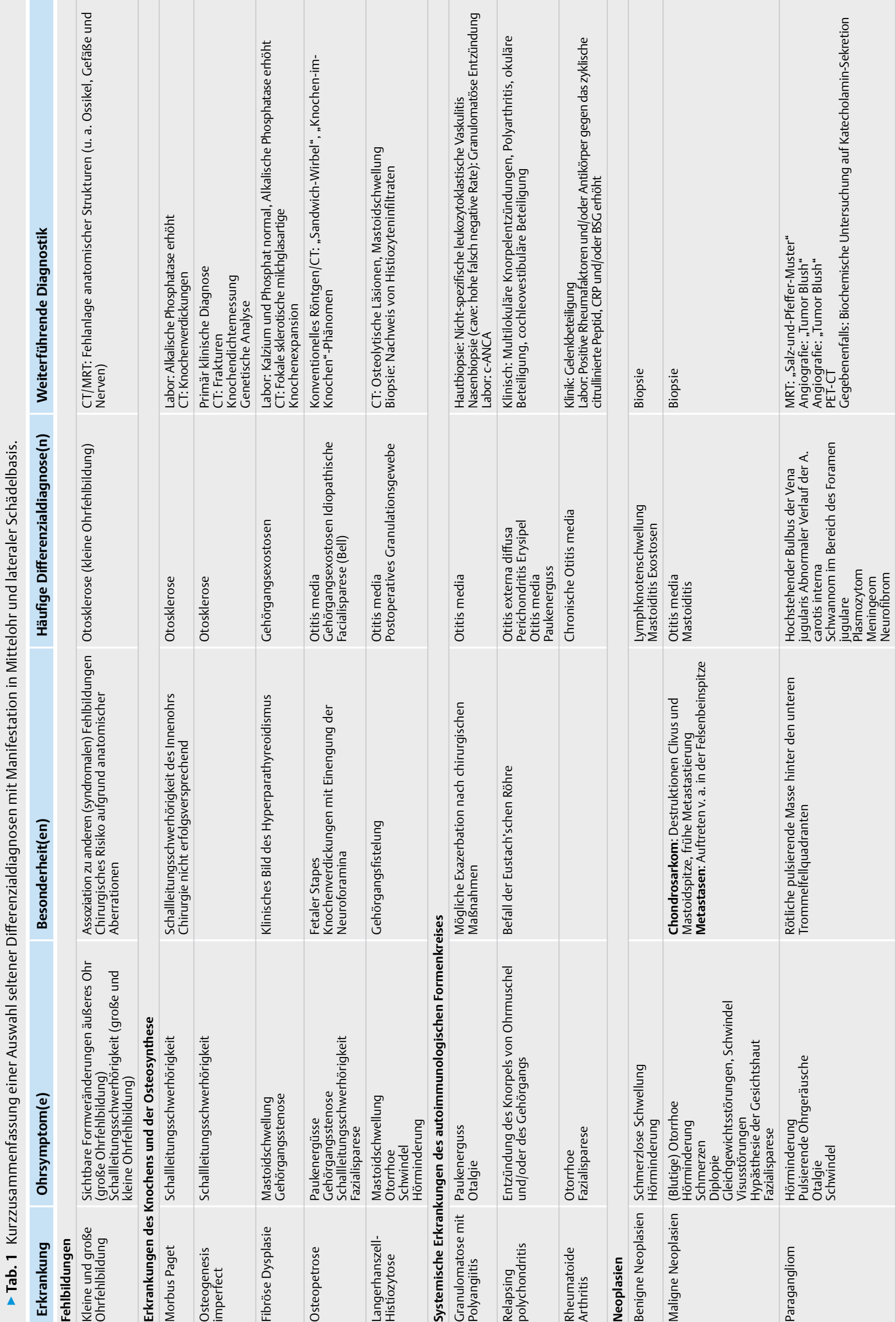


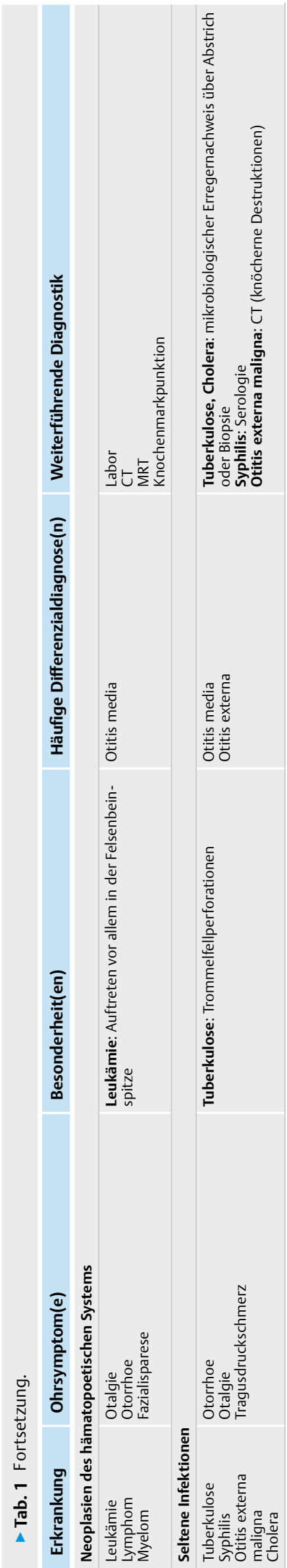

plikationen in der Chirurgie führen. In Fällen von Fehlbildung ist die Arteria stapedia in bis zu 1:5'000-1:10’000 Fällen vorhanden [22]. Eine Ligatur kann zur zentralen Minderperfusion, eine Verletzung zu bedrohlichen Blutungen führen [23].

Weiterhin sind Gefäßanomalien insbesondere bei der Differenzialdiagnose eines pulssynchronen Ohrgeräusches zu berücksichtigen. Es kommen u. a. Anomalien des Bulbus Venae jugularis, des Sinus sigmoideus, der Arteria carotis interna sowie arteriovenöse Fisteln und Malformationen in Frage [24]. Der Tinnitus kann auskultatorisch bei den meisten Fehlbildungen auch für den Untersucher hörbar sein [25]. Im Falle einer venösen Fehlbildung wird der Tinnitus häufiger rechts wahrgenommen, da die Größe der rechten Vena jugularis in der Regel gegenüber links dominiert [26]. Ein hochstehender Bulbus Venae jugularis kann neben Schwindel und Tinnitus eine Schallleitungsschwerhörigkeit verursachen [27-29]. Diese entsteht entweder durch Kontakt zu den Ossikeln oder durch eine Invasion ins knöcherne Labyrinth, wodurch eine Drittfensterläsion (mit Schalleitungsschwerhörigkeit des Innenohres) entsteht $[29,30]$. Eine aberrante Arteria carotis interna ist auf eine Fehlentwicklung während der Embryogenese zurückzuführen. Die Otoskopie zeigt eine rötliche pulsierende Masse hinter dem Trommelfell, die einem Paragangliom des Glomus tympanicum ähnelt. Die Diagnose der jeweiligen Anomalien wird durch die Kombination aus CT/MR-Angiografie und diagnostischer Digitaler Subtraktionsangiografie gestellt [25], welche grundsätzlich bei jedem pulsatilen Tinnitus indiziert ist. Die CT kann zusätzlich eine Aussage über die knöcherne Bedeckung der Gefäßverläufe machen [31-33]. Die Behandlung richtet sich nach der Ausprägung und der subjektiven Beeinträchtigung. Bei arterio-venösen Fisteln besteht das Risiko eines Apoplexes, einer Epilepsie oder einer Hirnblutung [34]. Die Behandlungsoptionen umfassen neben der interventionell-radiologischen Embolisation, der neurochirurgischen Resektion oder einer Radiatio eine symptomatisch medikamentöse Therapie und klinisch radiologischen Verlaufskontrollen [35, 36]. Bei venösen Fehlbildungen kann eine Ligatur erfolgen [25].

\section{Erkrankungen des Knochens 3.1 Morbus Paget (Osteodystrophia deformans, Ostitis deformans, Paget-Syndrom)}

Die Erkrankung wurde erstmals 1873 durch Czerny beschrieben und als „Osteitis deformans“ bezeichnet. Ihren Namen erhielt sie durch Sir James Paget $[37,38]$. Die Ätiologie ist unbekannt, insbesondere existiert bis heute keine sichere Evidenz dafür, dass die Ursache der Erkrankung entzündlichen Ursprungs ist. Diskutiert werden infektiologische Ursachen wie eine Syphilis-Infektion und Paramyxoviren [39], eine endokrine Dysfunktion, autoimmune Ursachen, vaskuläre Läsionen, entzündliche Ursachen und erbliche Faktoren [40]. Mehrere Genloci wurden mit dem Morbus Paget assoziiert. Unter anderem wurde eine Mutation im SQSTM1-Gen beschrieben, welches das Sequestom-1-Protein codiert [41]. Hierbei handelt es sich um ein Autophagosom-cargo-Protein, das andere Proteine zur selektiven Autophagozytose bindet. Die Erkrankung betrifft Männer und Frauen gleichermaßen bei einer Inzidenz bis $3 \%$ im Alter von 40 Jahren und nimmt mit steigender Lebensdekade zu (bis $10 \%$ bei 90 -Jährigen) [42,43]. Neben der Osteoporose handelt es sich beim Morbus Paget, der nur in etwa 30 \% der Fälle 

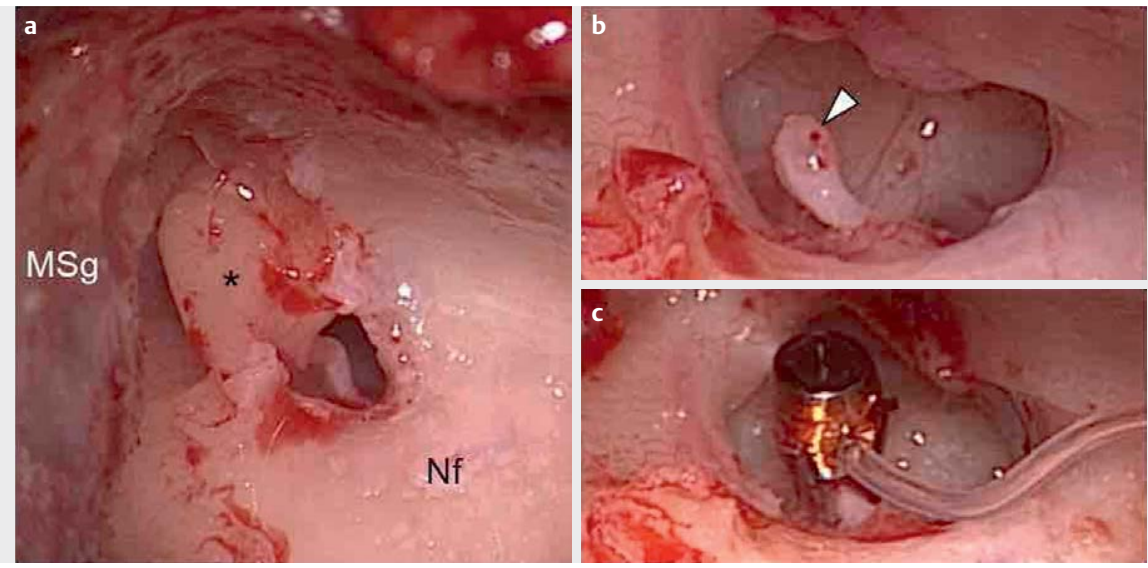

- Abb. 1 Gehörgangsatresie bei großer Ohrfehlbildung bei einem 8-jährigen Kind mit Schallleitungsschwerhörigkeit. a Intraoperative Darstellung des fixierten Hammer-Amboss-Komplexes (Stern). MSg: mittlere Schädelgrube; Nf: Nervus fazialis. b Ansicht auf das Stapesköpfchen (weiße Pfeilspitze) nach Entfernen des Hammer-Amboss-Komplexes. c Ankopplung des Floating Mass Transducers einer Vibrant Soundbridge durch einen CliP Coupler auf das Stapesköpfchen am mobilen Stapes.
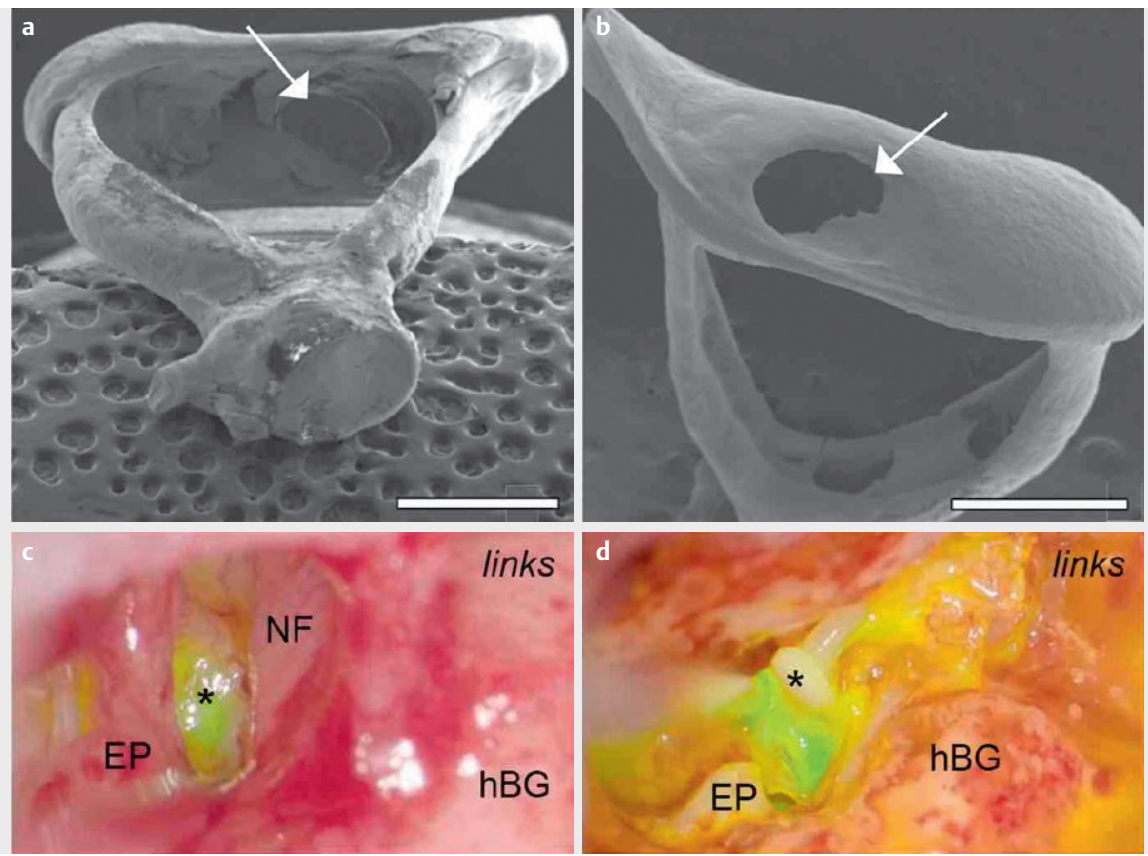

Abb. 2 Kongenitaler Stapesfußplattendefekt links bei einem 20 Monate alten Jungen mit beidseitiger Schläfenbeinmalformation (Cochlea-Aplasie rechts, „Incomplete Partition Type I“ links). Durch ein Bagatelltrauma führte die Stapesfußplattenmalformation auf der linken Seite zur Otorhinoliquorrhoe und schließlich zur Diagnosestellung. a-b Elektronenmikroskopische Darstellung des kongenitalen Stapesfußplattendefektes (Pfeil). Maßstabsbalken: 1 mm. c-d Intraoperative Darstellung der Perforation in der Stapesfußplatte (Asterisk) mit intrathekaler Fluoreszinapplikation. c Der Blick auf den Stapes in situ zeigt einen fluoreszinmarkierten Liquoraustritt durch die Stapesfußplatte. d Bei der Entnahme des Stapes kommt es zum Liquoraustritt aus dem ovalen Fenster. hBG horizontaler Bogengang; NF Nervus fazialis; EP Eminentia pyramidalis. Abbildung modifiziert nach [20].

zu Lebzeiten diagnostiziert wird, um die zweithäufigste Erkrankung des Knochens. Eine Beteiligung des Mittelohres kommt vor, ist jedoch insgesamt selten. Die Prävalenz einer Beteiligung des Schläfenbeins beim Morbus Paget wird auf bis zu $1 \%$ bei kaukasischen Erwachsenen geschätzt [44]. Beim Morbus Paget kommt es nicht in jedem Fall zu Deformitäten der Extremitätenknochen, so wie der Terminus „Osteitis deformans“ vermuten ließe. Etwa ein Drittel der Patienten ist beschwerdefrei. Mögliche Symptome sind Knochen- schmerzen, Verbiegung oder Verkürzung der Beine („Säbelscheidentibia“) oder eine Zunahme des Kopfumfangs.

Typischerweise kommt es zu einem phasenweisen Verlauf, welcher im ersten Schritt durch die Stimulation des Knochenabbaus (osteolytische Phase) mit vermehrter Vaskularisierung und fibrösem Umbau des Knochens einhergeht. Im zweiten Schritt (gemischte Phase) kommt es zu einem überschießenden Knochenanbau. Die dritte, osteoblastische Phase ist durch eine zunehmende Entvaskularisierung charakterisiert. Hierbei entsteht ein aufgetrie- 


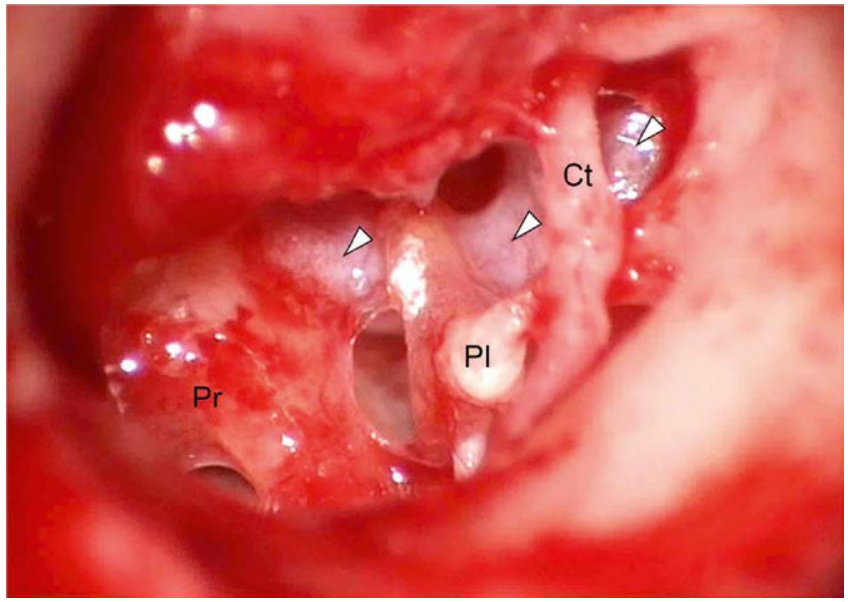

- Abb. 3 Intraoperativer tympanoskopischer Situs einer A. stapedia bei einem 20-jährigen Patienten mit Schallleitungsschwerhörigkeit des linken Ohres. Die A. stapedia läuft unter dem vorderen Stapesschenkel hindurch (weiße Pfeilspitzen). PI Processus lenticularis, $\mathbf{P r}$ Promontorium, Ct Chorda tympani, weiße Pfeilspitzen: A. stapedia.

bener, wenig stabiler Knochen mit erhöhter Frakturneigung. Im Mittelohr können Mikrofrakturen bspw. die Stapesfußplatte betreffen ( $\mathbf{A} \mathbf{A b} \mathbf{b} . \mathbf{4 a}-\mathbf{c})$ [45]. Im vierten Schritt kommt es zu einem langsamen Umbauprozess in einen beinahe normal aussehenden Lamellenknochen. Diese letzte Phase ist überwiegend in subklinischen Fällen mit Schädelbeteiligung und daher ausschließlich histologisch zu finden. Am häufigsten betrifft die Erkrankung Becken, Femur und Tibia. Selten kommt es zu einer Beteiligung der Ossikel [46], welche sich bspw. durch eine Stapesfixation zeigen kann [47]. Die klinische Symptomatik bei Mittelohrbeteiligung ist gekennzeichnet durch einen unauffälligen ohrmikroskopischen Befund, eine Schallleitungsschwerhörigkeit oder kombinierte Schwerhörigkeit und ausgefallene Stapediusreflexe [44]. Die Schallleitungsschwerhörigkeit wird jedoch nicht mit dem Ossikelumbau assoziiert [48]. Zu den möglichen Erklärungen für die Schallleitungskomponente zählen neben der Beteiligung der Ossikel und des Knochens im Epitympanon oder ovalem Fenster [46] eine Gehörgangsverengung, eine Fibrosierung des Trommelfells, Kalzifizierungen im Anulus fibrosus des Trommelfells, eine Atrophie des Trommelfells, eine Verengung der Eustach'schen Röhre oder eine Tympanofibrose [48]. Histologisch sind derartige Veränderung jedoch nicht sicher nachweisbar [49]. Es wird ebenfalls diskutiert, dass die Hörminderung durch Veränderungen in Knochendichte, Masse und Form zu erklären sind, welche zu einer Dämpfung der Feinmechanik in der Signalübertragung führen [49]. Monsell et al. beschrieben eine Korrelation zwischen der Knochendichte der cochleären Kapsel und der Luftleitungsschwelle sowie der Schallleitungskomponente [50, 51]. Merchant und Rosowski untersuchten acht Schläfenbeine von Patienten mit Morbus Paget mit Laserdopplervibrometrie. In 3 Fällen zeigten sich dabei eine relative Hypermobilität des Umbo, so wie sie auch bei Dehiszenzen des superioren Bogengangs nachgewiesen werden konnte [27]. Weiterhin wurden multiple Mikrofrakturen der otischen Kapsel in allen 8 Fällen beobachtet. Folglich wird angenommen, dass die akustische Energie durch die Frakturen im Sinne einer Drittfensterläsion von der Cochlea weggeleitet wird und dadurch zu einer Schallleitungsschwerhörigkeit des Innenohrs führt [27, 52]. Aufgrund der Schallleitungsschwerhörigkeit besteht die Gefahr der Fehleinschätzung eines Morbus Paget als Otosklerose mit dem Risiko einer erfolglosen chirurgischen Behandlung [47].

Zur Diagnostik des Morbus Paget zählen daher neben Reintonaudiometrie und Stapediusreflexen im Falle einer Mittelohrbeteiligung die Labordiagnostik, welche eine erhöhte Alkalische Phosphatase zeigt. Im konventionellen Röntgen lassen sich bei Frühmanifestation Osteolysen nachweisen. In der Computertomografie (CT) können sich im Schläfenbein Knochenverdickungen, eine Verlagerung der Arteria carotis interna, eine Erweiterung des Mastoids mit Reduktion der Pneumatisierung, eine Verengung des inneren Gehörgangs sowie, sehr selten, eine Nervenkompression zeigen [53]. Häufiger wird durch das Wachstum des Mastoids eine Erweiterung des inneren Gehörgangs beschrieben $[45,48]$. In der Szintigrafie zeigt sich ein vermehrter Technetium-99m-Uptake im befallenen Knochen, weshalb sie eine sinnvolle Ergänzung der radiologischen Abklärung sein kann. Gegebenenfalls kann eine Biopsie des befallenen Knochens zur histologischen Sicherung beitragen.

Die Behandlung des Morbus Paget besteht in der Hemmung der Osteoklastenaktivität durch Bisphosphonate, wodurch die Deformität verhindert werden kann. Zusätzlich kommen Analgetika zum Einsatz. Die weitere Behandlung ist symptomatisch durch die Behandlung der Frakturen ( $\bullet$ Abb. 5), Kalziumzufuhr und Vitamin D sowie Physiotherapie.

Der Morbus Paget kann sich in Mittelohr und Mastoid manifestieren und zu einer (am ehesten im Innenohr lokalisierten) Schallleitungsschwerhörigkeit führen. Eine Behandlung erfolgt jedoch systemisch. Bei Patienten mit Schallleitungsschwerhörigkeit und weiteren klinischen Hinweisen für einen Morbus Paget kann daher eine diagnostische Bildgebung ( $\vee$ Abb. 4d, e) hilfreich sein um die Erkrankung von der Otosklerose abzugrenzen und eine chirurgische Behandlung durch Ossikuloplastik zu verhindern, welche als nicht erfolgsversprechend gilt [47, 54].

\subsection{Osteogenesis imperfecta}

Die Osteogenesis imperfecta $(\mathrm{Ol})$ ist eine genetische Bindegewebserkrankung, welche durch einen fragilen, frakturanfälligen Knochen charakterisiert ist. Eine Genmutation eines der beiden Typ-IKollagen-Gene (COL1A1 oder COL1A2) werden bei $80-90 \%$ der Patienten beschrieben.

Die Ol wird in 4 Typen entsprechend der klinischen Manifestation, radiologischen Kriterien und dem Vererbungsmuster eingeteilt [55, 56]: Die OI Typ I wird autosomal dominant vererbt. Es handelt sich um die mildeste Form. Klinisch ist sie charakterisiert durch blaue Skleren, nicht-deformierende Frakturen und eine normale Körpergröße. In 50\% der Fälle kann es zu einer Hörminderung kommen. Bei der OI Typ II handelt es sich um die schwerste Form, die bereits in utero mit multiplen Frakturen einhergeht und häufig zu Totgeburten führt. Die OI Typ II wird entweder autosomal dominant vererbt oder entsteht durch sporadische Neumutation. Die OI Typ III manifestiert sich mit häufigen Frakturen und progredienter Knochendeformierung von Kindheit an. Initial bestehen bläuliche Skleren, später sind sie weiß. In 50 \% der Fälle besteht eine Hörminderung. Zusätzlich kann es zur Kyphoskoliose, zu schwachen Gelenken, einer Trichterbrust, Zahnveränderungen und zu Schaltkno- 

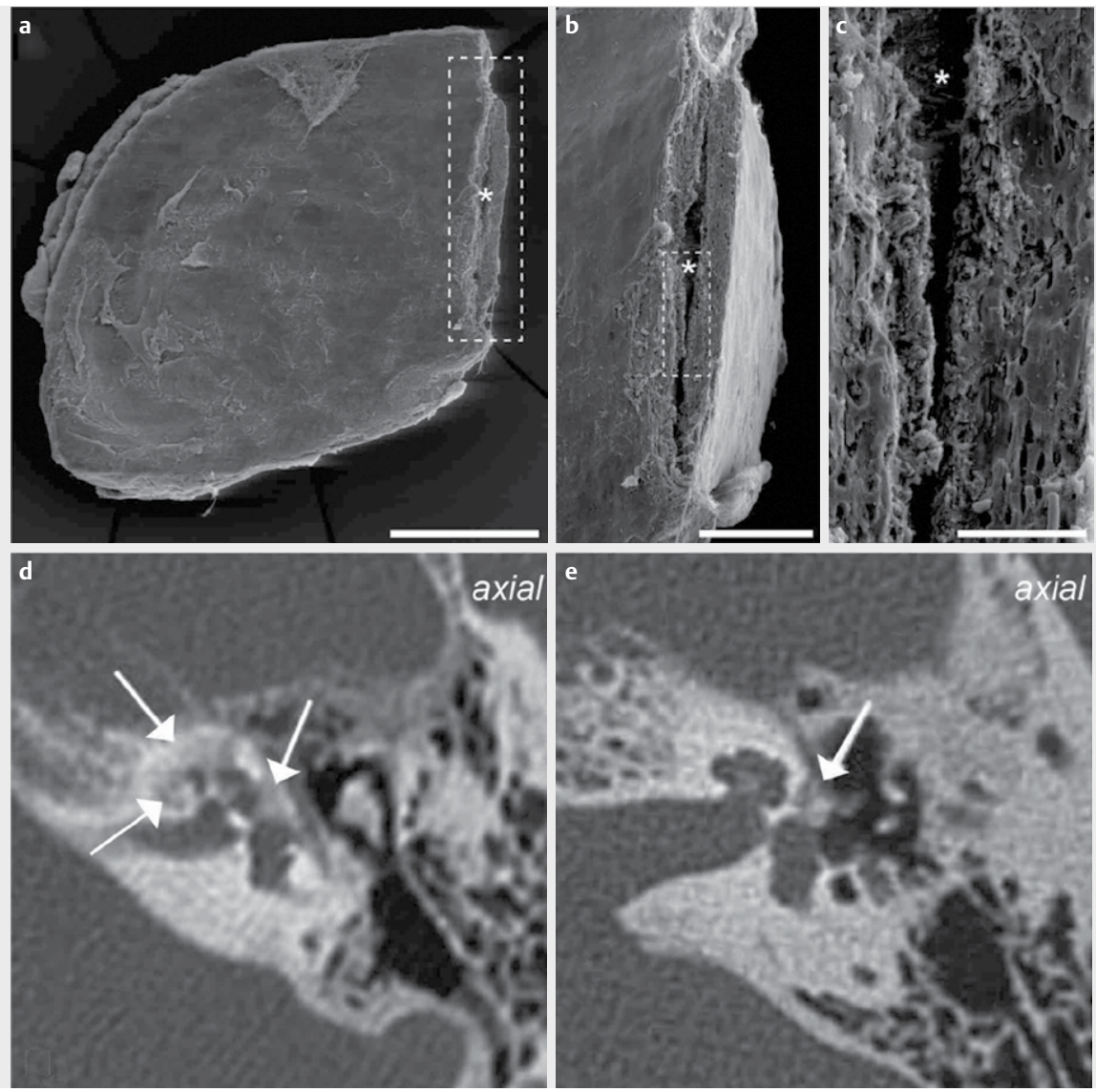

Abb. 4 a-c Rasterelektronenmikroskopische Darstellung einer Stapesfußplattenfraktur. Abbildung modifiziert nach [323]. a Ein Teil der Fußplatte

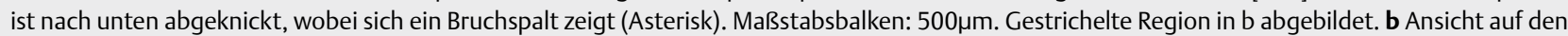

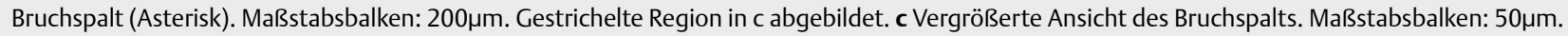
d-e CT-morphologische Unterscheidung zwischen Morbus Paget und der Otosklerose. d Beim Morbus Paget zeigen sich Umbauprozesse innerhalb der Cochlea (Pfeile). e Bei der fenestralen Otosklerose zeigen sich Plaques in der Fissula ante fenestram mit einer gemischt otospongiotisch-otosklerotischen Phase (Pfeil). Abbildung d-e modifiziert nach [54] (Mit freundlicher Genehmigung von S. Kösling, Institut für Radiologie, Universitätsklinikum Halle (Saale)).

chen des Schädels (kleine akzessorische Knochen innerhalb einer Schädelnaht) kommen. Die Vererbung erfolgt autosomal dominant oder rezessiv. Das Vererbungsmuster der OI Typ IV ist autosomal dominant. Klinisch ähnelt sie der OI Typ I, geht aber mit weißen Skleren einher. Eine Hörminderung besteht in nur 10-30\% der Fälle.

Otologische Symptome werden am häufigsten bei der OI Typ I beobachtet, wobei v. a. eine Hörminderung relevant ist. Dabei kann es sich um eine Schallleitungsschwerhörigkeit oder eine kombinierte Schwerhörigkeit handeln, welche zumeist auf Knochenumbauprozesse am Stapes zurückzuführen ist und der Otosklerose ähneln kann. Intraoperativ werden weiche, kalkartige Verdickungen der Stapesfußplatte, vaskularisierter Knochen in der ovalen Nische, bedeckt von vaskularisiertem Periost, eine fibröse Degeneration der Stapesschenkel sowie eine osteoporotische Fixation der Fußplatte ähnlich der Otosklerose beschrieben [57-60]. Eine chirurgische Hörrehabilitation durch eine Stapesplastik ist möglich, gilt aber aufgrund des weichen porösen Knochens und dem Risiko einer schwimmenden Fußplatte („floating footplate“) als chirurgisch anspruchsvoll [57-59]. Weitere allgemeine Behandlungsansätze liegen in der Behandlung der Frakturen, Orthesen, Physiotherapie und Bisphosphonaten als Inhibitor der Knochenresorption. Als neue
Ansätze befinden sich Knochenmarkstransplantation [61, 62], intrauterine Stammzellimplantation [63], Wachstumsfaktoren [64] und die Antikörpertherapie $[65,66]$ in experimenteller Erprobung.

\subsection{Fibröse Dysplasie}

Erstmalig beschrieben wurde die fibröse Dysplasie durch Weil [67]. Es handelt sich um eine chronische, langsam progrediente Erkrankung die z. B. im Rahmen des Albright Syndroms mit knöchernen Läsionen, abnormaler Pigmentierung („Café-au-lait-Flecken“), endokriner Dysfunktion und einer Pubertas praecox auftreten kann [68]. Histologisch ist die Erkrankung durch die Resorption von Knochen und einen fibrösen Umbau in Stroma sowie durch Knochenläsionen aus unreifen mesenchymalen, osteoblastischen Vorläuferzellen gekennzeichnet. Sie sind bedingt durch eine nicht-vererbbare aktivierende Mutation im Gen der $\alpha$-Untereinheit des stimulatorischen G-Protein codierenden Gens. Folglich kommt es zur Erhöhung von cyclischem Adenosinmonophosphat, was u. a. über die pathologische Aktivierung von zahlreichen Proteinkinasen neben diversen anderen Effekten zu den pathologischen Knochenläsionen führt $[69,70]$. 

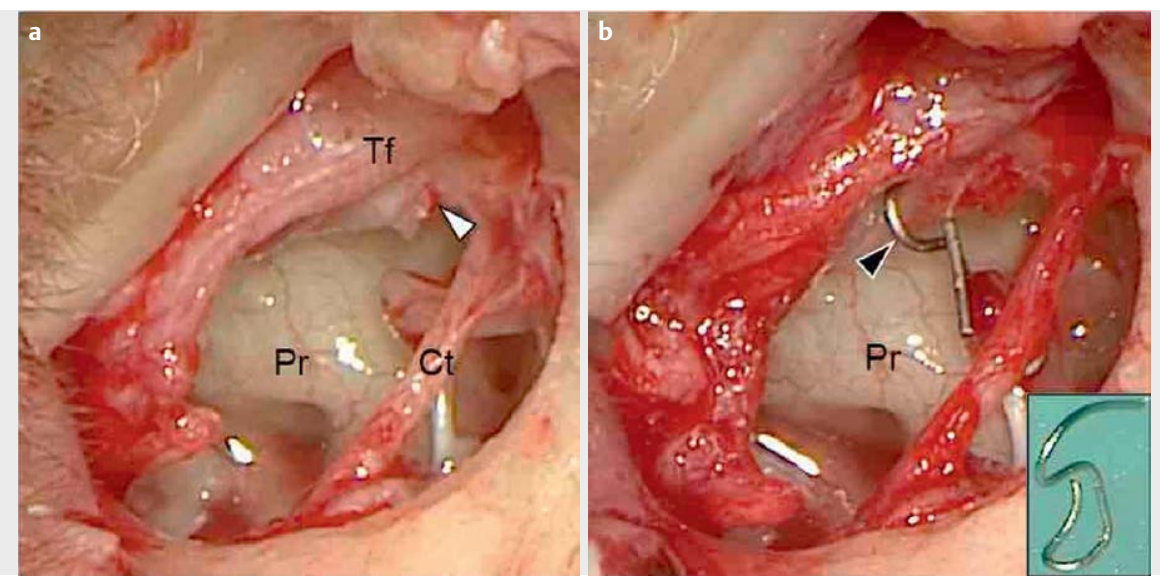

Abb. 5 a Intraoperative Sicht in die Paukenhöhle bei einer 30-jährigen Patientin mit Schallleitungsschwerhörigkeit nach Hammergrifffraktur (weiße Pfeilspitze). Tf Trommelfell, Pr Promontorium, Ct Chorda tympani. b Ansicht nach Rekonstruktion der Ossikelkette durch eine Malleostapediopexie (schwarze Pfeilspitze). Einschub unten rechts: Malleostapediopexie-Prothese aus Titandraht.

Symptomatisch wird die Erkrankung mit Beginn in der Kindheit. Man unterscheidet die monoostotische von der poliostotischen Form. Die poliostotische Form ist lebenslang progredient und involviert üblicherweise die langen Knochen. Der Schädelknochen ist in über 50 \% der Fälle betroffen. Die monoostotische Form ist die häufigere Variante und verstummt oft in der Pubertät. Sie beteiligt die langen Knochen, Gesichtsknochen und membranösen Knochen. Eine sarkomatöse Entartung der Knochenläsionen ist möglich [71-73]. Die Prävalenz liegt bei etwa 2.5\% [74]. Aufgrund der häufig auftretenden Knochenschmerzen und einer laborchemischen Erhöhung der alkalischen Phosphatase kann das klinische Bild der fibrösen Dysplasie einem Hyperparathyreoidismus ähneln. Aus diesem Grunde wird bei Patienten mit fibröser Dysplasie häufig über frustrane chirurgische Eingriffe unter dem Verdacht eines Nebenschilddrüsentumors berichtet [75]. Man unterscheidet die isolierte fibröse Dysplasie vom Hyperparathyreoidismus über die Labordiagnostik (Kalzium, Phosphat, alkalische Phosphatase). In der Labordiagnostik zeigt sich eine erhöhte alkalische Phosphatase die in $30 \%$ bei der poliostotischen Form auftritt. Kalzium und Phosphat hingegen sind bei der fibrösen Dysplasie meist normal.

In der Literatur existieren mehr als 100 berichtete Fälle von fibröser Dysplasie mit Schläfenbeinbeteiligung. Hierbei handelt es sich in $70 \%$ der Fälle um die monoostotische, in $23 \%$ der Fälle um die polyostotische Form und $7 \%$ traten im Rahmen des McCuneAlbright-Syndroms auf [48]. Klinisch kann es beim Befall des Schläfenbeins zu einer schmerzlosen Schwellung des Mastoids, weiteren knöchernen Deformitäten, pathologischen Frakturen und Hirnnervenlähmungen kommen. Durch eine progrediente Einengung des äußeren Gehörgangs kann es zur Schallleitungsschwerhörigkeit kommen. Sie ist das häufigste Symptom bei der fibrösen Dysplasie im Schläfenbein und wird in 80 \% der Fälle mit Schläfenbeinbeteiligung berichtet. Eine Fehlinterpretation als Gehörgangsexostosen ist häufig. Intraoperativ zeigt sich jedoch - anders als bei Exostosen - ein vaskularisierter Knochen mit spongiöser, grobkörniger Konsistenz. Ebenso kann die Beteiligung von Mittelohr oder eine Tubenobstruktion Ursache für eine Schallleitungsschwerhörigkeit sein. Radiologisch zeigen sich strahlendurchgängige Areale mit weicher rundlicher Begrenzung sowie teils röntgendichte Areale ( $\bullet$ Abb. 6).

Die allgemeine Behandlung der fibrösen Dysplasie besteht aus Physiotherapie und einer Behandlung der Frakturen. Die chirurgische Therapie wird nur symptomatisch oder als Biopsie zur Diagnosesicherung bzw. beim Verdacht auf eine Entartung eingesetzt. Die Gehörgangsplastik kann zur symptomatischen Behandlung der Schallleitungsschwerhörigkeit oder bei rezidivierenden Gehörgangsentzündungen sinnvoll sein. Vor einer geplanten chirurgischen Abtragung von Exostosen können in der CT mit teils strahlendurchgängigen, teils röntgendichten Arealen Hinweise für eine fibröse Dysplasie aufgedeckt werden. Eine regelmäßige Nachkontrolle ist wegen der Gefahr einer progredienten Einengung des Fazialiskanals und einem progredienten Hörverlust erforderlich.

\subsection{Osteopetrose („Albers-Schönberg-Syndrom“, "Marmorknochenkrankheit“)}

Bei der Osteopetrose kommt es zu einer stark erhöhten Knochendichte [76, 77], welche durch defekte Osteoklasten und die dadurch bedingte abnormale Knochenresorption verursacht wird. Gleichzeitig bestehen eine ungestörte Osteoblasten-Aktivität und dadurch gesteigerte Bildung von mineralisiertem Knochen und Knorpel. Die Prävalenz wird auf 1:20’000 geschätzt [78]. Es kommt zu einer fehlerhaften Resorption von kalzifiziertem Knorpel und primitivem Knochen, wodurch es zur Persistenz von mineralisiertem Knorpel und primitiver Knochenmatrix kommt, was die Reifung von Knochen verhindert. Die Erkrankung existiert als dominant vererbte benigne und rezessiv vererbte maligne Variante.

In der malignen Form tritt die Osteopetrose meist in der Kindheit in Erscheinung, ist rasch progressiv und weist eine hohe Mortalitätsrate auf. Ursache der malignen Osteopetrose ist in der Mehrzahl der Fälle eine Genmutation im TCIRG1 -Gen [78], welches eine Untereinheit der vakuolären Protonenpumpe kodiert. Als Folge der Osteopetrose kommt es zum Zurückdrängen des Knochenmarks und dadurch zur Anämie und Thrombozytopenie. Zusätzlich können eine Hepatosplenomegalie, eine Infektneigung, eine Einengung der Neuroforamina mit Neurodegeneration, frontaler Vor- 


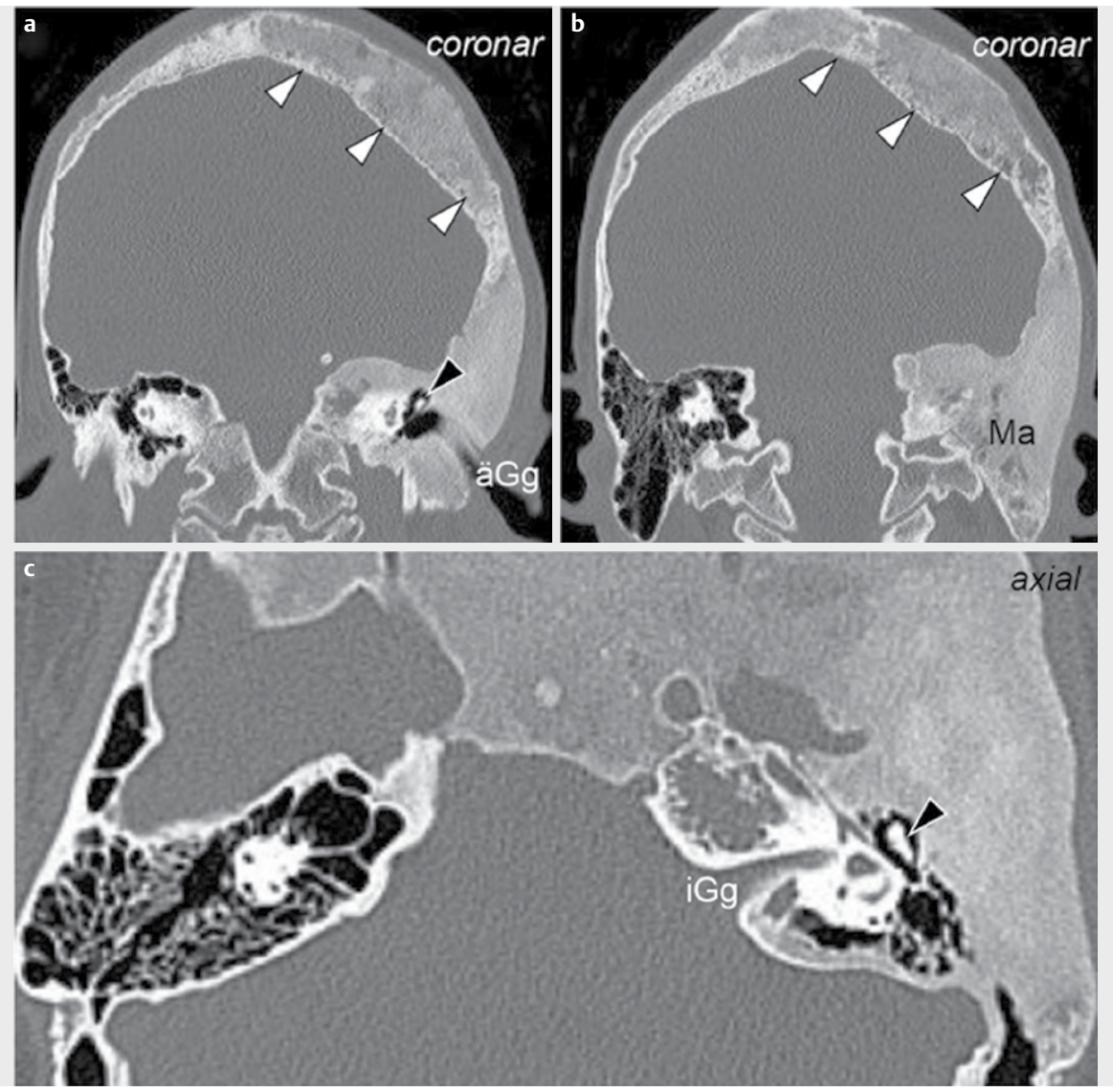

- Abb. 6 CT des Schädels bei einer 23-jährigen Patientin mit fibröser Dysplasie. a, b Es zeigt sich die pathognomonische fokale sklerotische milchglasartige Knochenexpansion mit Beteiligung der Schädelkalotte (weiße Pfeilspitzen), des Os zygomaticum, Os sphenoidale und des Schläfenbeins links. Der äußere Gehörgang (äGg) ist deutlich eingeengt. Der Malleus ist regelrecht konfiguriert (schwarze Pfeilspitze). Das linke Mastoid (Ma) weist einen fast vollständigen Verlust der Pneumatisierung auf. c Der innere Gehörgang (iGg) ist normal weit. Es finden sich ein regelrecht konfigurierter Malleus und Incus (schwarze Pfeilspitze) in einem belüfteten Mittelohr.

wölbung, Wachstumsverzögerung, Fazialisparese, Hör- und Sehminderung, Frakturen und mentaler Retardierung auftreten. Es besteht eine deutlich begrenzte Lebenserwartung (1. bis 2. Lebensdekade). Histologisch zeigt sich im Schläfenbein dichter, kalzifizierter Knochen von Labyrinth und Ossikeln [79], ein nicht pneumatisiertes Mastoid sowie ein fetaler Stapes ( $\bullet$ Abb. 7). Als ohrspezifische Symptomatik kann es zu rezidivierender Otitis media, Paukenergüssen, Gehörgangsstenosen und Schallleitungsschwerhörigkeit kommen [80, 81]. Als Therapie kommt bei der malignen Form eine Knochenmarktransplantation zum Einsatz [82].

Die benigne Form der Osteopetrose ist in der Regel asymptomatisch. Betroffene Patienten haben eine normale Lebenserwartung. Sie wird durch eine Genmutation im CLCN7-Gen verursacht, welches die $\alpha$-Untereinheit des Chlorid-Transporters ClC-7 kodiert [76]. Die Osteopetrose kann zu einer Einengung der Hirnnerven durch eine Schädelverdickung führen (Nervus opticus, Nervus trigeminus, Nervus vestibulocochlearis und Nervus fazialis). Spontane Fazialisparesen mit Spontanerholung treten als häufiges Erstsymptom auf. Bei Fazialisparesen im jungen Erwachsenen- oder Kindesalter, insbesondere bei rezidivierenden Paresen, ist daher zwingend an eine Bildgebung zu denken. Zusätzlich ist auf Zahninfektionen durch Osteomyelitis, Kieferverdickung, intrakraniellen
Venenstau durch die Schädelverdickung und eine dadurch bedingte Hirndruckerhöhung sowie auf eine kutane Syndaktylie, welche häufig zur Erstdiagnose führt, zu achten.

Eine Schwerhörigkeit kann durch die Einengung des Mittelohrraumes, durch knöcherne Einlagerungen in der ovalen Nische und eine dadurch bedingte Fixation der Gehörknöchelchen entstehen $[83,84]$. Weiter kann die Einengung des Anulus fibrosus zum Erschlaffen des Trommelfells und eine Verengung der Eustach'schen Röhre zum Paukenerguss als weitere Ursachen für eine Schallleitungsschwerhörigkeit führen [85]. Bezüglich der im Rahmen der Osteopetrose auftretenden Fazialisparesen wird über einen therapeutischen Erfolg durch die komplette, intratemporale Fazialisdekompression berichtet $[83,86,87]$. Bei erhöhtem Hirndruck kann die dekomprimierende Kraniotomie zur Reduktion des Hirndrucks führen. Eine Tympanoplastik kann zur Hörverbesserung beitragen.

\subsection{Langerhanszell-Histiozytose}

Bei der Langerhanszell-Histiozytose handelt es sich um eine Neoplasie-ähnliche Erkrankung, die zu einer akuten disseminierten Infiltration verschiedener Organsysteme führt und unbehandelt eine hohe Letalität hat. Hintergrund sind die Proliferation von benignen Histiozyten sowie die Ansammlung von pathologisch veränderten 


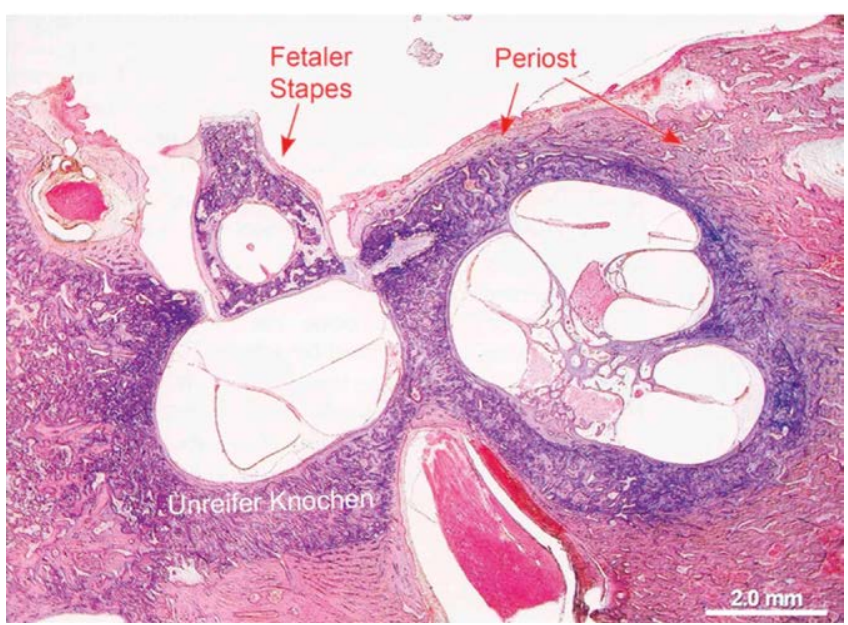

- Abb. 7 Osteopetrose des Schläfenbeines in einem axialen histopathologischen Schläfenbeinschnitt eines 15 Monate alten Jungen. Der Patient litt an einer mentalen Retardierung und einer kongenitalen beidseitigen Taubheit. Der Stapes zeigt eine fetale Form, charakterisiert durch eine Verdickung der Stapesschenkel und Fußplatte. Der unreife Knochen besteht aus einer Kombination aus kalzifiziertem Knorpel und dünnen Trabekeln lamellären Knochens. Der unreife Knochen ist verdickt und zeigt eine erhöhte Dichte. Abbildung modifiziert nach [48]

Langerhanszellen. Langerhanszellen sind inaktive dendritische Zellen im Stratum spinosum der Epidermis, die CD1a, S100-Protein und Langerin exprimieren $[88,89]$ und der Antigenpräsentation dienen. Langerhanszellen gehören zum mononukleär-phagozytären System. Ursache der Langerhanszell-Histiozytose ist am ehesten eine Proliferation der Langerhanszellen durch eine immunologische Dysfunktion. Die Inzidenz liegt zwischen 1:200'000 und 1:2'000'000. Es werden 3 Unterformen der Langerhanszell-Histiozytose unterschieden, auf die im Folgenden eingegangen werden soll.

\subsubsection{Unifokales eosinophiles Granulom}

Das eosinophile Granulom tritt üblicherweise bei jungen Erwachsenen und Kindern auf. Es handelt sich um die mildeste Form der Erkrankung und führt zu solitären osteolytischen Läsionen. In der Regel kommt es nur zur skelettalen Beteiligung der langen Röhrenknochen, Rippen, Wirbel, Schädel, und auch des Mastoids. Es kann zu kleinen Schläfenbeinläsionen mit möglicher Gehörgangs-Fistelung, zu Otalgie, mastoidaler Schwellung, zu Hirnnervenlähmungen durch knöcherne Läsionen am Foramen jugulare und zu Otorrhoe kommen. Die Behandlung liegt in der lokalen Kürettage und ggf. auch in einer Bestrahlung $[90,91]$.

\subsubsection{Hand-Schüller-Christian-Syndrom}

Das Hand-Schüller-Christian-Syndrom tritt bei Kindern unter dem 5. Lebensjahr, selten auch in der 2. oder 3. Lebensdekade auf. In 15-30\% kommt es zu einem tödlichen Ausgang. Im Gegensatz zum eosinophilen Granulom sind multifokale Läsionen in Knochen und Organen (z. B. in Leber oder Milz) mit eingelagerten Histiozyten, Cholesteroleinlagerungen und multinukleären Zellen üblich. Die extraskelettalen Manifestationen in Haut, Lymphknoten und Orga- nen sind selten. Zu den systemischen Symptomen zählen Fieber, wiederkehrende Infekte der oberen Atemwege, Appetitlosigkeit und Lymphknotenschwellungen. Die klinische Symptomatik am Ohr kann das Bild einer akuten oder einer chronischen Otitis media imitieren. Die Diagnose wird durch eine Biopsie und den Nachweis der Histiozyten erbracht. Gelegentlich kommt es zur Spontanregression. Die Behandlung besteht aus einer low-dose Chemotherapie zur systemischen Symptomkontrolle.

\subsubsection{Letterer-Siwe-Syndrom}

Hierbei handelt es sich um eine disseminierte, schnell voranschreitende, meist im Alter unter 3 Jahren auftretende Erkrankungsform, die zu einer diffusen Organbeteiligung führt. Es kann zur Hepatosplenomegalie, zu Lymphknoten-Schwellungen, zur Anämie, zu Hautausschlag und skelettalen Läsionen (v. a. am Schädel) kommen. Der Krankheitsverlauf ist akut febril und geht mit einer schlechten Prognose und hohen Mortalitätsrate einher [92]. Die Behandlung besteht aus Kortikosteroiden, zytotoxischen Substanzen wie Methotrexat, Vincritsin und Cyclophosphamid. Weiterhin stehen eine Bestrahlung, Knochenmark-transplantation oder Stammzelltransplantation [93] zur Verfügung. Im Fall eines Überlebens kommt es zu bleibenden Stigmata wie Minderwuchs, Diabetes insipidus, Exophthalmus, Lungenfibrose und Wirbelkörperkompressionen. In bis zu $25 \%$ der Fälle kommt es zu destruierenden Knochenläsionen mit Kalottendefekten. Diese können das Schläfenbein beteiligen und zu einer otologischen Symptomatik führen. Die Erkrankung manifestiert sich initial häufig am Ohr mit dem Auftreten von Granulationsgewebe, Polypen, Otorrhoe, retroaurikulärer Schwellung, Schwindel, Hörminderung und gelegentlich einem positiven Fistelzeichen [94-101]. Aufgrund der Ähnlichkeit zur chronischen Otitis media wird in der Literatur über häufige Mastoidoperationen vor der eigentlichen Diagnosestellung berichtet $[95,96,102,103]$. In der CT des Schläfenbeines finden sich knochendestruktive Läsionen [95, 96, 104]. Die Diagnose wird durch eine Biopsie aus den tiefen Abschnitten der Läsion gesichert ( $\bullet$ Abb. 8) [105].

Zusammenfassend können alle Formen der Langerhanszell-Histiozytose zu einem entzündlichen Erkrankungsbild führen. Bei CTmorphologisch beidseitig destruktiven Ohrerkrankungen, die mit erhöhter Blutsenkungsgeschwindigkeit und ohne sonstige Hinweise für eine Infektion einhergehen oder bei langfristig bestehendem Granulationsgewebe nach einer Ohr-OP mit persistierender Otorrhoe und Hautläsionen oder Gehörgangsfistelungen muss deshalb differenzialdiagnostisch an die Langerhanszell-Histiozytose gedacht werden und eine Biopsie erfolgen.

\subsection{Proteus-Syndrom}

Das Proteus-Syndrom verursacht einen Großwuchs von Haut, Knochen, Muskeln, Fettgewebe, Blut- und Lymphgefäßen. Die Ursache der Erkrankung ist bisher nicht geklärt. Als mögliche Ursachen werden Mutationen an den Genen AKT1, PTEN oder somatische Mutationen diskutiert. Bei Geburt sind die Betroffenen meist ohne offensichtliche äußere Veränderungen. Betroffene tragen ein erhöhtes Risiko für die Entwicklung bestimmter Tumoren wie bspw. einseitiger ovarieller Zystadenome, Hodentumore, Meningeome und Adenome der Speicheldrüsen. Die Erkrankung kann am Mastoid zu Knochenwucherungen und dadurch ähnlich wie bei Gehör- 


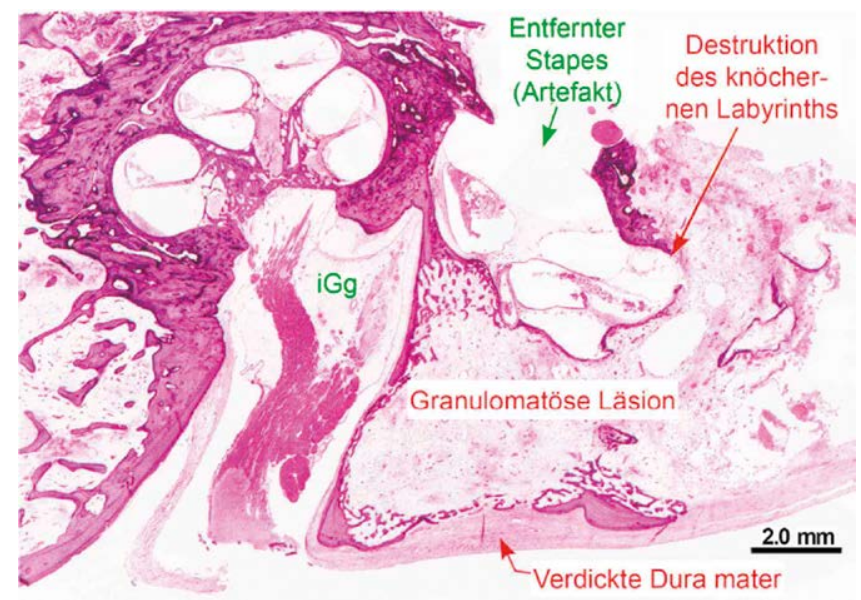

Abb. 8 Langerhanszell-Histiozytose (Letterer-Siwe-Erkrankung) in einem axialen histopathologischen Schnitt des Schläfenbeins eines 23 Monate alten Kindes mit bilateraler Otorrhoe. Zur Diagnose der Langerhanszell-Histiozytose führte die Biopsie des Gehörgangs. Die Histologie zeigt destruktive granulomatöse Läsionen in Mastoid und knöchernem Labyrinth sowie eine verdickte Dura mater. Der fehlende Stapes ist als Artefakt zu werten. iGg: innerer Gehörgang. Abbildung modifiziert nach [48].

gangsexostosen zur Gehörgangsobstruktion führen. Zur funktionellen Hörverbesserung kann eine chirurgische Gehörgangserweiterung indiziert sein. Intraoperativ zeigen sich die exostosenähnlichen Knochenwucherungen nicht als kompakter Knochen, sondern als reizlose und belüftete Mastoidzellen oder ähnlich der Konsistenz der fibrösen Dysplasie.

\section{Erkrankungen des autoimmunologischen Formenkreises}

\subsection{Granulomatose mit Polyangiitis}

Bei der Granulomatose mit Polyangiitis (ehemals Morbus Wegener) kommt es zum Auftreten nekrotisierender Granulome der oberen und unteren Atemwege, in Niere und selten auch in anderen Organen. Eine Manifestation im Fachgebiet der HNO kann durch rezidivierende Sinusitiden, Kopfschmerzen, Rhinorrhoe oder Otitis media auftreten. Laborchemisch lassen sich neben einer normochromen, normozytären Anämie auch eine Thrombozytose, positive Rheumafaktoren, eine Hyperglobulinämie (IgA) sowie Anti-Neutrophile cytoplasmatische Antikörper (c-ANCA) nachweisen. Des Weiteren besteht eine erhöhte Blutsenkungsgeschwindigkeit. Die Genese der Erkrankung ist nicht vollständig geklärt, wobei eine immunsystemvermittelte Störung vermutet wird. Hierbei kommt es zur Gewebezerstörung infolge eines entzündlichen Erkrankungsbildes mit anschließender Immunreaktion [106]. Teil der Immunreaktion ist die Produktion von c-ANCA, welche einen Zellschaden durch die Interaktion von Neutrophilen und Schleimhautgewebe hervorrufen. Die Diagnose wird histologisch aus wiederholten Biopsien sowie der Kombination von Klinik und dem Nachweis von c-ANCA gestellt. Es zeigen sich Zellnekrosen und entzündliche Granulome mit mehrzellkernigen Riesenzellen, Vaskulitiden und Mikroabszessen [48]. Die Erkrankung kann das Mastoid, das Mittelohr, das Trommelfell betreffen. Wenn die Eustach'sche Röhre be- troffen ist, ähnelt die Symptomatik der einer akuten Otitis media mit Paukenerguss. Weiterhin kann es zum Auftreten von Fazialisparesen [107] oder sensorineuralem Hörverlust kommen [108, 109]. Das Auftreten im Mittelohr kann mit einer Destruktion des runden Fensters, des Fallop'schen Kanals und des Innenohres einhergehen [110,111]. Die Therapie besteht aus Immunsuppressiva und Steroiden, welche zur Remission des Hörverlustes führen können [112]. Unbehandelt verläuft die Erkrankung in $90 \%$ der Fälle tödlich.

In der Konsequenz ist insbesondere bei der bilateralen, rezidivierenden oder protrahierten Otitis media an eine autoimmunologische Erkrankung zu denken und nach c-ANCA zu suchen. Chirurgische Maßnahmen sind bei der Granulomatose mit Polyangiitis aufgrund des Risikos von protrahierten Heilungsverläufen zurückhaltend zu stellen [113].

\subsection{Eosinophile Granulomatose mit Polyangiitis (Churg-Strauss-Syndrom)}

Die eosinophile Granulomatose mit Polyangiitis zählt ebenfalls zu den Vaskulitiden. Zu den Leitsymptomen gehört eine pulmonale Manifestation mit schweren allergischen Asthmaanfällen. Eine Manifestation in Mittelohr und Mastoid ist selten und kann zum Bild einer akuten Otitis media bzw. einer Mastoiditis oder einer chronisch granulierenden Otitis media führen $[114,115]$. Die konventionelle Behandlung mit Antibiose und Parazentese ist bei der eosinophilen Granulomatose mit Polyangiitis meist frustran. Wegweisend ist der Nachweis von perinukleären Antikörpern (p-ANCA). Die Therapie besteht aus Steroiden [116].

\subsection{Rezidivierende Polychondritis (Relapsing poly- chondritis)}

Die Erstbeschreibung erfolgte 1923 durch Jaksch-Wartenhorst [117]. Charakterisiert wir die Erkrankung durch rezidivierende Entzündungsreaktionen des Knorpels. Neben Ohrmuschel und Gehörgang können auch das Auge, das kardiovaskuläre System, Niere und Nervensystem betroffen sein. Die Ursache ist nicht bekannt. Häufig bestehen Assoziationen zu anderen Autoimmunerkrankungen. Es wird angenommen, dass es sich um eine Autoimmunreaktion auf Bindegewebe und Epitope handelt, welche infolge des Ausfalls regulierender Faktoren entsteht $[118,119]$. Typisch ist eine ein- oder beidseitige Entzündung der Ohrmuschel, aber auch der knorpelige Gehörgang kann betroffen sein und so dem Bild einer Otitis externa diffusa ähneln [120]. Durch einen Verschluss der Eustach'schen Röhre kann ebenfalls das Bild einer akuten Otitis media mit Paukenerguss entstehen. Die Diagnose erfolgt nach klinischen Kriterien und muss beim Auftreten von bilateralen Ohrmuschelentzündungen, $v$. a. in Kombination mit einer nicht-erosiven, seronegativen Polyarthritis, nasalen Knorpelentzündungen, Augenentzündungen (Konjunktivitis, Keratitis, Skleritis, Uveitis), Knorpelentzündungen des Respirationstraktes (laryngealer oder trachealer Knorpel) sowie einer vestibulocochleären Dysfunktion in Erwägung gezogen werden [121]. Die Behandlung besteht aus der Anwendung von Immunsuppressiva und Steroiden.

\subsection{Rheumatoide Arthritis}

Bei der rheumatoiden Arthritis handelt es sich um eine chronisch entzündliche Autoimmunerkrankung, deren Ursache nicht vollständig geklärt ist. Vermutet wird eine genetische Prädisposition, 
die zu einer erhöhten Immunreaktion auf einen initialen Infekt auftritt. Im Jahr 1989 beschrieben Hoffman et al. den Fall einer 69-jährigen Patientin mit Rheumatoider Arthritis und Befall von Mittelohr sowie Mastoid, welcher das klinische Bild einer chronischen Otitis media zeigte und in einer Fazialisparese resultierte [122]. Gussen et al. berichten vom Fall einer 55-jährigen Patientin mit Beteiligung des Hammer-Amboss-Gelenkes [123]. Histopathologisch werden in seltenen Fällen ein verdicktes Trommelfell und ein fibröser Umbau der Ossikelkette sowie eine Demineralisierung von Hammer und Amboss beschrieben [124]. Folglich kann das Bild einer akuten Otitis media und gegebenenfalls einer Fazialisparese bei Patienten mit rheumatoider Arthritis für einen akuten Schub der Grunderkrankung sprechen und erfordert ein gemeinsames Therapiekonzept mit der Rheumatologie.

\section{Neoplasien}

Verschiedene Neoplasien können sich in Mittelohr und lateraler Schädelbasis manifestieren. Die Anamnese nach Symptomatik und Vorerkrankungen (z. B. pulssynchrones Ohrgeräusch, bekannte neoplastische Erkrankungen in der Vorgeschichte, Noxen, syndromale Erkrankungen) kann erste Hinweise für die Ursache liefern. Die Diagnose kann je nach Befund durch eine weiterführende Diagnostik (z. B. radiologische Bildgebung) erhärtet und histologisch durch eine Biopsie gesichert werden. Die Behandlung richtet sich nach Entität und Symptomatik und besteht in der Regel entweder aus einer chirurgischen Resektion, einer medikamentösen Tumortherapie, Radiatio oder einer Kombinationtherapie.

\subsection{Neoplasien des hämatopoetischen Systems}

Erkrankungen des Blutes und des hämatopoetischen Systems lassen sich heute in die folgenden 4 Subkategorien gruppieren $[125,126]$.

1. Myeloide Neoplasien, welche von den Progenitorzellen im Knochenmark ausgehen, aus denen sich üblicherweise Erythrozyten, Granulozyten, Monozyten und Megakaryozyten entwickeln. Diese sind weiter unterteilt in die akute myeloische Leukämie, die myeloproliferativen Neoplasien (Chronisch Myeloische Leukämie, Polycythaemia vera, essentielle Thrombozytopenie) und myelodysplastische Syndrome.

2. Lymphoide Neoplasien gehen von den Progenitorzellen der Lymphozyten oder reifen Lymphozyten aus. Historisch werden sie weiter unterteilt in lymphoide Neoplasien mit Knochenmark- und Blutbeteiligung (Leukämie) und in Lymphommassen. Eine Abgrenzung ist jedoch nicht immer sicher möglich. Eine heute gängigere Klassifizierung ist die Unterteilung nach B-Zell, bzw. T-Zell- oder Natural-Killer-(NK)Zell-Lymphom. Das Hodgkin-Lymphom stellt eine weitere Unterkategorie dar und geht von den Keimzellen der B-Zellen aus.

3. Neoplasien mit myeloischem und lymphoidem Anteil, z. B. die akute Leukämie.

4. Histiozytäre/dendritische Neoplasien (z. B. histiozytäres Sarkom) ausgehend von den dendritischen Zellen oder Histiozyten.

Da die Mehrheit der Literatur, welche das Auftreten hämatologischer Erkrankungen im Ohr beschreibt, vor der Veröffentlichung der oben zitierten Klassifikation publiziert wurde, ist hier häufig eine ältere Terminologie (Leukämie, Lymphom, Myelom) gebräuchlich.

\subsubsection{Leukämie des Schläfenbeines}

Die Leukämie des Schläfenbeines ist histologisch durch eine diffuse Infiltration, Einblutungen und Umbau des Mastoidknochens (v. a. der Felsenbeinspitze) durch leukämische Zellen gekennzeichnet ( Abb. 9) [127-130]. Trommelfell und Mukosa des Mittelohres können durch leukämische Infiltrate verdickt sein und ein inflammatorisches Exsudat absondern. Häufig kommt es zu Sekundärinfektionen.

Eine Sonderform ist das Granulozytäre Sarkom, wobei es sich um eine extramedulläre Ansammlung von unreifen Zellen mit myeloischer Differenzierung außerhalb des Knochenmarks handelt. Zu den Symptomen, welche in erster Linie durch Wachstum bedingt sind, zählen Völlegefühl, Otalgie, Otorrhoe und Fazialisparese. Das Bild ähnelt einer Otitis media acuta [131]. Die Diagnostik umfasst eine CT, welche knöcherne Destruktionen zeigen kann, und eine Magnetresonanztomografie (MRT), welche eine Signalanreicherung in den entsprechenden Läsionen nach Kontrastmittelgabe aufweist.

\subsubsection{Myelom des Schläfenbeines}

Das Myelom des Schläfenbeines entspricht dem B-Zell Non-Hodgkin-Lymphom (Kategorie 2) und kann alle Körperknochen, vorwiegend Wirbelsäule und lange Röhrenknochen, betreffen. Es tritt meist zwischen dem 40. und 60. Lebensjahr auf. Das Schläfenbein ist in der Regel erst im terminalen Stadium betroffen. Histologisch imponiert der Ersatz des Knochens durch Plasmazellen (Myelomzellen). Die Symptomatik kann ebenfalls einer akuten Otitis media ähneln [132], wird aber in der Regel durch die anderen Manifestationsorte überschattet.

Erkrankungen des Blutes und des hämatopoetischen Systems können unter Umständen zur Erstmanifestation in Mittelohr und Mastoid führen und durch Otorrhoe und Mastoidschwellung einer akuten Otitis media oder einem Hautulkus ähneln (156). Aufgrund des möglichen aggressiven Krankheitsverlaufes ist eine frühzeitige Diagnose und Initiierung einer Chemotherapie notwendig.

\subsection{Maligne epitheliale Neoplasien}

Maligne epitheliale Neoplasien des Ohres haben ihren Ursprung in $60 \%$ an der Ohrmuschel, in $28 \%$ im Gehörgang, und in $12 \%$ im Mittelohr oder Mastoid [133]. Die Inzidenz liegt zwischen 1:4'000 und 1:20'000. Bei Auftreten im Mittelohr zeigen maligne epitheliale Neoplasien eine schlechtere Prognose als bei Auftreten im Gehörgangs oder der Ohrmuschel $[133,134]$. Maligne epitheliale Neoplasien der Ohrmuschel sind zu 2 Dritteln Basalzellkarzinome (früher als „Basaliome“ bezeichnet) und zu einem Drittel Plattenepithelkarzinome (früher als „Spinaliome“ bezeichnet). Im Mittelohr ist die Verteilung mit 2 Dritteln Plattenepithelkarzinomen und nur einem Drittel Basalzellkarzinome umgekehrt. Über das Auftreten des malignen Melanoms im Mittelohr existieren fast ausschließlich Fallberichte. In $11 \%$ der Fälle zeigt sich bei Erstdiagnose bereits eine lymphogene Metastasierung [133]. Das maligne Melanom zeigt mit einer Metastasierungsrate von etwa $50 \%$ eine äußerst schlechte Prognose [135]. Zu den möglichen Symptomen zählen Otorrhoe, 

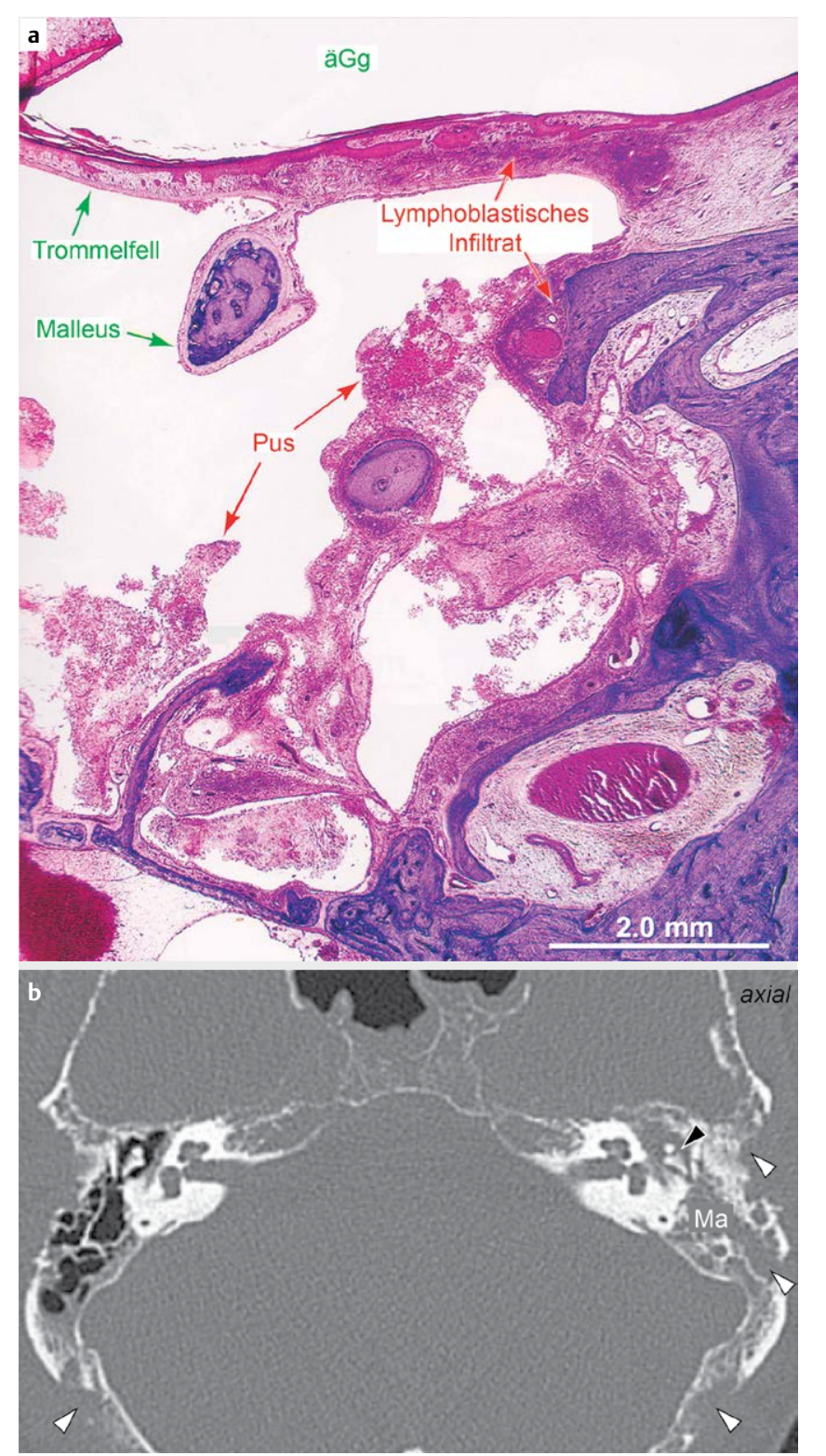

- Abb. 9 a Akute lymphozytäre Leukämie in einem axialen histopathologischen Schnitt des rechten Schläfenbeins eines 9-jährigen Jungen. Klinisch bestanden neben einer Otalgie ein hyperperfundiertes rechtes Trommelfell sowie eine teigige Mastoidschwellung. Der histopathologische Schnitt zeigt lymphoblastische Infiltrate, eine ödematöse Verdickung und Hypervaskularisation des Trommelfells sowie der Mittelohrmukosa. Weiterhin fand sich Pus im Cavum tympani. äGg: äußerer Gehörgang. Abbildung modifiziert nach [48]. b Axiale CT des Schläfenbeins eines 55-jährigen männlichen Erwachsenen mit chronisch lymphatischer Leukämie der B-Zell-Reihe (B$\mathrm{CLL})$. Es zeigen sich knöcherne Destruktionen der Schädelkalotte und des linken Mastoids (weiße Pfeilspitzen) mit vollständiger Verlegung der belüfteten Mastoidzellen. Ma Mastoid; schwarze Pfeilspitze Hammer-Amboss-Gelenk.

Hörminderung und Schmerzen [135]. Außerdem kann es zu einer Fazialisparese, Schwindel sowie zu mastoidaler Rötung oder Schwellung kommen $[133,136]$. Als Risikofaktor für das Auftreten von malignen epithelialen Tumoren des Mittelohres wird eine Bestrahlung genannt [137-140]. Die Diagnose wird durch die Biopsie oder eine Exzision gesichert. Die Therapie besteht aus der chirurgischen Resektion. Bei Mittelohrbeteiligung muss immer auch eine subtotale Petrosektomie durchgeführt werden.

\subsection{Glanduläre Neoplasien}

Zum Leitsymptom benigner glandulärer Neoplasien zählen schmerzlose Schwellungen und Hörminderung, bei malignen Neoplasien kann es zu Otorrhoe und Nervenparesen kommen. Es werden 4 Entitäten der glandulären Neoplasien nach Dehner und Chen unterschieden [141]. Murphy et al. beschrieben 1980 das Karzinoid des Mittelohres [142].

\subsubsection{Adenom}

Adenome können von den apokrinen Drüsen des Gehörgangs, meist von den Ceruminaldrüsen, ausgehen. Daher wurde ehemals der Begriff Ceruminom verwendet. Allerdings sind auch andere Drüsengewebe wie die Haarfollikel oder Talgdrüsen als Ursprung möglich. Drüsen haben einen zweischichtigen Aufbau und bestehen innen aus einer oxyphilen, außen aus einer myoepithelialen Schicht. Daher haben Neoplasien eine pleomorphe Zellpopulation aus basalen myoepithelialen Zellen (welche Cytokeratin Typ 5 und 6, S100 und das Tumorprotein p63 exprimieren) sowie aus luminalen ceruminösen Zellen, welche Cytokeratin Typ 7 exprimieren [143]. Gehen die Adenome vom Mittelohrepithel aus, zeigt sich lichtmikroskopisch ein durch den Tumor gebildeter Mukus im Zytoplasma oder im Drüsenlumen [144]. Histologisch besteht Ähnlichkeit zu gemischten Tumoren oder zum adenoidzystischen Karzinom. Vom Karzinom ist das Adenom durch eine fehlende Knochenarrosion zu unterscheiden. Klinisch zeigt sich eine Masse in Mittelohr oder Gehörgang, welche ein langsam progredientes Wachstum aufweist, welches mit einem langsamen Hörverlust assoziiert sein kann. Selten kann es zum Auftreten von Fazialisparesen [145] oder zu einem pulssynchronen Ohrgeräusch kommen [146].

\subsubsection{Pleomorphes Adenom}

Ein pleomorphes Adenom kann im Gehörgang auftreten und klinisch durch eine Schwellung auffällig werden. Es kann von den Zeruminaldrüsen oder in seltenen Fällen von ektopem Speicheldrüsengewebe ausgehen [147-152]. Mikroskopisch ist das pleomorphe Adenom durch ein buntes histologisches Muster mit myxoiden Anteilen in $90 \%$, pseudokartilaginösen Anteilen in $50 \%$ und plattenepithelialen Anteilen in $25 \%$ gekennzeichnet [153].

\subsubsection{Adenoidzystisches Karzinom}

Beim adenoidzystischen Karzinom handelt es ich um ein vom apokrinen, seromuzinösen Ceruminaldrüsengewebe oder vom Speicheldrüsengewebe ausgehendes Malignom, das im Gehörgang auftreten kann. Zu den Symptomen zählen neben Schmerzen Schwellungen, hervorgerufen durch ein langsames Wachstum. Das Karzinom neigt zu Rezidiven nach chirurgischer Entfernung und zu Fernmetastasen. Die Rezidivrate wird mit $41 \%$ innerhalb eines durchschnittlichen Intervalls von acht Jahren angegeben [154]. Histologisch zeigt sich ein sogenanntes „Schweizer-Käse-Muster“, gekennzeichnet durch Zylinder mit hohlen Zentren und mit eingelagertem 
azidophilem mukösen Material. Differenzialdiagnostisch ist an ein Basalzellkarzinom, an Ceruminome, Mukoepidermoidkarzinome und Adenokarzinome zu denken [155].

\subsubsection{Adenokarzinome}

Adenokarzinome entwickeln sich aus Drüsenatypien der Zeruminaldrüsen [156, 157] oder Talgdrüsen [158, 159] des äußeren Gehörgangs oder Mittelohrepithel [160-162]. Differenzialdiagnostisch müssen Metastasen eines Adenokarzinoms in Betracht gezogen werden.

\subsubsection{Karzinoid des Mittelohres}

Die Erstbeschreibung erfolgte 1980 durch Murphy et al. [142]. Der Tumor geht von den neuroendokrinen Zellen (sogenannte Kulchitsky-Zellen) aus, welche in großer Zahl in Pankreas, Lunge und Gastrointestinaltrakt vorhanden sind und Peptidhormone synthetisieren. Von einem Auftreten des Karzinoids im Mittelohr sind am häufigsten Erwachsene überwiegend weiblichen Geschlechts betroffen [163]. Zur Symptomatik zählen Schallleitungsschwerhörigkeit sowie eine Schwellung oder Raumforderung im Mittelohr. Es wird eine Rezidivrate von $22 \%$ beschrieben. In $9 \%$ kann es zu Metastasen kommen [163]. Histologisch besteht Ähnlichkeit zum Adenom. Es wird diskutiert, dass es sich um den gleichen Tumor mit unterschiedlich ausgeprägter glandulärer und neuroendokriner Differenzierung handelt $[164,165]$.

\subsection{Sarkome}

\subsubsection{Osteogenes Sarkom}

Das osteogene Sarkom ist die häufigste maligne Neoplasie des Knochens und tritt zu etwa $75 \%$ bei Patienten zwischen dem 10. und 25. Lebensjahr auf. Zum Auftreten bei Kindern kann es im Rahmen des Retinoblastoms, Li-Fraumeni-Syndroms, Rothmund-ThomsonSyndroms oder Werners-Syndrom kommen [166]. Bei älteren Erwachsenen wird eine Assoziation mit dem Morbus Paget oder einer Bestrahlung beschrieben [167]. Das osteogene Sarkom geht von den mesenchymalen Stammzellen aus, welche zu Knochen, Bindegewebe oder Knorpel differenzieren können. Charakterisiert wird es durch ein malignes sarkomatöses Stroma mit Bildung von Osteoid (weicher, nicht mineralisierter Knochen) und Knochen. In 90\% der Fälle sind die Metaphysen der langen Röhrenknochen betroffen [168]. Ein Auftreten im Schläfenbein ist sehr selten [138, 169176]. Die vorhandenen Fallberichte lassen eine Assoziation zur Bestrahlung annehmen (z. B. bei Nasopharynxkarzinom oder Paragangliom). Die Prognose durch Bestrahlung induzierter Tumore ist schlecht [138]. Zu den Symptomen zählen eine umschriebene, langsam wachsende retroaurikuläre Schwellung von derber knöcherner Konsistenz, welche zur Haut verschieblich ist [174]. Gegebenenfalls kann diese Schwellung schmerzhaft sein und mit Otorrhoe einhergehen [173].

\subsubsection{Rhabdomyosarkom}

Das Rhabdomyosarkom betrifft in der Regel Kinder. Es kann sich in Orbita, Mundhöhle, Nase, Pharynx oder Mittelohr manifestieren ( Abb. 10) [177, 178]. Meist tritt es in der ersten Lebensdekade, unter dem fünften Lebensjahr auf [179]. Tritt ein Befall des Mittelohres auf, verläuft die Erkrankung fast immer tödlich [180,181]. Hierbei ist neben einer Ausdehnung in die Mastoidspitze und die mittlere Schädelgrube ein Wachstum entlang des Fallop'schen Kanals und des inneren Gehörgangs in die hintere Schädelgrube möglich $[182,183]$. Histologisch zeigen sich je nach Abstammung Rhabdomyoblasten oder quergestreifte Muskulatur und in der Immunfärbung muskelspezifische Proteine wie Actin, Myosin, Desmin und Myoglobulin. Elektronenmikroskopisch sind Myofilamente, Z-Banden, Desminfilamente zu sehen. Es existieren 4 histologische Untergruppierungen (embryonal, alveolär, botryoid, spindelzellig). Zu den Symptomen zählen eine blutige Otorrhoe, was die Gefahr einer Verwechslung mit einer akuten Otitis media birgt, sowie meist erst im späteren Stadium - eine Fazialisparese. Die Therapie ist in der Regel eine Polychemotherapie, welche in zertifizierten onkologischen Zentren durchgeführt werden soll. Die Therapie erfolgt nach Registrierung im Cooperative-Weichteilsarkomstudie (CWS)-Register „Soft Tissue Sarcoma Registry“ (SoTiSaR) und Empfehlung der CWS-Studienzentrale. Nur in Ausnahmefällen und nach Beurteilung durch ein chirurgisches Referenzzentrum für Rhabdomyosarkome ist eine chirurgische Therapie indiziert. Diese muss unter Berücksichtigung der funktionellen Ausfälle sorgfältig indiziert werden $[179,184,185]$.

\subsubsection{Chondrosarkom}

Knorpelneoplasien machen bis zu 33\% der Knochentumore aus. Eine Unterscheidung zum Chondrom ist schwierig [186]. Chondrosarkome betreffen in der Regel Erwachsene zwischen dem 25. und 50. Lebensjahr. Chondrosarkome weisen ein langsames Wachstum und eine gleiche Geschlechterverteilung auf. Die Klinik zeichnet sich durch eine frühe pulmonale Metastasierung, durch ein schnelles Wachstum und osteolytische Läsionen als Zeichen der Malignität aus [187, 188]. Ein Befall des Schläfenbeines ist sehr selten und tritt am ehesten in der Mastoidspitze und im Clivus auf [189-191]. Zu den Symptomen zählen Diplopie, Kopfschmerzen, Hörminderung, Gleichgewichtsstörungen, Visusveränderungen sowie eine Hypästhesie der Gesichtshaut. Weiterhin ist auch ein Befall des Gehörgangs möglich [189, 192].

\subsection{Paragangliome des Schläfenbeins (tympano- juguläre Paragangliome)}

Die Erstbeschreibung der gefäßreichen Paragangliome (früher als „Glomustumore“ bezeichnet; Glomus = autonomes Ganglion = Paraganglion) erfolgte 1941 durch Guild [193]. Es handelt sich um die häufigste Neoplasie des Mittelohres [194], welche von den parasympathischen Ganglienzellen ausgeht. Es werden 2 Arten von Paragangliomen beschrieben, „chromaffine“ (Epinephrin-produzierende) und nicht-,chromaffine“ (nicht Epinephrin-produzierende) [195]. Paragangliome treten meist sporadisch auf, wenige sind mit einem hereditären Syndrom assoziiert, typischerweise mit der Multiplen endokrinen Neoplasie Typ 2, dem von-Hippel-LindauSyndrom oder der Neurofibromatose Typ 1 [196, 197]. In seltenen Fällen kommt es zu einem multifokalen Auftreten [194, 198]. Die hereditären Paragangliome beruhen auf Keimbahnmutationen, welche den mitochondrialen Succinat-Dehydrogenase-Komplex betreffen. Bei den hereditären Paragangliomen kommt es häufiger als bei den sporadischen Paragangliomen zu einem multilokulären Auftreten, zur Manifestation in jüngerem Alter und zur Assoziation 

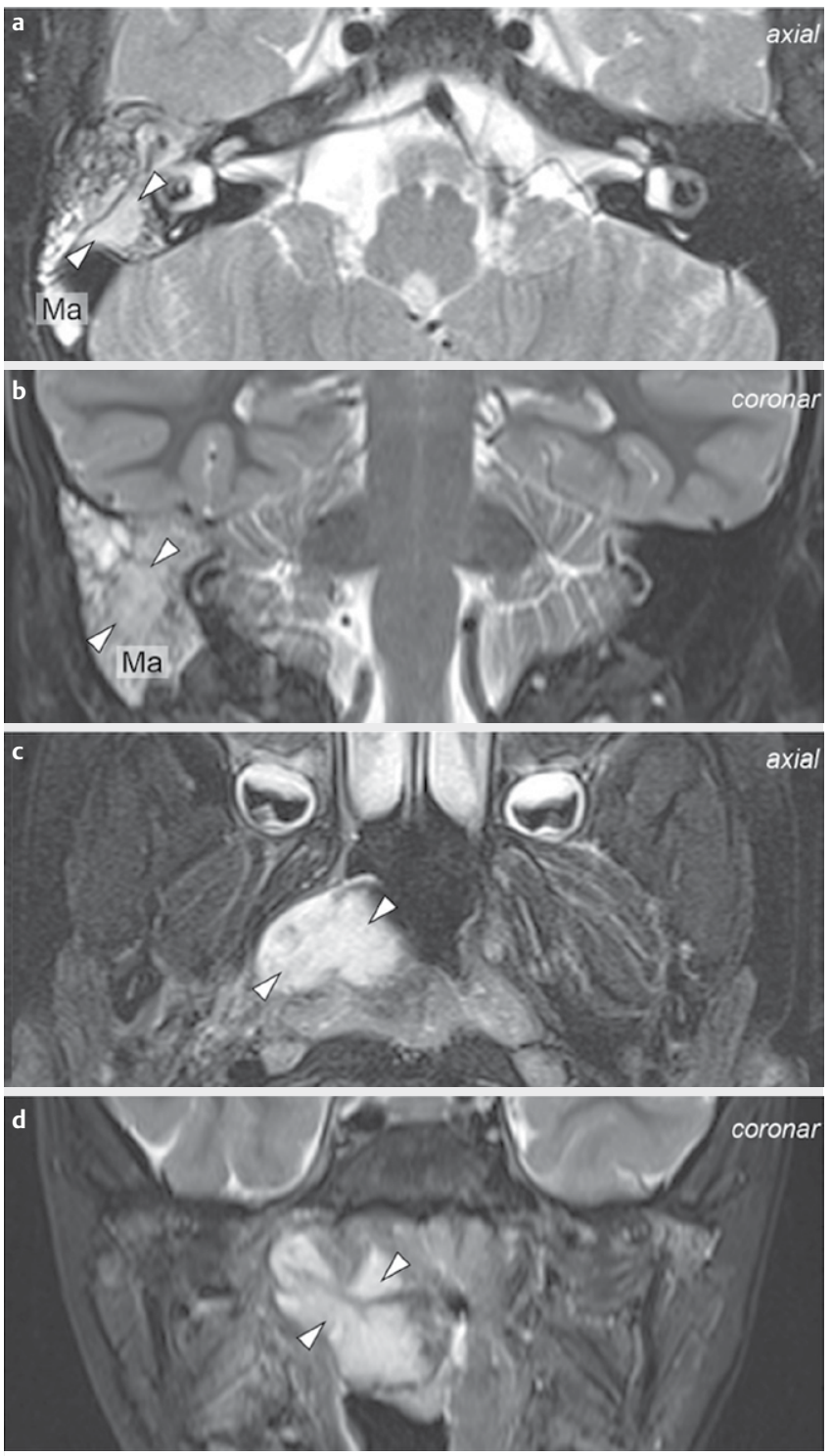

- Abb. 10 T2-gewichtete fettsupprimierte MRT-Aufnahmen eines 5-jährigen Jungen mit einem embryonalen Rhabdomyosarkom des rechten Mastoids und Epipharynx. Es zeigt sich ein hyperintenses Signalverhalten des Tumors (weiße Pfeilspitzen) mit vollständiger Verlegung der belüfteten Mastoidzellen (Ma, a, b). Über die Felsenbeinspitze dehnt sich der Tumor (weiße Pfeilspitzen, $\mathbf{c}, \mathbf{d}$ ) in den Epipharynx aus.

mit neuroendokrinen Tumoren. Daher wird bei Patienten mit Paragangliomen eine genetische Diagnostik empfohlen [199]. Das häufigste Muster besteht aus einem Paragangliomen des Mittelohres (Tumor des Glomus tympanicum im Mesotympanon) und der ipsilateralen Carotis-Gabel (Tumor des Glomus caroticum). Paragangliome treten meist im mittleren Alter auf, wobei Frauen häufiger betroffen sind als Männer [200]. Die Klassifikation der tympano-jugulären Paragangliomen erfolgt gemäß der Fisch-Klassifikation [201]. Das Paragangliom des Mittelohres (Fisch Typ A) hat seinen Ursprung im Glomus tympanicum und ist auf das Mittelohr begrenzt. Paragangliome der Fossa jugularis ossis temporalis (vom Glomus jugulare ausgehend) aber auch Paragangliome des Nervus
Vagus (vom Glomus vagale ausgehend) können das Schläfenbein destruieren. Bei Paragangliomen Typ D nach Fisch kommt es zu einer intrakraniellen Ausdehnung.

Zu den Symptomen zählen eine Hörminderung in 91-100\% der Fälle [202, 203], pulsierende Ohrgeräusche in etwa $52 \%$ der Fälle, Otalgie mit etwa 28 \% sowie Schwindel in etwa $25 \%$ der Fälle [202, 203]. In der klinischen Untersuchung zeigt sich klassischerweise eine rötliche pulsierende Masse hinter den unteren Trommelfellquadranten ( $\triangleright$ Video. 1). Differenzialdiagnostisch ist an einen hochstehenden Bulbus der Vena jugularis, an einen abnormalen Verlauf der Arteria carotis interna, an ein Schwannom im Foramen jugulare, ein Plasmozytom, Meningeom oder Neurofibrom zu denken [204]. Paragangliome der Fossa jugularis können frühzeitig durch ein verdrängendes Wachstum, bzw. durch Kompression zu Läsionen der kaudalen Hirnnerven führen. Durch Einwachsen in die belüfteten Mastoidzellen kann eine Infiltration des infralabyrinthären Raumes bereits vor radiologisch sichtbaren Knochendestruktionen erfolgen [205]. Anschließend können knöcherne Destruktion von Cochlea und vestibulärem Labyrinth auftreten [205]. Die Inzidenz des malignen Paraganglioms wird auf etwa 1:4'000'000 Menschen geschätzt [206, 207]. Fernmetastasen im Rahmen maligner Paragangliome sind selten, werden jedoch in bis zu $4 \%$ der Fälle beschrieben und können in Lunge, Leber oder Lymphknoten auftreten [208]. Ihre Gefäßversorgung beziehen Paragangliome des Mittelohres typischerweise aus der Arteria tympanica inferior und aus der Arteria pharyngea ascendens. Große Tumoren erhalten zusätzlich Blutzufluss aus der Arteria vertebralis [209]. Zur Diagnostik gehören eine MRT und eine Angiografie. In der T1gewichteten MRT zeigt sich typischerweise ein sogenanntes Salzund-Pfeffer-Muster aufgrund der unterschiedlichen Strömungsgeschwindigkeiten innerhalb des reich vaskularisierten Tumors ( $\triangleright \mathbf{A b b}$. 11) [210]. Die funktionelle nuklearmedizinische Bildgebung weist eine hohe Sensitivität für die Identifikation von Paragangliomen auf [211]. Sie ist indiziert bei Patienten unter 40 Jahren, bei positiver genetischer Diagnostik, wenn eine positive Familienanamnese für Paragangliome vorliegt oder bei besonders großen Paragangliomen um ein multilokuläres Auftreten bzw. eine Metastasierung auszuschließen [212]. Die Therapie richtet sich u. a. nach der Tumorgröße, den betroffenen Strukturen, dem Alter bei Diagnosestellung, der Hormonexpression und weiteren Begleiterkrankungen. Eine Indikation zur Operation wird in der Regel bei kleineren Tumoren gestellt, bei denen mit der chirurgischen Resektion ein Funktionserhalt angestrebt werden kann. Sie geht mit einer vorherigen Embolisation einher. Bei Inoperabilität, hohem Alter oder schweren Begleiterkrankungen die das Operationsrisiko und die postoperative Morbidität erhöhen, steht als Alternative eine Radiatio mit guten Langzeitergebnissen zur Verfügung [213-215]. Bei multilokulärem oder bei metastasiertem Wachstum kann auch eine Radiorezeptor Therapie indiziert sein [216].

\subsection{Metastasen}

In Mittelohr und Mastoid auftretende Metastasen können ihren Primarius in Brust, Niere, Lunge, Magen, Larynx, Prostata, Schilddrüse, Cervix, Leber, Hirn oder Haut haben [217, 218]. Da Metastasen meist erst im späten Krankheitsverlauf auftreten sind die Symptome häufig durch die Symptomatik des Primärtumors oder durch weitere Metastasen überschattet. Schläfenbeinmetastasten ähneln 

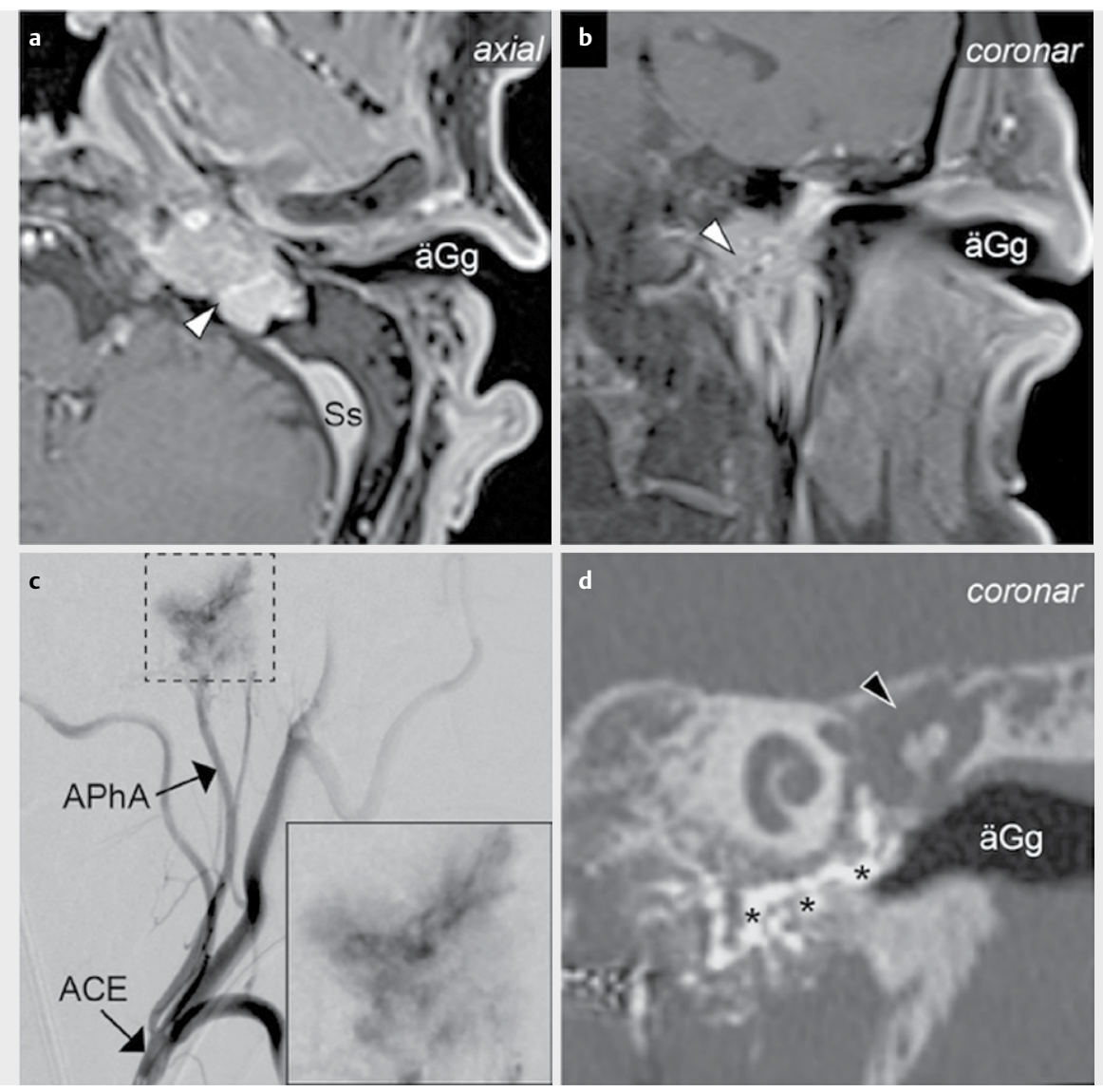

- Abb. 11 Parangangliom des Glomus tympanicum links. a, b Die kontrastmittelverstärkte T1-gewichtete MRT-Aufnahme mit Fettsuppression zeigt das Paragangliom (weiße Pfeilspitze), welches das Cavum tympani obliteriert. b Kontrastverstärkte T1-gewichtete MRT-Aufnahme nach Kontrastmittelgabe. Die Gefäße stellen sich als das pathognomonische hypointense „Salz-und-Pfeffermuster“ des Paraganglioms mit Fließunterbrechungen aufgrund von hoher Vaskularität dar (weiße Pfeilspitze). c In der selektiven Angiografie zeigt sich das Paragangliom als typischer „Tumor Blush“ (gestrichelter Kasten, vergrößerte Ansicht als Einschub unten rechts) mit Gefäßzuflüssen aus der A. pharyngea ascendens (APhA) aus dem Stromgebiet der A. carotis externa (ACE). d Coronare CT des Schläfenbeins nach erfolgter Embolisation mit Flüssigembolisat (Histoacryl; Sterne). Das Cavum tympani ist im hypo- und mesotympanalen Anteil durch das Paragangliom verlegt (schwarze Pfeilspitze). äGg äußerer Gehörgang; Ss Sinus sigmoideus.

dem Primarius histologisch, sind aber oft weniger differenziert [48]. Sie können osteolytische Eigenschaften besitzen oder eine Knochenproliferation anregen. Meist wachsen sie zu Anfang destruierend, können aber auch knochenreparierende Eigenschaften aufweisen (z. B. Mamma und Prostata). Am häufigsten treten Metastasen des Schläfenbeines in der Felsenbeinspitze auf [217, 219]. Die Symptome sind abhängig vom Ort des Auftretens und von der Größe. Beim Befall von äußerem Gehörgang, Mittelohr, Mastoid und Tuba auditiva können Schallleitungsschwerhörigkeit und Schmerzen auftreten. Bei der meningealen Karzinomatose handelt es sich um eine Sonderform mit Ausbreitung in den Subarachnaoidalraum und den inneren Gehörgang wodurch es zu einem Befall der Hirnnerven und Innenohr kommen kann.

\subsection{Benigne Blut- und Lymphgefäßneoplasien}

Hämangiome und Lymphangiome sind embryonale Tumoren. Lymphangiome wie auch Hämangiome des Schläfenbeins, insbesondere unter Beteiligung des Mittelohrs sind äußerst selten [220, 221]. Die Symptomatik beim Auftreten im Mittelohr kann
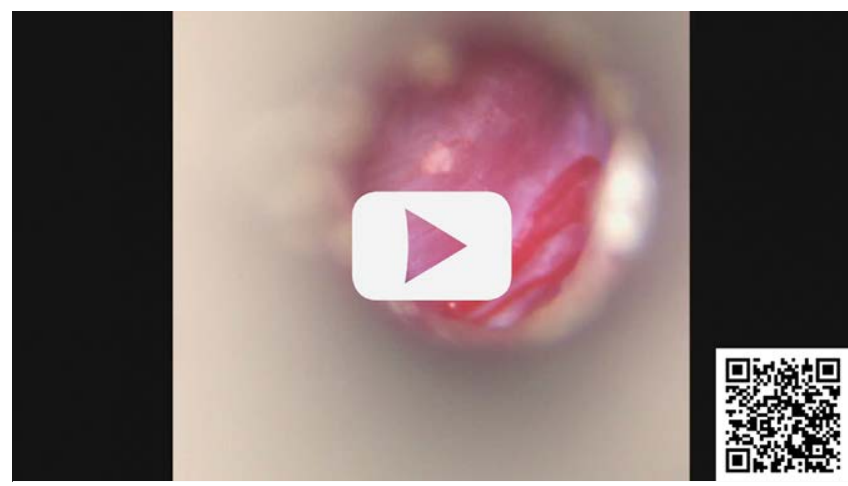

- Video. 1 Paragangliom des Mittelohres. Die Ohrmikroskopie zeigt eine rötliche pulsierende Masse in den unteren Trommelfellquadranten.

neben einer Schallleitungsschwerhörigkeit eine Lähmung des Nervus fazialis umfassen [221].

\subsection{Teratom}


Beim Teratom handelt es sich um Gewebe ektodermalen, mesodermalen und endodermalen Ursprungs ohne Funktion und klare Struktur mit einem Auftreten an dafür nicht vorgesehenen Lokalisationen. Üblicherweise sind Ovarien, Testes, Retroperitoneum oder Mediastinum betroffen. Ein Auftreten an der Schädelbasis und selten auch im Schläfenbein ist beschrieben [48, 222, 223].

\subsection{Raumforderungen des inneren Gehörganges, des Innenohres, des Kleinhirnbrückenwinkels und der Pyramidenspitze}

Tumoren des Kleinhirnbrückenwinkels machen rund $10 \%$ aller intrakraniellen Tumoren aus. Nahezu $90 \%$ aller Kleinhirnbrückenwinkel-Tumoren sind Vestibularisschwannome und Meningeome. Andere Kleinhirnbrückenwinkel-Tumoren umfassen Epidermoidzysten, Arachnoidalzysten, Lipome, Schwannome anderer Hirnnerven, Metastasen, vaskuläre Läsionen (z. B. Paragangliome oder Hämangiome) und Cholesterolgranulome [224-226]. Kleinhirnbrückenwinkel-Tumoren werden symptomatisch indem sie eine Kompression der neurovaskulären Strukturen verursachen. Zu den typischen Manifestationen gehören ein unilateraler Hörverlust, Schwindel und Tinnitus. In Abhängigkeit von Größe und Dignität können sie zusätzlich zu Gesichtsschmerzen, einer Fazialisparese, Stimmbandlähmung, Dysphagie, Diplopie oder einer Hirnstammkompression führen [224].

\subsubsection{Vestibularisschwannom}

Das Vestibularisschwannom ist ein gutartiger Tumor, der seinen Ursprung an der Nervenscheide einer der beiden Vestibularnerven oder in seltenen Fällen am Nervus cochlearis haben kann [227]. Durch die sogenannte Fünf-Rezeptor-Diagnostik, bestehend aus einer Stimulation der 3 Bogengänge durch einen Video-Kopfimpuls-Test bzw. die kalorische Stimulation der lateralen Bogengänge sowie der Ableitung von okulären und zervikal vestibulär evozierten myogenen Potenzialen, lässt sich der Ursprungsnerv des Vestibularisschwannoms bestimmen [228]. Zur weiteren Funktionsdiagnostik gehört eine subjektive (Reintonaudiogramm, Sprachaudiogramm) und objektive (Hirnstammaudiometrie, otoakustische Emissionen) Hörmessung. Bei einer Asymmetrie im Reintonaudiogramm von $\geq 20 \mathrm{~dB}$ in 2 benachbarten Frequenzen oder unilateralem Tinnitus bzw. von einer Asymmetrie $\geq 15 \mathrm{~dB}$ in 2 benachbarten Frequenzen zwischen 2 und $8 \mathrm{kHz}$ wird eine Bildgebung durch eine Kontrastmittel-MRT empfohlen [229]. Letztere, hochauflösende radiologische Bildgebung ermöglicht eine frühe Detektion bereits bei kleiner Tumorgröße ( $\triangleright$ Abb. 12). Vestibularisschwannome umfassen 80 \% der Tumoren im Kleinhirnbrückenwinkel und sind damit die am häufigsten auftretende Tumorentität in der hinteren Schädelgrube beim Erwachsenen [230]. Zu den Behandlungsoptionen zählen die Chirurgie, die Observation (insbesondere kleiner, bzw. größenstationärer Tumore) und die Radiatio. Die Therapieentscheidung erfolgt individualisiert und interdisziplinär: Bei asymptomatischen oder symptomarmen Vestibularisschwannomen besteht des Behandlungskonzept in der Regel in regelmäßigen Bildgebungs-Kontrollen nach festgelegten Kontrollintervallen zusammen mit klinischen Verlaufskontrollen („Wait and control“, „Wait and scan“, „Wait and test and scan“, „Watchful waiting“) [231]. In der Literatur werden Wachstumsraten zwischen 1-2 mm pro Jahr bis hin zu Wachstumsraten von 17 mm pro Jahr angegeben [232, 233].
Eine Behandlungsindikation besteht im Fall eines Wachstums ( $>3$ mm/Jahr [234]), bei Hirnstammkontakt oder Hirnstammkompression sowie beim Auftreten von beeinträchtigendem Schwindel. Weitere Behandlungsindikation bestehen bei einer Verschlechterung des Hörens, des Gleichgewichts oder einer Funktionsverschlechterung des Nervus fazialis. Das Auftreten intralabyrinthärer Schwannome (intracochleär und/oder intravestibulär) hingegen ist deutlich seltener und wird mit bis zu $10 \%$ der auftretenden Vestibularisschwannome angegeben [52, 235-237]. Während Gleichgewichtsstörungen zur häufigsten Erstsymtomatik bei Vestibularisschwannomen des Kleinhirnbrückenwinkels gehören, sind intralabyrinthäre Schwannome insbesondere bei der Differenzialdiagnose des Hörsturzes von Bedeutung [237]. Im Falle eines transmodiolären oder transmakulären Wachstums stellen Sie aufgrund der notwendigen Abwägung einer vollständigen Resektion gegenüber einer möglichen Hörrehabilitation mit $\mathrm{Cl}$ eine besondere Herausforderung dar [238].

\subsubsection{Meningeom}

Meningeome treten meist sporadisch auf, können aber auch bei familiären Syndromen wie bspw. der Neurofibromatose Typ II auftreten. Sie machen mit 3\% bis $10 \%$ die zweithäufigste Entität von Kleinhirnbrückenwinkel-Tumoren aus [239]. Die meisten Meningeome sind gutartig und langsam wachsend. Nur etwa $1 \%$ der Meningeome im Kleinhirnbrückenwinkel werden symptomatisch. Meningeome unterscheiden sich in Pathogenese und radiologischen Merkmalen vom Vestibularisschwannomen [240,241], sind aber hinsichtlich der klinischen Präsentation und der audiovestibulären Untersuchung kaum zu unterscheiden [224, 239].

\subsubsection{Epidermoidzyste}

Epidermoidzysten umfassen etwa 5 \% der KleinhirnbrückenwinkelTumoren. Sie entwickeln sich aus während der Embryogenese versprengten ektodermalen Einschlüssen. Die Zyste ist mit Plattenepithel ausgekleidet und mit Lamellen aus abgeschilferten Hornhauttrümmern gefüllt. Die meisten Epidermoidzysten sind gutartig. Selten wird über Plattenepithelkarzinome, die aus Epidermoidzysten entstehen, berichtet [242, 243]. Epidermoidzysten weisen im Vergleich zu Vestibularisschwannomen eine höhere Rate an Beteiligungen des Nervus fazialis und Nervus trigeminus auf. Weitere wegweisende Symptome, die zur Differenzialdiagnose beitragen, können hemifaziale Spasmen, Gesichtshypästhesien oder Neuralgien sein [224, 239]. Zudem ist eine Unterscheidung anhand der radiologischen Bildgebung möglich [241].

\section{Infektiologische Erkrankungen}

\subsection{Tuberkulose}

Bei der Ohrmanifestation der Tuberkulose kommt es typischerweise zum Auftreten von multiplen Trommelfellperforationen, welche beidseitig auftreten können. In bis zu $3 \%$ weltweit ist die akute Otitis media durch Tuberkulose bedingt [244]. Eine Assoziation zwischen der Reaktivierung von Tuberkulose und dem HI-Virus wird angenommen [245]. Die Erkrankung beginnt meist mit einer ödematösen Schwellung des Trommelfells und einer Infiltration durch Riesenzellen. Charakteristisch ist die Formation von Tuberkeln aus epitheloiden Zellen, lymphoiden Zellen und Langerhanszellen. Als 

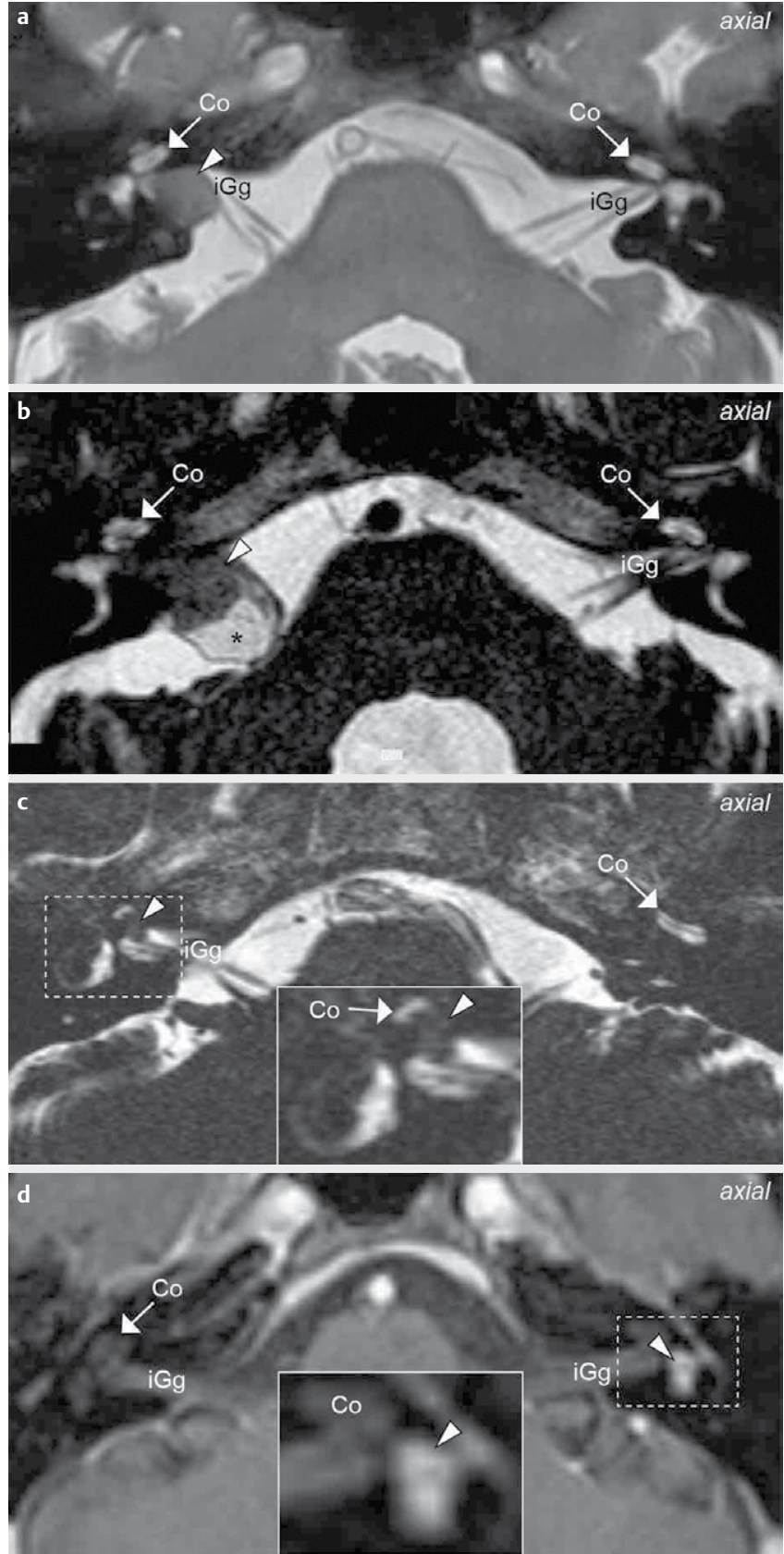

Abb. 12 Lokalisationen des Vestibularisschwannoms. a Stark T2-gewichtete MRT-Aufnahme eines 56-jährigen Patienten mit intrameatalem Vestibularisschwannom der rechten Seite (weiße Pfeilspitze). b Stark T2-gewichtete MRT-Aufnahme eines 68-jährigen Patienten mit intra- und extrameatalem Vestibularisschwannom der rechten Seite (weiße Pfeilspitze) mit zystoidem Anteil (Stern), welcher Hirnstammkontakt hat. c Stark T2-gewichtete MRT-Aufnahme eines 49-jährigen Patienten mit intracochleärem Schwannom mit transmodiolärem Wachstum der rechten Seite (weiße Pfeilspitze) (gestrichelter Kasten, vergrößerte Ansicht als Einschub unten mittig). d T1-gewichtete MRT-Aufnahme nach Kontrastmittelgabe eines 49-jährigen Patienten mit intravestibulärem Schwannom im linken Vestibulum mit Übergang in den horizontalen Bogengang (weiße Pfeilspitze), gestrichelter Kasten, vergrößerte Ansicht als Einschub unten mittig. Co: Cochlea; iGg: innerer Gehörgang.
Folge entstehen Ulzerationen und purulente Exsudate, gefolgt von einer Knochenresorption. Die Behandlung erfolgt im frühen Stadium antibiotisch oder chirurgisch [246]. Häufig erfolgt unter dem klinischen Bild einer rezidivierenden oder nach Chirurgie persistierenden Mastoiditis die chirurgische Behandlung und die mikrobiologische Diagnose folgt erst postoperativ [247]. Insbesondere bei einer prolongierten Otitis media und/oder multiplen Trommelfellperforationen muss eine Tuberkulose gesucht werden, welche über den mikrobiologischen Nachweis von säurefesten Stäbchen aus Ohrabstrich oder Gewebebiospie diagnostiziert wird.

\subsection{Otosyphilis}

Die Syphilis (Lues) wird durch das Bakterium Treponema pallidum verursacht, kann kongenital oder erworben auftreten und kann als Teil einer Neurosyphilis das audiovestibuläre System betreffen. Die Inzidenz eines Hörverlust, welcher jedoch meistens das Innenohr betrifft, liegt bei der Syphilis zwischen 18\% und 90\% [248]. Insbesondere immunsupprimierte Patienten mit einer HIV-Infektion sind gefährdet für das Auftreten einer Otosyphillis [249]. Neben der typischen MeningoNeuro-Labyrinthitis kann es auch zu einer Osteitis des Schläfenbeines kommen. Diese kann auch die Ossikelkette betreffen [250]. Zur Behandlung werden Antibiotika und Steroide eingesetzt.

\subsection{Otitis externa necroticans}

Bei der Otitis externa necroticans handelt es sich um eine aggressive Osteomyelitis des Schläfenbeines und der Schädelbasis. Ursprung ist in der Regel der knöcherne Anteil des äußeren Gehörgangs. Der verbreitetste Keim ist Pseudomonas aeruginosa, aber auch eine Pilzbesiedelung spielt eine zunehmend große Rolle und kann die Therapieentscheidung beeinflussen [251, 252]. Die Erkrankung betrifft typischerweise ältere Erwachsene, wobei der Diabetes mellitus als wichtiger Risikofaktor gilt [253-255]. Histologisch kommt es zu einer Umwandlung des Knochens in Granulationsgewebe mit Einschmelzung des Mastoid- und Schläfenbeinknochens. Die Ausbreitung erfolgt vorwiegend entlang kompakten Knochens [256, 257]. Unbehandelt breitet sich die Erkrankung aus und kann zu teils lebensbedrohlichen Komplikationen wie Mastoiditis, Hirnnervenparesen, Phlebitiden oder Thrombosen des Sinus Sigmoideus oder der Vena jugularis interna, zur Sepsis sowie zur Osteomyelitis der Schädelbasis führen. Deshalb sind bei prolongiertem Verlauf einer Otitis externa mit aufgeweichtem Gehörgangsknochen und bei Patienten mit Diabetes mellitus eine Bildgebung durch CT sowie eine Biopsie indiziert. Die Behandlung besteht neben einer topischen antiseptischen und antibiotischen Behandlung aus einer systemischen Antibiose, die abstrichgerecht für mindestens 4-6 Wochen und gegebenenfalls um antifugale Medikamente erweitert erfolgen sollte [258]. Bei ausbleibender Besserung unter konservativer Therapie kann eine chirurgische Behandlung notwendig werden [255]. Eine weitere Therapiealternative stellt die hyperbare Sauerstofftherapie dar [259].

\subsection{Cholera}

Die Familie der Vibrionen weist mehr als 200 Serogruppen auf. Die häufigsten sind die Cholera-Toxin produzierenden Serogruppen 01 und 0139, die eine epidemische Cholera mit anschließenden Durchfallerkrankungen verursachen [260, 261]. Eine zweite Gruppe ist durch selbstlimitierende mildere gastrointestinale Infektionen gekennzeichnet, die mit extraintestinalen Infektionen wie Sep- 
tikämie, Wundinfektion, Haut- und Weichteilinfektionen, Peritonitis, Meningitis, Cholangitis und Ohrinfektionen assoziiert sein kann $[262,263]$. Die Erregerübertragung erfolgt in erster Linie über nicht oder unzureichend gefiltertes Trinkwasser und kontaminierte Lebensmittel. In der Literatur wird über einige wenige Fälle von Otitis media oder Otitis externa berichtet, die durch Vibrio cholerae non01/0139 verursacht wurden [263]. Als Risikofaktor gilt das Baden in Schwimmbad, stehendem Gewässer oder in der Ostsee [263].

Zusammenfassend ist insbesondere bei prolongierten Entzündungen von Gehörgang und Mittelohr eine mikrobiologische Untersuchung durch einen Abstrich und/oder eine Gewebebiopsie obligat und schließlich wegweisend für seltene Erreger.

\section{Varia}

\subsection{Pneumatozele des Schläfenbeins}

Hierbei handelt es sich um eine an Größe zunehmende zystische Höhle, welche mit Luft gefüllt ist und über die Grenzen des Schläfenbeines hinaus mit der retroaurikulären Haut oder den extraduralen Schädelräumen in Verbindung stehen kann. Als Ursachen werden Infektionen oder Traumata angenommen [264]. Die Symptomatik kann aus Kopfschmerzen und Schwindel bestehen [265]. Eine Symptomzunahme durch Valsalva-Manöver kann hinweisend für das Vorliegen einer Pneumatozele sein. Die Diagnose wird in der CT des Schläfenbeines durch das Vorliegen von Septierungen innerhalb der Pneumatozele gestellt [266]. Die Therapie besteht in der sorgfältigen Ausräumung und Verschluss der belüfteten Mastoidzellen [267].

\subsection{Otogene primäre Mukozele des Mastoids}

Mukozelen sind langsam wachsende Zysten, die durch Aufblähung eines Hohlorgans oder eines Hohlraums mit Schleim entstehen. Mukozelen zeigen Anzeichen einer chronisch sterilen Infektion und haben die Fähigkeit, eine knöcherne Remodellierung oder Reabsorption zu bewirken. Mukozelen können primär oder sekundär nach einer chronischen Entzündung, einem Trauma, einer Narbe von einer früheren Operation oder nach Strahlentherapie sowie seltener auch nach Neoplasien auftreten [268-270]. Ihr Auftreten im Mastoid ( $>$ Abb. 13) ist sehr selten, wobei in der Literatur fast ausschließlich Fallberichte existieren [271-279]. Im Falle von knöchernen Erosionen und Destruktionen am Mukozelenrand kann es zu intra- und extrakraniellen Komplikationen kommen [280]. Zur Behandlung der Mukozelen gehört die Marsupialisation, bei der diese über natürliche Drainagewege abgeleitet wird, während die Schleimhaut geschont wird. Bei Mukozelen im Mastoid ist eine chirurgische Behandlung indiziert, da sie sich mit dem Risiko für Infektionen und intra- bzw. extrakranielle Komplikationen ausdehnen können [280]. Eine geeignete chirurgische Behandlung kann die vollständige Entfernung der Läsion durch Mastoidektomie sein um das Risiko eines Rezidivs zu verringern [280].

\subsection{Otogener Pneumocephalus}

Der otogene Pneumocephalus ist gekennzeichnet durch Luft welche durch einen Duradefekt nach intrakraniell in den Subarachnoidalraum, das Hirnparenchym oder die Ventrikelräume vordringt. Zu den Symptomen zählen Kopfschmerzen, Otorrhoe, Meningismus und Schwindel [281]. Als mögliche Ursachen werden Traumata, Komplikationen der Ohrchirurgie, die Otitis media oder ein Cho- lesteatom beschrieben [282]. Bei einer Genese durch Traumata gehen sie häufig mit einer Liquorfistel einher. Bei einer Verursachung durch die Otitis media oder ein Cholesteatom kann es zur Komplikation eines intrakraniellen Abszesses kommen. Die Therapie besteht aus einer Kombination aus Druckentlastung und Defektverschluss. Beim postoperativen Spannungspneumocephalus ist eine sofortige Nadelaspiration durchzuführen. Bei persitierendem Pneumocephalus ist die Revisionschirurgie mit Defektverschluss indiziert [282].

\subsection{Spontane (Meningo-)Enzephalozele}

Ein ausgedünntes Tegmen tympani gilt als Risikofaktor für die Entstehung von spontanen Enzephalozelen, welche mit Liquorlecks einhergehen können. Mehrere Mechanismen kommen für die Ausdünnung, bzw. Arrosion des Tegmen tympani in Frage. Hierzu zählen u. a. angeborene Defekte, chronische Mittelohrerkrankungen, intrakranielle Hypertonie, Traumata und Adipositas [283-285]. Die Symptomatik spontaner Enzephalozelen kann aus Schallleitungsschwerhörigkeit, Schwindel, Oto-Liquorrrhoe oder Völlegefühl des Ohres bestehen [285-287]. Die Diagnose wird durch die Kombination aus CT und MRT und ggf. zusätzlich durch den Nachweis von $\beta_{2^{-}}$ Transferrin oder $\beta$-Trace-Protein gestellt [20]. In der klinischen Untersuchung kann sich ein Paukenerguss zeigen. Eine Behandlungsindikation besteht insbesondere im Falle eines Liquorlecks. Die Therapie besteht aus einem chirurgischen Verschluss des Defekts mit Verstärkung von Dura und Tegmen tympani und kann je nach Größe des Defekts über einen transmastoidalen Zugang zur mittleren Schädelgrube, einen transtemporalen Zugang („middle-cranial-fossa-approach“) oder durch einen kombinierten Zugangsweg erfolgen [286, 287].

\subsection{Ektopes Hirngewebe}

Eine weitere seltene Differenzialdiagnose für Weichgewebe im Mittelohr stellt das Auftreten von ektopem Hirngewebe dar. Einzelne Fallberichte existieren über eine Manifestation u. a. in der Nase, der Zunge oder Orbita [288-290]. Auch eine Manifestation im Mastoid wird beschrieben [291-294]. Die Histopathologie erbringt den Nachweis von Hirngewebe. Eine Unterscheidung zwischen Enzephalozele und ektopem Hirngewebe erfolgt radiologisch bzw. klinisch, intraoperativ durch eine intakte Dura [294-296].

\subsection{Idiopathisches oder spontanes Hämatotympanon}

Es handelt sich um ein nicht vollständig verstandenes Krankheitsbild, welches als Variante der akuten Otitis media interpretiert wird [297]. Klinisch zeigt sich ein schwarzblaues Trommelfell. Die Färbung des hämolysierten Blutes resultiert aus wiederkehrenden Blutungen im Mittelohr, kombiniert mit einer Abflussstörung durch die Eustach'sche Röhre [297]. Als Ursache der Blutung werden Cholesterolgranulome angenommen, welche a. e. Folge einer Otitis media sind [48]. Eine chirurgische Ausräumung der Granulome mit Paukendrainage wird als wirksame Therapie beschrieben [298, 299].

\subsection{Gorham-Stout-Syndrom}

Das Gorham-Stout-Syndrom ist eine spontane, ausgeprägte Osteolyse. Zugrunde liegt eine lokale Proliferation kleiner Blut- und Lymphgefäße, mit anschließender progredienter Zerstörung und Resorption des Knochens. Die Symptome sind abhängig von der Lokalisation der Manifestation. Das häufigste Symptom sind lokale 

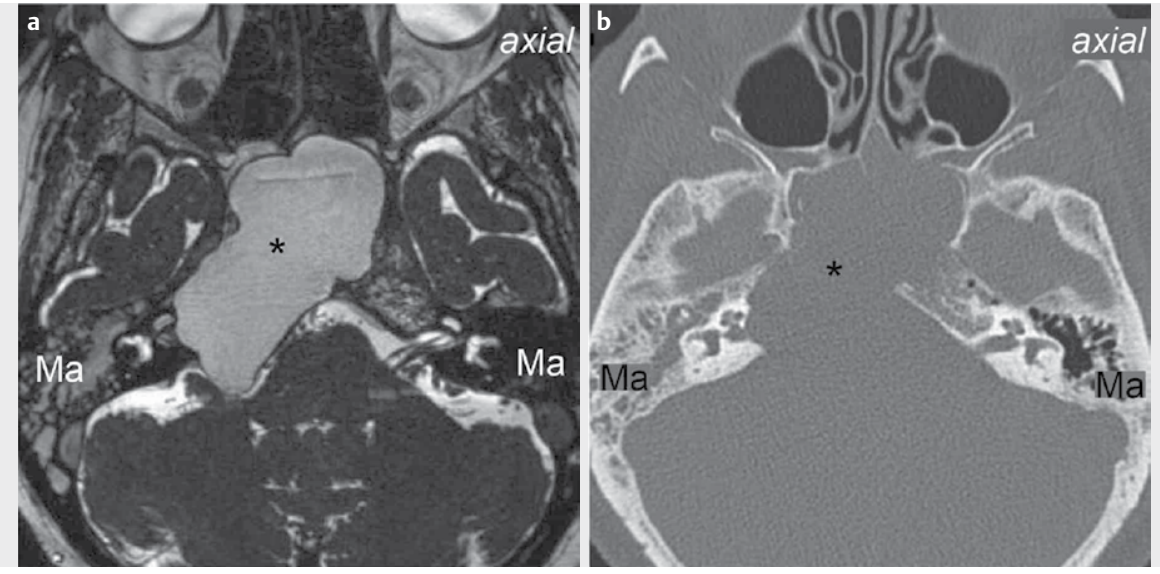

Abb. 13 Mukozele mit Befall der rechten Felsenbeinspitze (Asterisk) mit Hirnnervenbeteiligung VII \& VIII. a T2 gewichtete MRT des Mastoid. Es zeigt sich ein hyperintenses Signalverhalten der Mukozele welche bis in die Keilbeinhöhle reicht mit vollständiger Verlegung der belüfteten Mastoidzellen. b CT des Schläfenbeines. Es zeigt sich eine Knochendestruktion der Felsenbeinspitze mit Verlust der knöchernen Begrenzung zum Cerebellum. Ma Mastoid.

Schmerzen. Bei einem Befall des Schläfenbeins kann es zur Ertaubung kommen [300]. Die Diagnose wird unter Ausschluss der Differenzialdiagnosen anhand der klinischen, radiologischen und histologischen Befunde gestellt [300,301]. Die Behandlungsoptionen umfassen u. a. eine Strahlentherapie, Bisphosphonate und Interferon- $\alpha 2 b$ [302]. Eine chirurgische Intervention an der Otobasis kann bspw. durch Liquorrhoe oder durch eine medulläre Kompression erforderlich werden [303].

\subsection{Cholesteringranulom}

Das Cholesteringranulom ist eine Entzündungsreaktion mit Fremdkörper-Riesenzellen auf Blutabbauprodukte und stellt sich klinisch als eine Zyste mit einer dicken faserigen Auskleidung dar, die mit bräunlich-gelber Flüssigkeit gefüllt ist. Es kann in Mittelohr, Mastoid und Felsenbeinspitze auftreten und gilt mit einem Anteil von $40 \%$ als die häufigste gutartige Läsion der Felsenbeinspitze [304]. Ein Auftreten in Mastoid und Mittelohr wird bei unklarer Inzidenz als wesentlich seltener angegeben [304]. Eine schlechte Pneumatisierung oder Blutungen im Mastoid gelten als prädisponierende Faktoren [305]. Cholesteringranulome in Mittelohr und lateraler Schädelbasis sind häufig asymptomatisch, können aber bei zunehmender Größe zu Cephalgien, Hörminderung oder Hirnnervenausfällen führen [306]. In der MRT zeigt sich eine hohe Signalintensität in der T1- und T2- Wichtung. Die CT kann für Aussagen über die Verdrängung knöcherner Strukturen bzw. knöcherne Destruktionen herangezogen werden [304]. Die Therapie besteht entweder in regelmäßigen Verlaufskontrollen oder in symptomatischen Fällen in der chirurgischen Resektion [307-309].

\subsection{Riesenzellgranulom}

Das Riesenzellgranulom ist ein reaktiver Prozess ausgelöst durch ein Trauma oder eine Entzündung [310,311]. Es handelt sich um eine seltene knöcherne Läsion des Kopfes- und Halses, die sich überwiegend in Maxilla und Mandibula manifestiert. Die Beschreibung einer Manifestation im Mastoid ist selten und besteht ausschließlich aus Fallberichten [312, 313]. Die Symptomatik hängt von den beteiligten Strukturen ab und kann u. a. Schallleitungsschwerhörigkeit, Tinnitus, Schwindel, lokale Schwellungen oder eine Schwäche des Nervus fazialis umfassen [314]. Die Behandlungsoptionen bestehen aus der Kürettage, der chirurgischen Exzision und der Strahlentherapie [315, 316]. Eine vollständige chirurgische Exzision ist aufgrund der Rezidivraten bei unvollständiger Resektion anzustreben [317].

\section{Danksagung}

Besonderer Dank gilt Herrn Professor Dr. Robert Mlynski für die zahlreichen Anmerkungen und Anregungen zum Manuskript sowie die Bereitstellung des Bildmaterials für die Abbildungen 1, 3, 4a-c, 5, 9b, 13. Ebenfalls ein großer Dank gilt Herrn Dr. David Bächinger für die kritische Durchsicht des Manuskriptes sowie für seine konstruktive Unterstützung bei der Erstellung der Abbildungen. Herrn Professor Dr. Sönke Langner, Institut für diagnostische und interventionelle Radiologie, Kinder- und Neuroradiologie, sei für das Bildmaterial der Abbildungen 6, 10 und 11 sowie PD Dr. Marcus Frank, Institut für Elektronenmikroskopie Universitätsmedizin Rostock, für die elektronenmikroskopischen Aufnahmen der Abbildung 2 gedankt.

Interessenkonflikt

Die Autorin gibt an, dass kein Interessenkonflikt besteht.

\section{Literature}

[1] Jahrsdoerfer RA, Yeakley JW, Aguilar EA, Cole RR, Gray LC. Grading system for the selection of patients with congenital aural atresia. Am J Otol 1992; 13: 6-12

[2] Jahrsdoerfer RA. Congenital atresia of the ear. Laryngoscope. 1978; 88: $1-48$

[3] Weerda H. Classification of congenital deformities of the auricle. Facial Plast Surg 1988; 5: 385-388 
[4] Patterson ME, Linthicum FH]. Congenital hearing impairment. Otolaryngol Clin North Am 1970; 3: 201-219

[5] Gerhardt H], Otto HD. Stapedial malformation. Acta Otolaryngol 1970; 70: 35-44

[6] Teunissen EB, Cremers WR. Classification of congenital middle ear anomalies. Report on 144 ears. Ann Otol Rhinol Laryngol 1993; 102: 606-612

[7] Fu Y, Dai P, Zhang T. The location of the mastoid portion of the facial nerve in patients with congenital aural atresia. Eur Arch Otorhinolaryngol 2014; 271: 1451-1455

[8] Mündnich K, Terrahe K. Missbildungen des Ohres. In Berendes ], Link R, Zöllner F Eds. Ohr I, Band 5; Stuttgart: 1979: p 1-49

[9] Chang SO, Min YG, Kim CS, Koh TY. Surgical management of congenital aural atresia. Laryngoscope 1994; 104: 606-611

[10] Gorlin R, Pindborg J, Cohen M. Oculoauriculovertebral dysplasia. In: Syndromes of the head and neck. 2nd ed. New York: 1976: p 546-552

[11] Phelps PD, Poswillo D, Lloyd GA. The ear deformities in mandibulofacial dysostosis (Treacher Collins syndrome). Clin Otolaryngol Allied Sci 1981; 6: 15-28

[12] Jahrsdoerfer RA, Aguilar EA, Yeakley JW, Cole RR. Treacher Collins syndrome: an otologic challenge. Ann Otol Rhinol Laryngol 1989; 98 : 807-812

[13] Boggering B. Oto-vertebral syndrome. Fortschr Med 1975; 93 : 1452-1455

[14] Frenzel H. Hearing Rehabilitation in Congenital Middle Ear Malformation. Adv Otorhinolaryngol 2018; 81: 32-42

\section{FAZIT}

Seltene Erkrankungen von Mittelohr und lateraler Schädelbasis können in ihrer Symptomatik den gängigen Erkrankungen der Hals-Nasen-Ohrenheilkunde ähneln, wodurch das Risiko einer verzögerten Diagnose besteht. Bei einer Otitis media, welche nicht auf eine antibiotische Behandlung anspricht, muss zum Ausschluss von seltenen Infektionen ein Abstrich, insbesondere auch auf Mykobakterien erfolgen [318]. Insbesondere bei pulmonalem Befall und gleichzeitiger Otorrhoe oder aber bei multiplen Trommelfellperforationen sollte an eine Ohrmanifestation der Tuberkulose gedacht werden. Weiterhin können die Begleiterkrankungen des Patienten wegweisend sein. So muss insbesondere bei immunsupprimierten Patienten mit HIV-Infektion auch an seltene Keime wie die Otosyphillis gedacht werden und das Risiko einer Otitis externa necroticans bei älteren Patienten mit Diabetes mellitus bedacht werden. Insbesondere bei langwierigen, rezidivierenden oder bilateralen Otitiden muss an ein autoimmunologisches Geschehen gedacht werden, z. B. an eine Granulomatose mit Polyangiitis. Zusätzlich ist bei Mittelohr- und Mastoiderkrankungen ohne Ansprechen auf eine Antibiose eine Biopsie zum Ausschluss von Malignomen oder Erkrankungen des hämatopoetischen Systems sowie des autoimmunologischen Formenkreises obligat. Ergänzt wird sie durch eine entsprechende Serologie. Insbesondere bei CT-morphologisch nachweisba- ren beidseitig destruktiven Ohrerkrankungen, die mit erhöhter Blutsenkungsgeschwindigkeit und ohne sonstige Hinweise für eine Infektion einhergehen oder bei langfristig bestehendem Granulationsgewebe nach einer tympanomastoidalen Operation mit persistierender Otorrhoe und Hautläsionen, ist an systemische Ursachen wie bspw. an eine Histiozytose oder eine Vaskulitis zu denken.

Asymmetrische Hör- oder Gleichgewichtsbefunde oder Ausfälle der kaudalen Hirnnerven können auf neurologische Erkrankungsbilder hinweisen oder Erstmanifestation von Neoplasien und Läsionen des Schläfenbeines sein. Ein einseitiger Tinnitus bspw. kann

in 1-5\% der Fälle als Erstsymptom beim Vestibularisschwannom auftreten und ein pulssynchrones Ohrgeräusch kann auf ein Paragangliom oder eine Gefäßanomalie hinweisen. Diese Symptome sollten deshalb auch ohne auffällige Trommelfellbefunde obligat radiologisch abgeklärt werden. Bei Raumforderungen in der Felsenbeinspitze muss differenzialdiagnostisch auch an Fernmetastasen und seltene Knochen- oder Knorpeltumore gedacht werden. Die Bildgebung der Wahl besteht deshalb in der Regel zunächst aus einer hochauflösenden CT des Schläfenbeins. Zur weiteren Diagnostik kann eine MRT ergänzt werden. Eine Ausnahme stellt z. B. das Vestibularisschwannom dar, bei dem die initiale Bildgebung aus einer Kontrastmittel-MRT bestehen sollte. Eine Biopsie kann über verschiedene Zugangswege erfolgen und sichert die Diagnose [319]. Wichtig ist hierbei eine enge interdisziplinäre Zusammenarbeit und konkrete Fragestellungen mit Schilderung der klinischen Symptomatik, z. B. für die untersuchenden Histopathologen, Humangenetiker oder Molekularpathologen.

Vor jeder Operation ist eine ausführliche Diagnostik erforderlich. Insbesondere wenn Hinweise für Fehlbildungen bestehen, ist zwingend eine Bildgebung zu ergänzen, um anatomische Varianten des Schläfenbeins zu erkennen und so operativen Komplikationen wie Blutungen, Liquorfisteln oder Verletzungen des Nervus fazialis zu vermeiden. Für die Qualitätssicherung in der Patientenversorgung und insbesondere auch bei chirurgischen Maßnahmen ist die Kenntnis seltener Erkrankungen ein wesentlicher Bestandteil und muss für die Beurteilung komplizierter langwieriger Krankheitsverläufe verfügbar sein. Hierbei spielt neben der Sensibilisierung der Mediziner auf seltene Differenzialdiagnosen eine Erfassung von Patientendaten in dafür vorgesehen Registern eine Rolle. Diese ermöglichen durch eine kumulative Datenspeicherung die Durchführung von Studien, welche über Fallberichte hinausgehen. Durch dieses wachsende Krankheitsverständnis kann eine Optimierung der Behandlungsoptionen erreicht werden [320-322]. Nur durch eine sorgfältige Erhebung und Dokumentation aller dafür erforderlichen diagnostischen Kriterien wie Anamnese, klinischen Befunden, Bildgebung, Labor sowie Ergebnisse mikrobiologischer, histologischer und mit wachsender Bedeutung molekularpathologischer und genetischer Untersuchungen kann hierbei eine vollständige Diagnose gestellt werden und die adäquate Behandlung initiiert werden. 
[15] Mlynski R, Schwager K. Funktionelle Rekonstruktion bei Ohrfehlbildungen. In: Bumm K editor. Korrektur und Rekonstruktion der Ohrmuschel. $1^{\text {st }}$ ed. Saarbrücken; 2016: 275-291

[16] Beutner D, Delb W, Frenzel H, Hoppe U, Hüttenbrink KB, Mlynski R et al. Guideline "Implantable hearing aids"- short version: German S2k guideline of the Working Group of German-Speaking Audiologists, Neurootologists and Otologists (ADANO), of the German Society of Oto-Rhino-Laryngology, Head and Neck Surgery (DGHNO) in colla. HNO 2018; 66: 71-76

[17] Thompson H, Ohazama A, Sharpe PT, Tucker AS. The origin of the stapes and relationship to the otic capsule and oval window. Dev Dyn 2012; 241: 1396-1404

[18] Herther C, Schindler RA. Mondini's dysplasia with recurrent meningitis. Laryngoscope 1985; 95: 655-658

[19] Tandon S, Singh S, Sharma S, Lahiri AK. Use of Intrathecal Fluorescein in Recurrent Meningitis after Cochlear Implantation. Vol. 28: Iranian journal of otorhinolaryngology. Iran 2016; 221-226

[20] Weiss NM, Andus I, Schneider A, Langner S, Schroder S, Schraven SP et al. Intrathecal Application of a Fluorescent Dye for the Identification of Cerebrospinal Fluid Leaks in Cochlear Malformation. J Vis Exp 2020

[21] Frenzel H, Sprinzl G, Widmann G, Petersen D, Wollenberg B, Mohr C. Grading system for the selection of patients with congenital aural atresia for active middle ear implants. Neuroradiology 2013; 55: 895-911

[22] Schuknecht H. Gavin Livingstone Memorial Lecture. Anatomical variants and anomalies of surgical significance. J Laryngol Otol 1971; 85: $1238-1241$

[23] Hogg ID, Stephens CB, Arnold GE. Theoretical anomalies of the stapedial artery. Ann Otol Rhinol Laryngol 1972; 81: 860-870

[24] Lyu A-R, Park S], Kim D, Lee HY, Park Y-H. Radiologic features of vascular pulsatile tinnitus - suggestion of optimal diagnostic image workup modalities. Acta Otolaryngol 2018; 138: 128-134

[25] Hofmann E, Behr R, Neumann-Haefelin T, Schwager K. Pulsatile tinnitus: imaging and differential diagnosis. Dtsch Arztebl Int 2013; 110: $451-458$

[26] Friedmann DR, Eubig J, McGill M, Babb JS, Pramanik BK, Lalwani AK. Development of the jugular bulb: a radiologic study. Otol Neurotol Off Publ Am Otol Soc Am Neurotol Soc [and] Eur Acad. Otol Neurotol 2011; 32: 1389-1395

[27] Merchant SN, Rosowski J]. Conductive hearing loss caused by third-window lesions of the inner ear. Otol Neurotol Off Publ Am Otol Soc Am Neurotol Soc [and] Eur Acad. Otol Neurotol 2008; 29: 282-289

[28] Sayit AT, Gunbey HP, Fethallah B, Gunbey E, Karabulut E. Radiological and audiometric evaluation of high jugular bulb and dehiscent high jugular bulb. J Laryngol Otol 2016; 130: 1059-1063

[29] Koo YH, Lee JY, Lee JD, Hong HS. Dehiscent high-riding jugular bulb presenting as conductive hearing loss: A case report. Medicine (Baltimore) 2018; 97: e11067

[30] Friedmann DR, Le BT, Pramanik BK, Lalwani AK. Clinical spectrum of patients with erosion of the inner ear by jugular bulb abnormalities. Laryngoscope 2010; 120: 365-372

[31] Maroldi R, Farina D, Palvarini L, Marconi A, Gadola E, Menni K et al. Computed tomography and magnetic resonance imaging of pathologic conditions of the middle ear. Eur J Radiol 2001; 40: 78-93

[32] Kaftan S, Sarach V, Kahle G. Vascular structure in the middle ear. Aberrant course of the internal carotid artery in the left tympanic membrane. HNO 2002; 50: 864-865

[33] Heimlich F, Dörfler A, Wallner F. An aberrant course of the internal carotid artery through the middle ear. HNO 1999; 47: 986-989
[34] Sun W, Germans MR, Sebök M, Fierstra J, Kulcsar Z, Keller A et al. Outcome Comparison Between Surgically Treated Brain Arteriovenous Malformation Hemorrhage and Spontaneous Intracerebral Hemorrhage. World Neurosurg 2020; 139: e807-e811

[35] Mohr JP, Overbey JR, Hartmann A, Kummer von R, Al-Shahi Salman R, $\mathrm{Kim} \mathrm{H}$ et al. Medical management with interventional therapy versus medical management alone for unruptured brain arteriovenous malformations (ARUBA): final follow-up of a multicentre, non-blinded, randomised controlled trial. Lancet Neurol 2020; 19: 573-581

[36] Zipfel G], Shah MN, Refai D, Dacey RG], Derdeyn CP. Cranial dural arteriovenous fistulas: modification of angiographic classification scales based on new natural history data. Neurosurg Focus 2009; 26: E14

[37] Paget J. On a form of chronic inflammation of bones (osteitis deformans). Med Chir Trans 1877; 60: 37-64

[38] Paget J. Additional cases of osteitis deformans. Med Chir Trans 1882; 65: $225-236$

[39] Mills BG, Singer FR, Weiner LP, Holst PA. Immunohistological demonstration of respiratory syncytial virus antigens in Paget disease of bone. Proc Natl Acad Sci U S A 1981; 78: 1209-1213

[40] Siris ES. Seeking the elusive etiology of Paget disease: a progress report. Vol. 11: Journal of bone and mineral research: the official journal of the American Society for Bone and Mineral Research. United States 1996; 1599-1601

[41] Eekhoff EWM, Karperien M, Houtsma D, Zwinderman AH, Dragoiescu C, Kneppers ALJ et al. Familial Paget's disease in The Netherlands: occurrence, identification of new mutations in the sequestosome 1 gene, and their clinical associations. Arthritis Rheum 2004; 50 : 1650-1654

[42] Koller F. Über die Heredität der ostitis deformans. Helv Med Acta 1946; 13: 389-400

[43] Schmorl G. Über ostitis deformans Paget. Virchows Arch 1932; 283 : 694-751

[44] Bozorg Grayeli A. Progressive hearing loss with stapes fixation [Internet]. 2006; Available from https://www.orpha.net/consor/ cgi-bin/OC_Exp.php?lng = EN\&Expert $=3235$

[45] Lindsay JR, Suga F. Paget's disease and sensori-neural deafness: temporal bone histopathology of Paget's disease. Laryngoscope 1976; 86: 1029-1042

[46] Nager GT. Paget's disease of the temporal bone. Ann Otol Rhinol Laryngol 1975; 84: 1-32

[47] Waltner JG. Stapedectomy in Paget's disease. Histological and clinical studies. Arch Otolaryngol 1965; 82: 355-358

[48] McKenna M], Merchant SN. 15. Disorders of Bone. In: Merchant SN, Nadol JBJ editors, Schuknechts's Pathology of the ear. $3^{\text {rd }}$ ed. 2010: 715-774

[49] Khetarpal U, Schuknecht HF. In search of pathologic correlates for hearing loss and vertigo in Paget's disease. A clinical and histopathologic study of 26 temporal bones. Ann Otol Rhinol Laryngol Suppl 1990; 145: 1-16

[50] Monsell EM. The mechanism of hearing loss in Paget's disease of bone. Laryngoscope 2004; 114: 598-606

[51] Monsell EM, Bone HG, Cody DD, Jacobson GP, Newman CW, Patel SC et al. Hearing loss in Paget's disease of bone: evidence of auditory nerve integrity. Am J Otol 1995; 16: 27-33

[52] Dlugaiczyk ]. Seltene Erkrankungen des vestibulären Labyrinths: von Zebras, Chamäleons und Wölfen im Schafspelz (accepted for publication). Laryngorhinootologie 2021

[53] Applebaum EL, Clemis JD. Temporal bone histopathology of Paget's disease with sensorineural hearing loss and narrowing of the internal auditory canal. Laryngoscope 1977; 87: 1753-1759

[54] Kösling S, Plontke SK, Bartel S. Imaging of otosclerosis. Rofo. 2020 
[55] Sillence DO, Senn A, Danks DM. Genetic heterogeneity in osteogenesis imperfecta. J Med Genet 1979; 16: 101-116

[56] Sillence DO, Rimoin DL, Danks DM. Clinical variability in osteogenesis imperfecta-variable expressivity or genetic heterogeneity. Birth Defects Orig Artic Ser 1979; 15: 113-129

[57] Armstrong BW. Stapes surgery in patients with osteogenesis imperfecta. Ann Otol Rhinol Laryngol 1984; 93: 634-635

[58] Garretsen T], Cremers CW. Stapes surgery in osteogenesis imperfecta: analysis of postoperative hearing loss. Ann Otol Rhinol Laryngol 1991; 100: 120-130

[59] Patterson CN, Stone HB $3^{\text {rd }}$. Stapedectomy in Van der Hoeve's syndrome. Laryngoscope 1970; 80: 544-558

[60] Opheim O. Loss of hearing following the syndrome of Van der Hoeve-de Kleyn. Acta Otolaryngol 1968; 65: 337-344

[61] Sinder BP, Novak S, Wee NKY, Basile M, Maye P, Matthews BG et al. Engraftment of skeletal progenitor cells by bone-directed transplantation improves osteogenesis imperfecta murine bone phenotype. Stem Cells 2020; 38: 530-541

[62] Lee LR, Peacock L, Ginn SL, Cantrill LC, Cheng TL, Little DG et al. Bone Marrow Transplantation for Treatment of the Col1a2(+/G610C) Osteogenesis Imperfecta Mouse Model. Calcif Tissue Int 2019; 104: 426-436

[63] Gotherstrom C, Westgren M, Shaw SWS, Astrom E, Biswas A, Byers $\mathrm{PH}$ et al. Pre- and postnatal transplantation of fetal mesenchymal stem cells in osteogenesis imperfecta: a two-center experience. Stem Cells Transl Med 2014; 3: 255-264

[64] Perosky JE, Khoury BM, Jenks TN, Ward FS, Cortright K, Meyer B et al. Single dose of bisphosphonate preserves gains in bone mass following cessation of sclerostin antibody in Brtl/ + osteogenesis imperfecta model. Bone 2016; 93: 79-85

[65] Cosman F, Crittenden DB, Adachi JD, Binkley N, Czerwinski E, Ferrari S et al. Romosozumab Treatment in Postmenopausal Women with Osteoporosis. N Engl J Med 2016; 375: 1532-1543

[66] Bacon S, Crowley R. Developments in rare bone diseases and mineral disorders. Ther Adv Chronic Dis 2018; 9: 51-60

[67] Weil A. Pubertas praecox und Knochenbrüchigkeit.In: Pubertas praecox und Knochenbrüchigkeit. $1^{\text {st }}$ ed. Klin: Wschr; 1922: 2114-2115

[68] Albright F, Butler A, Hampton A, Smith P. Syndrome characterized by osteitis fibrosa disseminata, areas of pigmentation and endocrine dysfunction, with precocious puberty in females. N Engl J Med 1937; 216: 727-746

[69] Marie P]. Cellular and molecular basis of fibrous dysplasia. Histol Histopathol 2001; 16: 981-988

[70] Weinstein LS. G(s)alpha mutations in fibrous dysplasia and McCune-Albright syndrome. J Bone Miner Res 2006; 21P120-4

[71] Cheng MH, Chen YR. Malignant fibrous histiocytoma degeneration in a patient with facial fibrous dysplasia. Ann Plast Surg 1997; 39: 638-642

[72] Van Rossem C, Pauwels P, Somville J, Camerlinck M, Bogaerts P, Van Schil PE. Sarcomatous degeneration in fibrous dysplasia of the rib cage. Ann Thorac Surg 2013; 96: e89-e90

[73] Yabut SMJ, Kenan S, Sissons HA, Lewis MM. Malignant transformation of fibrous dysplasia. A case report and review of the literature. Clin Orthop Relat Res 1988; 228: 281-289

[74] Hartley I, Zhadina M, Collins MT, Boyce AM. Fibrous Dysplasia of Bone and McCune-Albright Syndrome: A Bench to Bedside Review. Calcif Tissue Int 2019; 104: 517-529

[75] Pritchard JE. Fibrous dysplasia of the bones. Am J Med Sci 1951; 222: 313-332
[76] Cleiren E, Benichou O, Van Hul E, Gram J, Bollerslev J, Singer FR et al. Albers-Schonberg disease (autosomal dominant osteopetrosis, type II) results from mutations in the CICN7 chloride channel gene. Hum Mol Genet 2001; 10: 2861-2867

[77] de Vernejoul MC, Benichou O. Human osteopetrosis and other sclerosing disorders: recent genetic developments. Calcif Tissue Int 2001; 69: 1-6

[78] Stark Z, Savarirayan R. Osteopetrosis. Orphanet J Rare Dis 2009; 4: 5

[79] Myers EN, Stool S. The temporal bone in osteopetrosis. Arch Otolaryngol 1969; 89: 460-469

[80] Wong ML, Balkany TJ, Reeves J, Jafek BW. Head and neck manifestations of malignant osteopetrosis. Otolaryngology 1978; 86: ORL 585-594

[81] Dozier TS, Duncan IM, Klein AJ, Lambert PR, Key LLJ. Otologic manifestations of malignant osteopetrosis. Otol Neurotol Off Publ Am Otol Soc Am Neurotol Soc [and] Eur Acad. Otol Neurotol 2005; 26: 762-766

[82] Coccia PF, Krivit W, Cervenka J, Clawson C, Kersey JH, Kim TH et al. Successful bone-marrow transplantation for infantile malignant osteopetrosis. N Engl J Med 1980; 302: 701-708

[83] Hamersma H. Osteopetrosis (Marble bone disease) of the temporal bone. Laryngoscope 1970; 80: 1518-1539

[84] Jones MD, Mulcahy ND. Osteopathia striata, osteopetrosis, and impaired hearing. A case report. Arch Otolaryngol 1968; 87: $116-118$

[85] Milroy CM, Michaels L. Temporal bone pathology of adult-type osteopetrosis. Arch Otolaryngol Head Neck Surg 1990; 116: 79-84

[86] Yarington CT], Sprinkle PM. Facial palsy in osteopetrosis. Relief by endotemporal decompression. JAMA 1967; 202: 549

[87] Hamersma H, Hofmeyr L. Too much bone: the middle ear in sclerosing bone dysplasias. Adv Otorhinolaryngol 2007; 65: 61-67

[88] Schmitz L, Favara BE. Nosology and pathology of Langerhans cell histiocytosis. Hematol Oncol Clin North Am 1998; 12: 221-246

[89] Valladeau J, Ravel O, Dezutter-Dambuyant C, Moore K, Kleijmeer M, Liu $Y$ et al. Langerin, a novel C-type lectin specific to Langerhans cells, is an endocytic receptor that induces the formation of Birbeck granules. Immunity 2000; 12: 71-81

[90] Greenberger JS, Crocker AC, Vawter G, Jaffe N, Cassady JR. Results of treatment of 127 patients with systemic histiocytosis. Medicine (Baltimore) 1981; 60: 311-338

[91] Smith DG, Nesbit ME], D’Angio G], Levitt SH. Histiocytosis X: role of radiation therapy in management with special reference to dose levels employed. Radiology 1973; 106: 419-422

[92] Sims DG, Histiocytosis X. follow-up of 43 cases. Arch Dis Child 1977; 52: $433-440$

[93] Arceci RJ, Brenner MK, Pritchard J. Controversies and new approaches to treatment of Langerhans cell histiocytosis. Hematol Oncol Clin North Am 1998; 12: 339-357

[94] McCaffrey TV, McDonald TJ. Histiocytosis X of the ear and temporal bone: review of 22 cases. Laryngoscope 1979; 89: 1735-1742

[95] Tos M. A survey of Hand-Schuller-Christian's disease in otolaryngology. Acta Otolaryngol 1966; 62: 217-228

[96] Schuknecht HF, Perlman HB. Hand-Schuller-Christian disease and eosinophilic granuloma of the skull. Ann Otol Rhinol Laryngol 1948; 57: 643-676

[97] Dingley AR. Eosinophil granuloma of the temporal bone. J Laryngol Otol 1952; 66: 285-287

[98] Falkinburg LW, Littleton TR, Hunt RR, Horwitz M. Bilateral eosinophilic granulomas of the mastoid processes. Report of a case in a two-year-old boy, with review. AMA Arch Otolaryngol 1959; 70: 292-296 
[99] Martin TH. Solitary eosinophilic granuloma of the temporal bone. A case report. Laryngoscope 1969; 79: 2165-2171

[100] Sweet RM, Kornblut AD, Hyams VJ. Eosinophilic granuloma in the temporal bone. Laryngoscope 1979; 89: 1545-1552

[101] Cunningham MJ, Curtin HD, Jaffe R, Stool SE. Otologic manifestations of Langerhans' cell histiocytosis. Arch Otolaryngol Head Neck Surg 1989; 115: 807-813

[102] Chisolm JJ. Otorhinologic aspects of Hand-Schuller-Christian's disease. Laryngoscope 1954; 64: 486-496

[103] Levy R, Sarfaty SM, Schindel J. Eosinophilic granuloma of the temporal bone. Two cases with bilateral involvement. Arch Otolaryngol 1980; 106: 167-171

[104] Hudson WR, Kenan PD. Otologic manifestations of histiocytosis X. Laryngoscope 1969; 79: 678-693

[105] Schuknecht HF. Histiocytosis X Otolaryngol Head Neck Surg (1979). 1980; 88: 544-547

[106] Levine S, Stone J. Pathogenesis of Wegener's granulomatosis and related vasculitides. 2007; p. www.uptodate.com version 15.3 .

[107] Calonius IH, Christensen CK. Hearing impairment and facial palsy as initial signs of Wegener's granulomatosis. J Laryngol Otol 1980; 94: 649-657

[108] Karmody CS. Wegener's granulomatosis: presentation as an otologic problem. Otolaryngology 1978; 86: ORL 573-584

[109] Kornblut AD, Wolff SM, deFries HO, Fauci AS. Wegener's granulomatosis. Otolaryngol Clin North Am 1982; 15: 673-683

[110] Blatt I, Lawrence M. otologic manifestations of fatal granulomatosis of respiratory tract: Lethal midline granuloma - Wegener's granulomatosis. Arch Otolaryngol 1961; 73: 639-643

[111] Ohtani I, Baba Y, Suzuki C, Sakuma H, Kano M. Temporal bone pathology in Wegener's granulomatosis. Fukushima J Med Sci 2000; 46: $31-39$

[112] McDonald TJ, DeRemee RA. Wegener's granulomatosis. Laryngoscope 1983; 93: 220-231

[113] Amiraraghi N, Robertson S, lyer A. Primary otological manifestations of granulomatosis with polyangiitis: a case series. J Laryngol Otol 2015; 129: 179-182

[114] Bacciu A, Bacciu S, Mercante G, Ingegnoli F, Grasselli C, Vaglio A et al. Ear, nose and throat manifestations of Churg-Strauss syndrome. Acta Otolaryngol 2006; 126: 503-509

[115] Rahne T, Plontke S, Keyßer G. Vasculitis and the ear: a literature review. Curr Opin Rheumatol 2020; 32: 47-52

[116] Ishiyama A, Canalis RF. Otological manifestations of Churg-Strauss syndrome. Laryngoscope 2001; 111: 1619-1624

[117] Jaksch-Wartenhorst. Polychondropathia. Wien Arch 1923; 6: 93-100

[118] Herman JH, Dennis MV. Immunopathologic studies in relapsing polychondritis. J Clin Invest 1973; 52: 549-558

[119] Michet CJ. Etiology and pathogenesis of relapsing polychondritis [Internet]. 2020;Available from https://www.uptodate.com/contents/ etiology-and-pathogenesis-of-relapsing-polychondritis

[120] Bachor E, Blevins NH, Karmody C, Kuhnel T. Otologic manifestations of relapsing polychondritis. Review of literature and report of nine cases. Auris Nasus Larynx 2006; 33: 135-141

[121] McAdam LP, O'Hanlan MA, Bluestone R, Pearson CM. Relapsing polychondritis: prospective study of 23 patients and a review of the literature. Medicine (Baltimore) 1976; 55: 193-215

[122] Hoffman RA, Horten B. Rheumatoid nodule of the temporal bone. J Laryngol Otol 1989; 103: 768-770

[123] Gussen R. Atypical ossicle joint lesions in rheumatoid arthritis with sicca syndrome (Sjogren syndrome). Arch Otolaryngol 1977; 103: 284-286
[124] Castillo Bustamante M, Gandhi D, Kozin E, Remenschneider A. Otopathological changes of the middle and inner ear in rheumatoid arthritis. In Boston 2019

[125] Swerdlow S, Campo E, Harris N. World Health Organization Classification of Tumors of Haematopoietic and Lymphoid Tissues. IARC Press; 2008

[126] Freedman A, Friedberg J, Aster J. Classification of the hematopoietic neoplasms [Internet]. 2020; Available from: www.uptodate.com

[127] Zechner G, Altmann F. The temporal bone in leukemia. Histological studies. Ann Otol Rhinol Laryngol 1969; 78: 375-387

[128] Schuknecht HF, Igarashi M, Chasin WD. Inner Ear Hemorrhage in Leukemia. A Case Report. Laryngoscope 1965; 75: 662-668

[129] Hallpike CS, Harrison MS. Clinical and pathological observations of a case of leukaemia with deafness and vertigo. J Laryngol Otol 1950; 64: 427-430

[130] Druss JG. Aural manifestations of leukemia. Arch Otolaryngol 1945; 42: $267-274$

[131] Thompson DH, Ross DG, Reid JW. Granulocytic sarcoma (chloroma) initially seen as acute mastoiditis. Arch Otolaryngol 1982; 108: 388-391

[132] Li W, Schachern PA, Morizono T, Paparella MM. The temporal bone in multiple myeloma. Laryngoscope 1994; 104: 675-680

[133] LEWIS JS. Cancer of the ear: a report of 150 cases. Laryngoscope. 1960; 70: 551-579

[134] Broders AC. SQUAMOUS-CELL EPITHELIOMA OFTHE SKIN: A STUDY OF 256 CASES. Ann Surg 1921; 73: 141-160

[135] Maxwell AK, Takeda H, Gubbels SP. Primary Middle Ear Mucosal Melanoma: Case Report and Comprehensive Literature Review of 21 Cases of Primary Middle Ear and Eustachian Tube Melanoma. Ann Otol Rhinol Laryngol 2018; 127: 856-863

[136] Bradeley WH, Maxwell JH. Neoplasms of the middle ear and mastoid: report of fifty-four cases. Laryngoscope 1954; 64: 533-556

[137] Applebaum EL. Radiation-induced carcinoma of the temporal bone. Otolaryngol Head Neck Surg 1979; 87: 604-609

[138] Lustig LR, Jackler RK, Lanser MJ. Radiation-induced tumors of the temporal bone. Am J Otol 1997; 18: 230-235

[139] Ruben RJ, Thaler SU, Holzer N. Radiation induced carcinoma of the temporal bone. Laryngoscope 1977; 87: 1613-1621

[140] Beal DD, Lindsay JR, Ward PH. Radiation-Induced Carcinoma of the Mastoid. Arch Otolaryngol 1965; 81: 9-16

[141] Dehner LP, Chen KT. Primary tumors of the external and middle ear. Benign and malignant glandular neoplasms. Arch Otolaryngol 1980; 106: $13-19$

[142] Murphy GF, Pilch BZ, Dickersin GR, Goodman ML, Nadol JB]. Carcinoid tumor of the middle ear. Am J Clin Pathol 1980; 73: 816-823

[143] Thompson LDR, Nelson BL, Barnes EL. Ceruminous adenomas: a clinicopathologic study of 41 cases with a review of the literature. Am J Surg Pathol 2004; 28: 308-318

[144] Hyams V], Michaels L. Benign adenomatous neoplasm (adenoma) of the middle ear. Clin Otolaryngol Allied Sci 1976; 1: 17-26

[145] Zahtz GD, Zielinski B, Abramson AL. Benign adenoma of the middle ear cavity causing facial paralysis. Otolaryngol Head Neck Surg 1981; 89: 624-627

[146] Sudhoff H, Gehl H-B, Brasch F, Riemann R, Todt I. A rare pathology of the petrous part of the temporal bone: adenoma of the middle ear. HNO 2020; 68: 55-58

[147] SMITH HW, DUARTE I. Mixed tumors of the external auditory canal. Arch Otolaryngol 1962; 75: 108-113

[148] Baker BB, DeBlanc GB. Pleomorphic adenoma of the external auditory canal. Ear Nose Throat ] 1977; 56: 81-83 
[149] Collins RJ, Yu HC. Pleomorphic adenoma of the external auditory canal. An immunohistochemical and ultrastructural study. Cancer 1989; 64: 870-875

[150] Haraguchi H, Hentona H, Tanaka H, Komatuzaki A. Pleomorphic adenoma of the external auditory canal: a case report and review of the literature. J Laryngol Otol 1996; 110: 52-56

[151] Tsukahara K, Suzuki M, Tokashiki R, Motohashi R, Iwaya K. Pleomorphic adenoma of the external auditory canal complicated by hearing loss secondary to chronic otitis media. Auris Nasus Larynx 2006; 33: 183-186

[152] Markou K, Karasmanis I, Vlachtsis K, Petridis D, Nikolaou A, Vital V. Primary pleomorphic adenoma of the external ear canal. Report of a case and literature review. Am J Otolaryngol 2008; 29: 142-146

[153] Mosby C. Pathology. 4th ed. Anderson W editor.1961: 113-117

[154] Dong F, Gidley PW, Ho T, Luna MA, Ginsberg LE, Sturgis EM. Adenoid cystic carcinoma of the external auditory canal. Laryngoscope 2008; 118: 1591-1596

[155] Furstenberg A. Primary adenocarcinoma of the middle ear and mastoid. Ann Otol Rhinol Laryngol 1924; 33: 677-689

[156] Michel RG, Woodard BH, Shelburne JD, Bossen EH. Ceruminous gland adenocarcinoma: a light and electron microscopic study. Cancer 1978; 41: 545-553

[157] Jan J-C, Wang C-P, Kwan P-C, Wu S-H, Shu H-F. Ceruminous adenocarcinoma with extensive parotid, cervical, and distant metastases: case report and review of literature. Arch Otolaryngol Head Neck Surg 2008; 134: 663-666

[158] Doble HP 2 ${ }^{\text {nd }}$, Snyder GG $3^{\text {rd }}$. Carpenter RJ $3^{\text {rd }}$. Sebaceous cell carcinoma of the external auditory canal. Otolaryngol Head Neck Surg 1981; 89: 685-688

[159] Ray J, Worley GA, Schofield JB, Shotton JC, al-Ayoubi A. Rapidly invading sebaceous carcinoma of the external auditory canal. J Laryngol Otol 1999; 113: 578-580

[160] Schuller DE, Conley J], Goodman JH, Clausen KP, Miller W]. Primary adenocarcinoma of the middle ear. Otolaryngol Head Neck Surg 1983; 91: 280-283

[161] Glasscock ME $3^{\text {rd }}$, McKennan KX, Levine SC, Jackson CG. Primary adenocarcinoma of the middle ear and temporal bone. Arch Otolaryngol Head Neck Surg 1987; 113: 822-824

[162] Benecke JEJ, Noel FL, Carberry JN, House JW, Patterson M. Adenomatous tumors of the middle ear and mastoid. Am J Otol 1990; 11: 20-26

[163] Ramsey MJ, Nadol JBJ, Pilch BZ, McKenna MJ. Carcinoid tumor of the middle ear: clinical features, recurrences, and metastases. Laryngoscope 2005; 115: 1660-1666

[164] Devaney KO, Ferlito A, Rinaldo A. Epithelial tumors of the middle ear - are middle ear carcinoids really distinct from middle ear adenomas? Acta Otolaryngol 2003; 123: 678-682

[165] Torske KR, Thompson LDR. Adenoma versus carcinoid tumor of the middle ear: a study of 48 cases and review of the literature. Mod Pathol an Off J United States Can Acad Pathol Inc 2002; 15: 543-555

[166] Wang LL, Gebhardt MC, Rainusso N. Osteosarcoma: Epidemiology, pathogenesis, clinical presentation, diagnosis, and histology [Internet]. 2009; p. www.uptodate.com version 17.2 Available from: https://www.uptodate.com/contents/osteosarcoma-epidemiologypathogenesis-clinical-presentation-diagnosis-and-histology

[167] Mirabello L, Troisi RJ, Savage SA. Osteosarcoma incidence and survival rates from 1973 to 2004: data from the Surveillance, Epidemiology, and End Results Program. Cancer 2009; 115: 1531-43

[168] Papagelopoulos PJ, Galanis EC, Vlastou C, Nikiforidis PA, Vlamis JA, Boscainos PJ et al. Current concepts in the evaluation and treatment of osteosarcoma. Orthopedics 2000; 23: 858-859

[169] Naufal PM. Primary sarcomas of the temporal bone. Arch Otolaryngol 1973; 98: 44-50
[170] Coventry MB, Dahlin DC. Osteogenic sarcoma; a critical analysis of 430 cases. J Bone Joint Surg Am 1957; 39-A: 741-57. discussion, 757-758.

[171] Gertner R, Podoshin L, Fradis M. Osteogenic sarcoma of the temporal bone. J Laryngol Otol 1983; 97: 627-631

[172] Sataloff RT, Myers DL, Spiegel JR, Roberts BR, Telian S. Total temporal bone resection for osteogenic sarcoma. Ear Nose Throat J 1988; 67: 626-627. 630-632, 634 passim.

[173] Sharma SC, Handa KK, Panda N, Banerjee AK, Mann SB. Osteogenic sarcoma of the temporal bone. Am J Otolaryngol 1997; 18: 220-223

[174] Seely DR, Gates GA. Parosteal osteogenic sarcoma of the mastoid bone. Ann Otol Rhinol Laryngol 1997; 106: 729-732

[175] Goh YH, Chong VF, Low WK. Temporal bone tumours in patients irradiated for nasopharyngeal neoplasm. J Laryngol Otol 1999; 113: 222-228

[176] Isikdogan A, Buyukcelik A, Erekul S, Pamir A. De novo osteogenic sarcoma of mastoid bone. Sarcoma 2002; 6: 79-81

[177] Wiener ES. Head and neck rhabdomyosarcoma. Semin Pediatr Surg 1994; 3: 203-206

[178] Friedmann DR, Peng R, Fang Y, McMenomey SO, Roland JT, Waltzman $\mathrm{SB}$. Effects of loss of residual hearing on speech performance with the $\mathrm{Cl} 422$ and the Hybrid-L electrode. Cochlear Implants Int 2015; 16: $277-284$

[179] Durve DV, Kanegaonkar RG, Albert D, Levitt G. Paediatric rhabdomyosarcoma of the ear and temporal bone. Clin Otolaryngol Allied Sci 2004; 29: 32-37

[180] Alexy Z. A case of rhabdomyosarcoma in the middle ear. Monatsschr Ohrenheilkd Laryngorhinol 1968; 102: 15-18

[181] Jaffe BF, Fox JE, Batsakis JG. Rhabdomyosarcoma of the middle ear and mastoid. Cancer 1971; 27: 29-37

[182] Karatay S. Rhabdomyosarcoma of the middle ear. Arch Otolaryngol 1949; 50: 330-334

[183] Myers EN, Stool S, Weltschew A. Rhabdomyosarcoma of the middle ear. Ann Otol Rhinol Laryngol 1968; 77: 949-958

[184] Wiatrak BJ, Pensak ML. Rhabdomyosarcoma of the ear and temporal bone. Laryngoscope 1989; 99: 1188-1192

[185] Hawkins DS, Anderson JR, Paidas CN, Wharam MD, Qualman S], Pappo AS et al. Improved outcome for patients with middle ear rhabdomyosarcoma: a children's oncology group study. J Clin Oncol 2001; 19: 3073-3079

[186] Reliability of histopathologic and radiologic grading of cartilaginous neoplasms in long bones. J Bone Joint Surg Am 2007; 89: 2113-2123

[187] Lindbom A, Soderberg G, Spjut H]. Primary chondrosarcoma of bone. Acta radiol 1961; 55: 81-96

[188] O’Neal LW, Ackerman LV. Chondrosarcoma of bone. Cancer 1952; 5: 551-577

[189] Coltrera MD, Googe PB, Harrist T], Hyams V], Schiller AL, Goodman $\mathrm{ML}$. Chondrosarcoma of the temporal bone. Diagnosis and treatment of 13 cases and review of the literature. Cancer 1986; 58: 2689-2696

[190] Muckle RP, De la Cruz A, Lo WM. Petrous apex lesions. Am J Otol 1998; 19: 219-225

[191] Oghalai JS, Buxbaum JL, Jackler RK, McDermott MW. Skull base chondrosarcoma originating from the petroclival junction. Otol Neurotol Off Publ Am Otol Soc Am Neurotol Soc [and] Eur Acad. Otol Neurotol 2005; 26: 1052-1060

[192] Worley GA, Wareing MJ, Sergeant RJ. Myxoid chondrosarcoma of the external auditory meatus. J Laryngol Otol 1999; 113: 742-743

[193] Guild S. A hitherto unrecignized structure, the glomus jugularis, in man. Anat Rec 1941; 79:

[194] Spector G], Maisel RH, Ogura JH. Glomus tumors in the middle ear. I. An analysis of 46 patients. Laryngoscope 1973; 83: 1652-1672 
[195] Watzka M. Die Paraganglien. In: Mikr Handbuch Anat Mensch. $4^{\text {th }}$ ed. 1943

[196] van Baars FM, Cremers CW, van den Broek P, Veldman JE. Familial glomus tumors: clinical and genetic aspects. Acta Otorhinolaryngol Belg 1981; 35: 50-55

[197] Baysal BE. Clinical and molecular progress in hereditary paraganglioma. J Med Genet 2008; 45: 689-694

[198] Al-Mefty O, Teixeira A. Complex tumors of the glomus jugulare: criteria, treatment, and outcome. J Neurosurg 2002; 97: 1356-1366

[199] Boedeker CC, Hensen EF, Neumann HPH, Maier W, van Nederveen FH, Suárez $C$ et al. Genetics of hereditary head and neck paragangliomas. Head Neck 2014; 36: 907-916

[200] Brown JS. Glomus jugulare tumors revisited: a ten-year statistical follow-up of 231 cases. Laryngoscope 1985; 95: 284-288

[201] Fisch U. Microsurgery of the skull base. In: Microsurgery of the skull base.Stuttgart: Thieme; 1988: p 149-153

[202] McCabe BF, Fletcher M. Selection of therapy of glomus jugulare tumors. Arch Otolaryngol 1969; 89: 156-159

[203] Alford BR, Guilford FR. A comprehensive study of tumors of the glomus jugulare. Laryngoscope 1962; 72: 765-805

[204] Megerian CA, McKenna MJ, Nadol JB]. Non-paraganglioma jugular foramen lesions masquerading as glomus jugulare tumors. Am J Otol 1995; 16: 94-98

[205] House WF, Glasscock ME $3^{\text {rd }}$. Glomus tympanicum tumors. Arch Otolaryngol 1968; 87: 550-554

[206] Welander ], Söderkvist P, Gimm O. Genetics and clinical characteristics of hereditary pheochromocytomas and paragangliomas. Endocr Relat Cancer 2011; 18: R253-R276

[207] Prades CA, Atassi B, Nazeer H. Metastatic Malignant Paraganglioma: A Case Report and Review of Literature. Vol. 8, World journal of oncology. 2017; p 92-95

[208] Brewis C, Bottrill ID, Wharton SB, Moffat DA. Metastases from glomus jugulare tumours. J Laryngol Otol 2000; 114: 17-23

[209] Glasscock ME $3^{\text {rd }}$, Harris PF, Newsome G. Glomus tumors: diagnosis and treatment. Laryngoscope 1974; 84: 2006-2032

[210] Olsen WL, Dillon WP, Kelly WM, Norman D, Brant-Zawadzki M, Newton TH. MR imaging of paragangliomas. AJR Am J Roentgenol 1987; 148: 201-204

[211] Itani M, Mhlanga J, Mariani-Costantini R. Imaging of Pheochromocytoma and Paraganglioma. [Internet]. Paraganglioma: A Multidisciplinary Approach. [Internet]. Brisbane (AU): Codon Publications; 2019. Chapter 3. 2019. Available from: www.ncbi.nlm.nih.gov/books/ NBK543223/. doi: 10.15586/paraganglioma.2019.ch3

[212] Taïeb D, Timmers H], Hindié E, Guillet BA, Neumann HP, Walz MK et al. EANM 2012 guidelines for radionuclide imaging of phaeochromocytoma and paraganglioma. Eur J Nucl Med Mol Imaging 2012; 39: 1977-1995

[213] Reith W, Kettner M. Diagnosis and treatment of glomus tumors of the skull base and neck. Radiologe 2019; 59: 1051-1057

[214] Hafez RFA, Morgan MS, Fahmy OM, Hassan HT. Long-term effectiveness and safety of stereotactic gamma knife surgery as a primary sole treatment in the management of glomus jagulare tumor. Clin Neurol Neurosurg 2018; 168: 34-37

[215] Patel NS, Carlson ML, Pollock BE, Driscoll CLW, Neff BA, Foote RL et al. Long-term tumor control following stereotactic radiosurgery for jugular paraganglioma using 3D volumetric segmentation. J Neurosurg 2018; 1-9

[216] Taïeb D, Jha A, Treglia G, Pacak K. Molecular imaging and radionuclide therapy of pheochromocytoma and paraganglioma in the era of genomic characterization of disease subgroups. Endocr Relat Cancer 2019; 26: R627-R652
[217] Gloria-Cruz TI, Schachern PA, Paparella MM, Adams GL, Fulton SE. Metastases to temporal bones from primary nonsystemic malignant neoplasms. Arch Otolaryngol Head Neck Surg 2000; 126: 209-214

[218] Schuknecht $H$. Temporal bone removal at autopsy. Preparation and uses. Arch Otolaryngol 1968; 87: 129-137

[219] Belal AJ. Metastatic tumours of the temporal bone. A histopathological report. J Laryngol Otol 1985; 99: 839-846

[220] Roubaud J-C, Leclere J-C, Mornet E, Marianowski R. Haemangioma of the temporal bone. Eur Ann Otorhinolaryngol Head Neck Dis. 2020;

[221] Hirai R, Ikeda M, Kishi H, Nomura Y, Shigihara S. A case of middle-ear cavernous lymphangioma with facial palsy. J Laryngol Otol 2011; 125: 405-409

[222] Carli ], Andre J. Teratologicaltype dysembryoplastic tumor of the temporomastoid region. Ann Otolaryngol 1958; 75: 791-792

[223] Navratil J. Teratome der Paukenhöhle und der Tuba eustachii. Acta Otolaryngol 1965; 60: 360-366

[224] Lalwani AKXIV. Skull Base. In: Current Diagnosis \& Treatment in Otolaryngology: Head \& Neck Surgery. $3^{\text {rd }}$ ed. McGraw-Hill Education; 2011: p 769-844

[225] Dazert S, Aletsee C, Brors D, Mlynski R, Sudhoff H, Hildmann H et al. Rare tumors of the internal auditory canal. Eur Arch oto-rhino-laryngology Off J Eur Fed Oto-Rhino-Laryngological Soc Affil with Ger Soc Oto-Rhino-Laryngology. Head Neck Surg 2005; 262: 550-554

[226] Scherl C. Seltene Erkrankungen im Kopf-Hals-Bereich Teil III: Speicheldrüsen und Nervus Facialis (accepted for publication). Laryngorhinootologie 2021;

[227] Roosli C, Linthicum FH], Cureoglu S, Merchant SN. What is the site of origin of cochleovestibular schwannomas? Audiol Neurootol 2012; 17: $121-125$

[228] Rahne T, PlößI S, Plontke SK, Strauss C. Preoperative determination of nerve of origin in patients with vestibular schwannoma. HNO 2018; 66: 16-21

[229] Waterval J, Kania R, Somers T. EAONO Position Statement on Vestibular Schwannoma: Imaging Assessment. What are the Indications for Performing a Screening MRI Scan for a Potential Vestibular Schwannoma? J Int Adv Otol 2018; 14: 95-99

[230] Hasso AN, Smith DS. The cerebellopontine angle. Semin Ultrasound CT MR 1989; 10: 280-301

[231] Somers T, Kania R, Waterval J, Van Havenbergh T. What is the Required Frequency of MRI Scanning in the Wait and Scan Management? J Int Adv Otol 2018; 14: 85-89

[232] Sakamoto T, Fukuda S, Inuyama Y. Hearing loss and growth rate of acoustic neuromas in follow-up observation policy. Auris Nasus Larynx 2001; 28: S23-S27

[233] Paldor I, Chen AS, Kaye AH. Growth rate of vestibular schwannoma. ] Clin Neurosci Off J Neurosurg Soc Australas 2016; 32: 1-8

[234] Kania R, Vérillaud B, Camous D, Hautefort C, Somers T, Waterval J et al. EAONO position statement on Vestibular Schwannoma: Imaging Assessment Question: How should growth of Vestibular Schwannoma be defined? J Int Adv Otol 2018; 14: 90-94

[235] Tieleman A, Casselman JW, Somers T, Delanote J, Kuhweide R, Ghekiere J et al. Imaging of intralabyrinthine schwannomas: a retrospective study of 52 cases with emphasis on lesion growth. AJNR Am J Neuroradiol 2008; 29: 898-905

[236] Schulz C, Eßer D, RosahI S, Baljić I, Kösling S, Plontke SK. Management of vestibular schwannomas. Laryngorhinootologie 2018; 97: 875-896

[237] Plontke SK, Rahne T, Pfister M, Götze G, Heider C, Pazaitis N et al. Intralabyrinthine schwannomas: Surgical management and hearing rehabilitation with cochlear implants. HNO 2017; 65: 136-148 
[238] Plontke SK, Caye-Thomasen P, Strauss C, Kösling S, Götze G, Siebolts $\mathrm{U}$ et al. Management of transmodiolar and transmacular cochleovestibular schwannomas with and without cochlear implantation. German version. HNO 2020; 68: 734-748

[239] Lalwani AK. Meningiomas, epidermoids, and other nonacoustic tumors of the cerebellopontine angle. Otolaryngol Clin North Am 1992; 25: 707-728

[240] Lalwani AK, Jackler RK. Preoperative differentiation between meningioma of the cerebellopontine angle and acoustic neuroma using MRI. Otolaryngol neck Surg Off J Am Acad Otolaryngol Neck Surg 1993; 109: 88-95

[241] Renowden S. Imaging of the cerebellopontine angle. Pract Neurol 2014; 14: 299-309

[242] Roh TH, Park YS, Park YG, Kim SH, Chang JH. Intracranial squamous cell carcinoma arising in a cerebellopontine angle epidermoid cyst: A case report and literature review. Medicine (Baltimore) 2017; 96: e9423

[243] Faltaous AA, Leigh EC, Ray P, Wolbert TT. A Rare Transformation of Epidermoid Cyst into Squamous Cell Carcinoma: A Case Report with Literature Review. Am J Case Rep 2019; 20: 1141-1143

[244] Turner A, Fraser J. Tuberculosis of the middle-ear cleft in children: A clinical and pathological study. J Laryngol Rhinol Otol 1915; 30 : 209-247

[245] Ognibene FP. Upper and lower airway manifestations of human immunodeficiency virus infection. Ear Nose Throat J 1990; 69: 424-431

[246] Saunders NC, Albert DM. Tuberculous mastoiditis: when is surgery indicated? Int J Pediatr Otorhinolaryngol 2002; 65: 59-63

[247] Jeanes AL, Friedmann I. Tuberculosis of the middle ear. Tubercle. 1960; 41: 109-116

[248] Tamari M], Itkin P. Penicillin and syphilis of the ear. Eye Ear Nose Throat Mon 1951; 30: 358-366. passim

[249] Smith M, Canalis R. Otologic manifestations of AIDS: The otosyphilis connection. Laryngoscope 1989; 99: 365-372

[250] Nadol J. Hearing loss of aquired syphilis: Diagnosis confirmed by incudectomy. Laryngoscope 1975; 85: 1888-1897

[251] Peled C, El-Seid S, Bahat-Dinur A, Tzvi-Ran LR, Kraus M, Kaplan D. Necrotizing Otitis Externa-Analysis of 83 Cases: Clinical Findings and Course of Disease. Otol Neurotol Off Publ Am Otol Soc Am Neurotol Soc [and] Eur Acad. Otol Neurotol 2019; 40: 56-62

[252] Abu Eta R, Gavriel H, Stephen K, Eviatar E, Yeheskeli E. The significance of tissue biopsy for fungi in necrotizing otitis externa. Eur Arch oto-rhino-laryngology Off J Eur Fed Oto-Rhino-Laryngological Soc Affil with Ger Soc Oto-Rhino-Laryngology - Head Neck Surg 2018; 275: 2941-2945

[253] Chandler JR. Malignant external otitis and facial paralysis. Otolaryngol Clin North Am 1974; 7: 375-383

[254] Chandler JR. Malignant external otitis. Laryngoscope 1968; 78: 12571294

[255] Chandler JR. Malignant external otitis: further considerations. Ann Otol Rhinol Laryngol 1977; 86: 417-428

[256] Nadol JBJ. Histopathology of Pseudomonas osteomyelitis of the temporal bone starting as malignant external otitis. Am J Otolaryngol 1980; 1: 359-371

[257] Kohut RI, Lindsay JR. Necrotizing (“malignant”) external otitis histopathologic processes. Ann Otol Rhinol Laryngol 1979; 88: 714-720

[258] Mahdyoun P, Pulcini C, Gahide I, Raffaelli C, Savoldelli C, Castillo L et al. Necrotizing otitis externa: a systematic review. Otol Neurotol Off Publ Am Otol Soc Am Neurotol Soc [and] Eur Acad. Otol Neurotol 2013; 34: 620-629
[259] Amaro CE, Espiney R, Radu L, Guerreiro F. Malignant (necrotizing) externa otitis: the experience of a single hyperbaric centre. Eur Arch oto-rhino-laryngology Off J Eur Fed Oto-Rhino-Laryngological Soc Affil with Ger Soc Oto-Rhino-Laryngology - Head Neck Surg 2019; 276: $1881-1887$

[260] Harris JB, LaRocque RC, Qadri F, Ryan ET, Calderwood SB. Cholera. Lancet (London, England) 2012; 379: 2466-2476

[261] Pang B, Yan M, Cui Z, Ye X, Diao B, Ren Y et al. Genetic diversity of toxigenic and nontoxigenic Vibrio cholerae serogroups 01 and 0139 revealed by array-based comparative genomic hybridization. J Bacteriol 2007; 189: 4837-4849

[262] Zhang X, Lu Y, Qian H, Liu G, Mei Y, Jin F et al. Non-O1, Non-0139 Vibrio cholerae (NOVC) Bacteremia: Case Report and Literature Review, 2015-2019. Vol. 13, Infection and drug resistance. New Zealand p 1009-1016

[263] Kechker P, Senderovich Y, Ken-Dror S, Laviad-Shitrit S, Arakawa E, Halpern M. Otitis Media Caused by V. cholerae O100: A Case Report and Review of the Literature. Front Microbiol 2017; 8: 1619

[264] Madeira JT, Summers GW. Epidural mastoid pneumatocele. Radiology 1977; 122: 727-728

[265] Krisht KM, Eli IM, Palmer CA, Schmidt RH. Giant Spontaneous Epidural Pneumatocele: Case Report and Review of the Literature. World Neurosurg 2015; 84: 2075. e7-12

[266] Schilde S, Plontke S, Seiwerth I, Kösling S. Abnormal mastoid pneumatization. HNO 2019; 67: 876-880

[267] Graf K. Spontaneous giant pneumatocele of the mastoid. Pract Otorhinolaryngol (Basel) 1955; 17: 462-466

[268] Keshet N, Abu-Tair ], Zaharia B, Abdalla-Aslan R, Aframian DJ, Zadik Y. Superficial oral mucoceles in cancer patient after radiation therapy: An overlooked yet imperative phenomenon. Vol. 52: Oral oncology. England 2016; p e1-e2

[269] Mnejja M, Hammami B, Achour I, Chakroun A, Charfeddine I, Frikha $M$ et al. Post-radiation mucocele in two patients treated for nasopharyngeal cancer. Cancer Radiother 2011; 15: 254-256

[270] Mark IHW, Tan HKK. Sphenoid mucocele after radiation for the treatment of nasopharyngeal carcinoma. J Otolaryngol - head neck Surg = Le J d'oto-rhino-laryngologie Chir cervico-faciale 2008; 37: E28-E31

[271] Tonni D, Sessa M, Redaelli de Zinis LO. Primary mucocele of the mastoid: An incidental finding. Vol. 8, Clinical case reports. England. 2020; p 461-465

[272] Karandikar A, Goh J, Loke SC, Yeo SB, Tan TY. Mucous retention cyst of temporal bone: a mimic of cholesteatoma on DW-MRI. Am J Otolaryngol 2013; 34: 753-754

[273] Ata N, Erkilic S. Mucous retention cyst of mastoid bone mimicking cholesteatoma. Ear Nose Throat J 2017; 96: E41-E42

[274] Waltner JC, Karatay S. Cysts of the mastoid bone. Arch Otolaryngol 1947; 46: 398-404

[275] Richardson GS. A cyst of the mastoid; report of a case. Ann Otol Rhinol Laryngol 1956; 65: 214-217

[276] Nomura Y, Takemoto K, Komatsuzaki A. The mastoid cyst. Report of a case. Laryngoscope 1971; 81: 438-446

[277] Zimmerman BE, Proud GO. Primary cysts of the mastoid process. Laryngoscope 1983; 93: 805-807

[278] Kavanagh KT, Giltman LI, Babin RW. Erosive mucosal cysts of the temporal bone. A case report with review of the pathogenesis. Am J Otol 1986; 7: 270-274

[279] Tan CY, Chong S. Shaw C-KL. Primary mastoid cyst. J Laryngol Otol 2013; 127: S48-S50

[280] Hwang PH, Jackler RK. Facial nerve dysfunction associated with cystic lesions of the mastoid. Otolaryngol Head Neck Surg 1998; 119: 668-672 
[281] Mohammed ER, Profant M. Spontaneous otogenic pneumocephalus. Acta Otolaryngol 2011; 131: 670-674

[282] Andrews JC, Canalis RF. Otogenic pneumocephalus. Laryngoscope. 1986; 96: 521-528

[283] Sanna M, Fois P, Russo A, Falcioni M. Management of meningoencephalic herniation of the temporal bone: Personal experience and literature review. Laryngoscope 2009; 119: 1579-1585

[284] Kenning T], Willcox TO, Artz G], Schiffmacher P, Farrell C], Evans ]J. Surgical management of temporal meningoencephaloceles, cerebrospinal fluid leaks, and intracranial hypertension: treatment paradigm and outcomes. Neurosurg Focus 2012; 32: E6

[285] Kutz JW], Tolisano AM. Diagnosis and management of spontaneous cerebrospinal fluid fistula and encephaloceles. Curr Opin Otolaryngol Head Neck Surg 2019; 27: 369-375

[286] Nelson RF, Roche JP, Gantz BJ, Hansen MR. Middle Cranial Fossa (MCF) Approach Without the Use of Lumbar Drain for the Management of Spontaneous Cerebral Spinal Fluid (CSF) Leaks. Otol Neurotol Off Publ Am Otol Soc Am Neurotol Soc [and] Eur Acad. Otol Neurotol 2016; 37: $1625-1629$

[287] Hernandez-Montero E, Caballero E, García-Ibanez L. Surgical management of middle cranial fossa bone defects: meningoencephalic herniation and cerebrospinal fluid leaks. Am J Otolaryngol 2020; 41: 102560

[288] BLACK BK, SMITH DE. Nasal glioma; 2 cases with recurrence. AMA Arch Neurol Psychiatry 1950; 64: 614-630

[289] Ofodile FA, Aghadiuno PU, Oyemade O, Adebonojo T. Heterotopic brain in the tongue. Plast Reconstr Surg 1982; 69: 120-124

[290] Scheiner A], Frayer WC, Rorke LB, Heher K. Ectopic brain tissue in the orbit. Eye (Lond) 1999; 13: 251-254

[291] Uğuz MZ, Arslanoğlu S, Terzi S, Etit D. Glial heterotopia of the middle ear. J Laryngol Otol 2007; 121: e4

[292] McGregor DH, Cherian R, Kepes J], Kepes M. Case reports: heterotopic brain tissue of middle ear associated with cholesteatoma. Am J Med Sci 1994; 308: 180-183

[293] Lee JI, Kim KK, Park YK, Eah KY, Kim JR. Glial choristoma in the middle ear and mastoid bone: a case report. J Korean Med Sci 2004; 19 : 155-158

[294] Plontke SK, Preyer S, Pressler H, Mundinger PM, Plinkert PK. Glial lesion of the infratemporal fossa presenting as a soft tissue middle ear mass - rudimentary encephalocele or neural crest remnant? 2000; 56: 141-147

[295] Abrahams J], Eklund JA. Diagnostic radiology of the cranial base. Clin Plast Surg 1995; 22: 373-405

[296] Koch BL, Ball WS]. Congenital malformations causing skull base changes. Neuroimaging Clin N Am 1994; 4: 479-498

[297] Lalwani AK, Jackler RK. Spontaneous hemotympanum associated with chronic middle ear effusion. Am J Otol 1991; 12: 455-458

[298] Maeta M, Saito R, Nakagawa F, Miyahara T. Surgical intervention in middle-ear cholesterol granuloma. J Laryngol Otol 2003; 117 : 344-348

[299] Paparella MM, Lim DJ. Pathogenesis and pathology of the "idiopathic" blue ear drum. Arch Otolaryngol 1967; 85: 249-258

[300] Plontke S, Koitschev A, Ernemann U, Pressler H, Zimmermann R, Plasswilm L. Massive Gorham-Stout osteolysis of the temporal bone and the craniocervical transition. HNO 2002; 50: 354-357

[301] Gorham LW, Stout AP. Massive osteolysis (acute spontaneous absorption of bone, phantom bone, disappearing bone); its relation to hemangiomatosis. J Bone Joint Surg Am 1955; 37-A 5: 985-1004

[302] Patel DV. Gorham's disease or massive osteolysis. Clin Med Res 2005; 3: $65-74$
[303] Simon F, Luscan R, Khonsari RH, Toubiana J, Belhous K, James S et al. Management of Gorham Stout disease with skull-base defects: Case series of six children and literature review. Int J Pediatr Otorhinolaryngol 2019; 124: 152-156

[304] Pace A, lannella G, Riminucci M, Corsi A, Magliulo G. Tympano-Mastoid Cholesterol Granuloma: Case Report and Review of the Literature. Clin Med Insights Case Rep 2020; 13: 1179547620958728

[305] Gore MR, Zanation AM, Ebert CS, Senior BA. Cholesterol granuloma of the petrous apex. Otolaryngol Clin North Am 2011; 44: 10431058

[306] Olcott C, Strasnick B. A blue middle ear mass: Cholesterol granuloma mimicking a glomus tumor and endolymphatic sac tumor. Am J Otolaryngol 2017; 38: 100-102

[307] Kohanski MA, Palmer JN, Adappa ND. Indications and endonasal treatment of petrous apex cholesterol granulomas. Curr Opin Otolaryngol Head Neck Surg 2019; 27: 54-58

[308] Sanna M, Dispenza F, Mathur N, De Stefano A, De Donato G. Otoneurological management of petrous apex cholesterol granuloma. Am J Otolaryngol 2009; 30: 407-414

[309] Raghavan D, Lee TC, Curtin HD. Cholesterol Granuloma of the Petrous Apex: A 5-Year Review of Radiology Reports with Follow-Up of Progression and Treatment. J Neurol Surg B Skull Base 2015; 76: 266-271

[310] Boedeker CC, Kayser G, Ridder G], Maier W, Schipper ]. Giant-cell reparative granuloma of the temporal bone: a case report and review of the literature. Ear Nose Throat J 2003; 82: 926-929. 933-934, 936-937

[311] Jaffe HL. Giant-cell reparative granuloma, traumatic bone cyst, and fibrous (fibro-oseous) dysplasia of the jawbones. Oral Surg Oral Med Oral Pathol 1953; 6: 159-175

[312] Dietz A, Duprez T, Lelotte J, Finet P, Wilms G. Letter to the editor: giant cell reparative granuloma of the temporal bone. Acta neurologica Belgica; Italy: 2020

[313] Bernard F, Troude L, Bouvier C, Roche P-H. "Giant cell reparative tumor: An exceptional differential diagnosis for a lytic lesion of the temporal bone". Neurochirurgie 2016; 62: 332-335

[314] Menge M, Maier W, Feuerhake F, Kaminsky J, Pfeiffer J. Giant cell reparative granuloma of the temporal bone. Acta Neurochir (Wien) 2009; 151: 397-399

[315] Ciappetta P, Salvati M, Bernardi C, Raco A, Di Lorenzo N. Giant cell reparative granuloma of the skull base mimicking an intracranial tumor. Case report and review of the literature. Surg Neurol 1990; 33: $52-56$

[316] Plontke SK-R, Adler C-P, Gawlowski J, Ernemann U, Friese SA, Plinkert PK. Recurrent giant cell reparative granuloma of the skull base and the paranasal sinuses presenting with acute one-sided blindness. Vol. 12, Skull base: official journal of North American Skull Base Society ... [et al.]. 2002; p 9-17

[317] Auclair PL, Cuenin P, Kratochvil F], Slater LJ, Ellis GL. A clinical and histomorphologic comparison of the central giant cell granuloma and the giant cell tumor. Oral Surg Oral Med Oral Pathol 1988; 66: 197-208

[318] Cho Y-S, Lee H-S, Kim S-W, Chung K-H, Lee D-K, Koh W-J et al. Tuberculous otitis media: a clinical and radiologic analysis of 52 patients. Laryngoscope 2006; 116: 921-927

[319] Plontke SK, Kösling S, Schilde S, Wittlinger J, Kisser U. The infracochlear approach for diagnostic petrous apicotomy. HNO 2019; 67: 791-795

[320] Kleijwegt M, Ho V, Visser O, Godefroy W, van der Mey A. Real Incidence of Vestibular Schwannoma? Estimations From a National Registry. Otol Neurotol Off Publ Am Otol Soc Am Neurotol Soc [and] Eur Acad. Otol Neurotol 2016; 37: 1411-1417 
[321] Quigley C, Deady S, Hughes E, McElnea E, Zgaga L, Chetty S. National incidence of eyelid cancer in Ireland (2005-2015). Eye (Lond) 2019; 33: 1534-1539

[322] Berner K, Zaikova O, Johannesen TB, Hall KS, Bruland ØS.Validity and completeness of the Scandinavian Sarcoma Group Central Register by comparison with a nationwide cohort of patients with osteosarcoma in Norway. Vol. 118, Journal of surgical oncology. United States 2018; p 246-247
[323] Heller ], Kraus F, Scheich M, Mlynski R. Therapie der traumatischen Stapesverletzung.In: 80th Annual Meeting of the German Society of Oto-Rhino-Laryngology, Head and Neck Surgery 2009 